University of Tennessee Health Science Center UTHSC Digital Commons

$12-1984$

\title{
Regulation of Luteinizing Hormone and Catecholamine Release
}

\author{
Benjamin Aaron Adler \\ University of Tennessee Health Science Center
}

Follow this and additional works at: https://dc.uthsc.edu/dissertations

Part of the Hormones, Hormone Substitutes, and Hormone Antagonists Commons, and the Medical Pharmacology Commons

\section{Recommended Citation}

Adler, Benjamin Aaron, "Regulation of Luteinizing Hormone and Catecholamine Release" (1984). Theses and Dissertations (ETD). Paper 562. http://dx.doi.org/10.21007/ptd.cghs.1984.0544.

This Dissertation is brought to you for free and open access by the College of Graduate Health Sciences at UTHSC Digital Commons. It has been accepted for inclusion in Theses and Dissertations (ETD) by an authorized administrator of UTHSC Digital Commons. For more information, please contact jwelch30@uthsc.edu. 


\title{
Regulation of Luteinizing Hormone and Catecholamine Release
}

\begin{abstract}
These studies tested the interrelated hypotheses that the ovarian hormones produce their positive feedback effects on luteinizing hormone (LH) secretion through activation of noradrenergic and adrenergic systems in specific hypothalamic regions. Furthermore, the ovarian hormones may alter the activity of opioid neuropeptide and Gamma-Aminobutyric Acid (GABA) systems to produce these alterations in catecholamine transmission and gonadotropin secretion. Radioimmunoassays were utilized to determine plasma LH and median eminence LHRH, and hypothalamic catecholamine concentrations were measured by radioenzymatic assay.
\end{abstract}

The first two studies tested whether epinephrine (EPI) synthesis inhibition blocks the accumulation of median eminence LHRH that precedes the ovarian hormone-induced LH surge and also to test whether the stimulatory ovarian hormone regimen enhances the activity of hypothalamic EPI systems.

Ovariectomized rats were primed with estradiol (EB), followed 2 days later by progesterone (Prog.).

Animals were treated before Prog, administration with saline, one of the EPI synthesis inhibitors SKF 64139 or LY 78335, or the norepinephrine (NE) synthesis inhibitor, FLA-63. The catecholamine synthesis inhibitors blocked or delayed the LH surge. FLA-63 completely prevented the accumulation of LHRH in the median eminence that preceded the rise in LH release. However, selective reduction in EPI levels with SKF 64139 only partially prevented this increase in LHRH. A second EPI synthesis inhibitor, LY 78335, delayed both the LH surge and the rise in LHRH.

In a second experiment, the administration of EB plus Prog, to ovariectomized rats increased the alphamethyltyrosine (aMT) induced depletion of EPI in the medial basal hypothalamus (MBH). The depletion of $\mathrm{NE}$ after synthesis inhibition was enhanced in both the MBH and preoptic-anterior hypothalamus (POA).

Experiments 3 and 4 examined a possible mechanism underlying these ovarian hormone effects on $\mathrm{LH}$ release and catecholamine activity. These studies tested whether the opiate antagonist, naloxone, which increases LH release, enhances the activity of NE and EPI neurons in the hypothalamus, and also tested whether morphine, an opiate agonist which decreases $\mathrm{LH}$ release, depresses the activity of hypothalamic NE and EPI activity. Administration of naloxone to EB-primed rats increased $\mathrm{LH}$ release and potentiated the depletion of $\mathrm{NE}$ in the $\mathrm{POA}$ and $\mathrm{MBH}$, and enhanced the decline of $\mathrm{EPI}$ and dopamine (DA) in the $\mathrm{MBH}$, suggesting increased catecholamine activity in these regions. Administration of the opiate agonist, morphine, to rats pretreated with EB and Prog., decreased LH and decreased the depletion of the catecholamines in the POA and $\mathrm{MBH}$, suggesting reduced activity. In most cases, naloxone antagonized the inhibitory effect of morphine.

Experiments 3, 6, and 7 examined the involvement of (GABA) systems in the positive feedback effects of EB and Prog, on LHRH and LH release. These studies tested 1) the effects of GABAergic drugs on the LH surge induced by EB and Prog., 2) whether GABA agonists reduce NE and EPI activity in the hypothalamus, and 3) whether a GABA agonist prevents the accumulation of median eminence LHRH induced by EB and Prog. Ovariectomized rats received the stimulatory EB plus Prog, treatment.

Simultaneously with Prog., rats received either saline, the barbiturate, phenobarbital, the GABAg agonist, baclofen, the GABA^ agonist, muscimol, or either the $\mathrm{GABA}^{\wedge}$ antagonist, bicuculline, or the putative GABAg antagonist, 5-aminovalerate. Additional experiments tested the effects of the GABA drugs on LH release in ovariectomized, hormonally untreated rats and in response to exogenous LHRH. The LH surge induced by EB+Prog. was blocked by treatment with either baclofen, muscimol, or phenobarbital. Bicuculline was ineffective in preventing the effect of baclofen and phonobarbital but partially prevented the effect of muscimol. Neither baclofen nor muscimol significantly affected LH release in hormonally untreated, ovariectomized rats or in rats receiving LHRH administration. In the results of Experiment 6, in 
EB plus Prog.-treated rats, baclofen and muscimol significantly reduced the concentrations of EPI and NE in the POA and MBH and prevented their decline after administration of otMT, suggesting decreased catecholamine transmission.

In Experiment 7, rats were primed with the ovarian hormones and received, concurrently with Prog., either saline, or baclofen. The GABAg agonist, baclofen, blocked the LH surge and selectively increased LHRH concentrations.

Experiment 8 tested 1) whether baclofen reverses the enhancement of $\mathrm{LH}$ release and catecholamine activity produced by naloxone, and 2) whether the opiate antagonist, nalmefene, prevents the blockade of the LH surge produced by baclofen. In the first study of Experiment 8, naloxone increased LH release and enhanced catecholamine activity in EB-primed rats. Baclofen was unable to reverse these effects. In the second study, baclofen administration to EB plus $\mathrm{P}$ treated rats blocked the LH surge and concomitant administration of nalmefene was unable to prevent this effect of baclofen.

These results suggest that: 1) the ovarian hormones activate both NE and EPI systems to stimulate the early afternoon rise of LHRH in the median eminence and to induce the subsequent LH surge, 2) the ovarian hormones may produce their positive feedback effects on LH secretion by removing an inhibitory GABA or opioid neuropeptide influence on catecholamine transmission, allowing NE and EPI to stimulate $\mathrm{LHRH}$, and subsequently, LH release, and 3) these modulatory actions of GABA and opiates may represent effects of two parallel, yet independent hypothalamic systems which regulate catecholamine neurotransmission and subsequently LH secretion.

\section{Document Type}

Dissertation

Degree Name

Doctor of Philosophy (PhD)

\section{Program}

Pharmacology

\section{Research Advisor}

William R. Crowley

\section{Keywords}

Catecholamines, Luteinizing Hormone, Pharmacology

\section{Subject Categories}

Chemicals and Drugs | Hormones, Hormone Substitutes, and Hormone Antagonists | Medical Pharmacology | Medicine and Health Sciences 


\title{
REGULATION OF LUTEINIZING HORMONE AND \\ CATECHOLAMINE RELEASE
}

\author{
A dissertation \\ Presented to the \\ Graduate Study Committee \\ of
}

The University of Tennessee Center for the Health

Sciences

\begin{abstract}
In Partial Fulfillment
of the Requirements for the Degree

Doctor of Philosophy
\end{abstract}

by

Benjamin Aaron Adler

December 1984 


\section{A23727518 r 1984}

\section{DEDICATION}

Peter Carlton Adler

15 Shevat 5713 - 27 Av 5728

olav hasholem 


\section{ACKNOWLEDGEMENTS}

The author would like to thank his major professor, Dr. William R. Crowley, for the individual professional guidance received during his graduate tenure as being invaluable in his development as an independent, productive scientist. Gratitude is also expressed to the other members of his graduate committee: Dr. C. E. Grosvenor, Dr. K. U. Malik, Dr. R. R. Mize, and Dr. I. Weinstein for their assistance and contributions to this work.

The author would like to express appreciation to C. 0. Lynch and B. L. Carroll for their technical assistance and to his wife Talynn Hanissian for the typing of the dissertation. The author would also like to thank the Graduate School of the University of Tennessee Center for the Health Sciences for financial support.

Finally, the author would like to thank his parents, Mr. and Mrs. Leonard and Rose Adler for donating their genes, and his wife Dr. Talynn Hanissian for her love. 
These studies tested the interrelated hypotheses that the ovarian hormones produce their positive feedback effects on luteinizing hormone (LH) secretion through activation of noradrenergic and adrenergic systems in specific hypothalamic regions. Furthermore, the ovarian hormones may alter the activity of opioid neuropeptide and Gamma-Aminobutyric Acid (GABA) systems to produce these alterations in catecholamine transmission and gonadotropin secretion. Radioimmunoassays were utilized to determine plasma LH and median eminence LHRH, and hypothalamic catecholamine concentrations were measured by radioenzymatic assay.

The first two studies tested whether epinephrine (EPI) synthesis inhibition blocks the accumulation of median eminence LHRH that precedes the ovarian hormone-induced LH surge and also to test whether the stimulatory ovarian hormone regimen enhances the activity of hypothalamic EPI systems. Ovariectomized rats were primed with estradiol (EB), followed 2 days later by progesterone (Prog.). Animals were treated before Prog. administration with saline, one of the EPI synthesis inhibitors SKF 64139 or LY 78335, or the norepinephrine (NE) synthesis inhibitor, FLA-63. The catecholamine synthesis inhibitors blocked or delayed the LH surge. FLA-63 completely prevented the accumulation of LHRH in the median eminence that preceded the rise in LH release. However, selective reduction in EPI levels with SKF 64139 only partially prevented this increase in LHRH. A second EPI synthesis inhibitor, LY 78335, delayed both the LH surge and the rise in LHRH. 
In a second experiment, the administration of EB plus Prog. to ovariectomized rats increased the alpha-methyltyrosine ( $\mathrm{MMT}$ ) induced depletion of EPI in the medial basal hypothalamus (MBH). The depletion of NE after synthesis inhibition was enhanced in both the MBH and preoptic-anterior hypothalamus (POA).

Experiments 3 and 4 examined a possible mechanism underlying these ovarian hormone effects on LH release and catecholamine activity. These studies tested whether the opiate antagonist, naloxone, which increases LH release, enhances the activity of NE and EPI neurons in the hypothalamus, and also tested whether morphine, an opiate agonist which decreases LH release, depresses the activity of hypothalamic NE and EPI activity. Administration of naloxone to EB-primed rats increased LH release and potentiated the depletion of NE in the POA and $\mathrm{MBH}$, and enhanced the decline of EPI and dopamine (DA) in the MBH, suggesting increased catecholamine activity in these regions. Administration of the opiate agonist, morphine, to rats pretreated with EB and Prog., decreased LH and decreased the depletion of the catecholamines in the $\mathrm{POA}$ and $\mathrm{MBH}$, suggesting reduced activity. In most cases, naloxone antagonized the inhibitory effect of morphine.

Experiments 5, 6, and 7 examined the involvement of (GABA) systems in the positive feedback effects of EB and Prog. on LHRH and LH release. These studies tested 1) the effects of GABAergic drugs on the LH surge induced by EB and Prog., 2) whether GABA agonists reduce NE and EPI activity in the hypothalamus, and 3) whether a CABA agonist prevents 
the accumulation of median eminence LHRH induced by EB and Prog. Ovariectomized rats received the stimulatory EB plus Prog. treatment. Simultaneously with Prog., rats received either saline, the barbiturate, phenobarbital, the $\mathrm{GABA}_{B}$ agonist, baclofen, the $\mathrm{GABA}_{A}$ agonist, muscimol, or either the $\mathrm{GABA}_{A}$ antagonist, bicuculline, or the putative $\mathrm{GABA}_{\mathrm{B}}$ antagonist, 5-aminovalerate. Additional experiments tested the effects of the GABA drugs on LH release in ovariectomized, hormonally untreated rats and in response to exogenous LHRH. The LH surge induced by EB+Prog. was blocked by treatment with either baclofen, muscimol, or phenobarbital. Bicuculline was ineffective in preventing the effect of baclofen and phonobarbital but partially prevented the effect of muscimol. Neither baclofen nor muscimol significantly affected LH release in hormonally untreated, ovariectomized rats or in rats receiving $L H R H$ administration. In the results of Experiment 6 , in $E B$ plus Prog.-treated rats, baclofen and muscimol significantly reduced the concentrations of EPI and NE in the POA and $\mathrm{MBH}$ and prevented their decline after administration of aMT, suggesting decreased catecholamine transmission.

In Experiment 7, rats were primed with the ovarian hormones and received, concurrently with Prog., either saline, or baclofen. The $\mathrm{GABA}_{B}$ agonist, baclofen, blocked the LH surge and selectively increased LHRH concentrations.

Experiment 8 tested 1) whether baclofen reverses the enhancement of LH release and catecholamine activity produced by naloxone, and 2) 
whether the opiate antagonist, nalmefene, prevents the blockade of the LH surge produced by baclofen. In the first study of Experiment 8 , naloxone increased LH release and enhanced catecholamine activity in EB-primed rats. Baclofen was unable to reverse these effects. In the second study, baclofen administration to EB plus $P$ treated rats blocked the LH surge and concomitant administration of nalmefene was unable to prevent this effect of baclofen.

These results suggest that: 1) the ovarian hormones activate both NE and EPI systems to stimulate the early afternoon rise of LHRH in the median eminence and to induce the subsequent LH surge, 2) the ovarian hormones may produce their positive feedback effects on LH secretion by removing an inhibitory GABA or opioid neuropeptide influence on catecholamine transmission, allowing NE and EPI to stimulate LHRH, and subsequently, LH release, and 3) these modulatory actions of GABA and opiates may represent effects of two parallel, yet independent hypothalamic systems which regulate catecholamine neurotransmission and subsequently LH secretion. 


\section{TABLE OF CONTENTS}

CHAPTER

PAGE

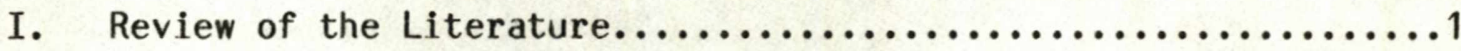

A. Introduction...............................

B. Regulation of LH Secretion by Ovarian Hormones...........1

C. Locus of Action of Ovarian Hormones in Regulation of

LH Secretion

1. Sites of Negative Feedback...................

2. Sites of Positive Feedback...................

D. Mechanism of Action of Ovarian Hormones...............

E. Role of Catecholamines in Regulation of LH Secretion

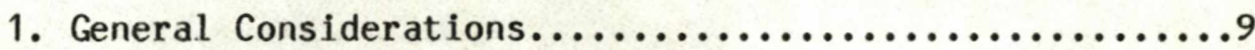

2. Catecholamine Involvement in Episodic LH Release......12

3. Catecholamine Involvement in the Preovulatory or Ovarian Hormone--Induced LH Surge......................

4. Local Modulation of Catecholamine Activity.........15

F. Role of Neuromodulatory Systems in Ovarian Hormone Feedback

1. The Endogenous Opioid Peptides--General

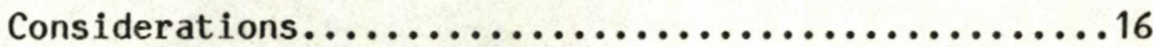

2. Endogenous Opioid Peptides and Ovarian Hormone Positive

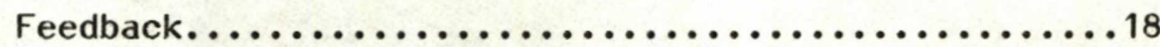


3. Gamma-Aminobutyric Acid (GABA)--General

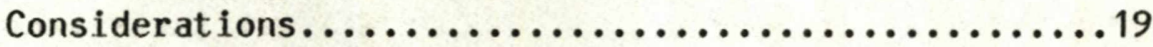

4. GABA and Ovarian Hormone Feedback...................

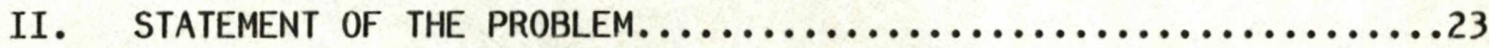

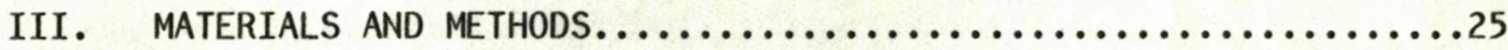

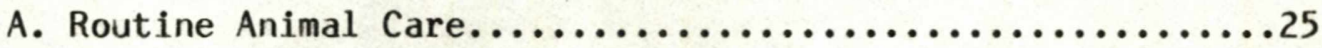

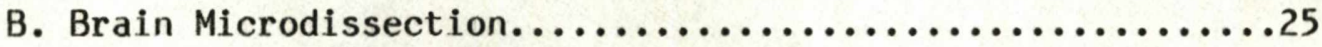

C. Regional Dissection of the Hypothalamus.................

D. The Alpha-Methyltyrosine Method.......................

E. Analytical Methods...............................

1. Catecholamines................................

2. Radioimmunoassay.................................

F. Hormone and Drug Treatments....................... 34

G. Statistical Analysis........................... 34

IV. RESULTS......................................

Effects of Phenylethanolamine- $\mathrm{N}$-methyl transferase and Dopamine-beta-hydroxylase inhibitors on Luteinizing hormone and LH-Releasing Hormone Surges Induced by

Ovarian Hormones (Experiment 1)....................... Effects of Ovarian Hormones on Catecholamine Activity 
in the Hypothalamus (Experiment 2).................40

Effects of Naloxone on Luteinizing Hormone and

Catecholamine Turnover in the Preoptic Area and

Medial Basal Hypothalamus of Estradiol-Primed

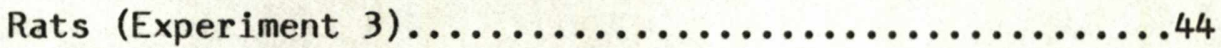

Effects of Morphine on Luteinizing Hormone Release

and Catecholamine Turnover in the Preoptic Area

and Medial Basal Hypothalamus of Estradiol Benzoate-

Progesterone Primed Rats (Experiment 4).............45

Effects of Gamma-Aminobutyric Acid Agonists and Antagonists on Luteinizing Hormone Secretion in

Ovariectomized and Ovariectomized, Ovarian Hormone-

Primed Rats (Experiment 5$)$...................... 52

Effects of Gamma-Aminobutyric Acid Agonists on

Catecholamine Turnover in the Preoptic Area

and Medial Basal Hypothalamus of Rats Treated

with Ovarian Hormones (Experiment 6) $\ldots \ldots \ldots \ldots \ldots \ldots \ldots$. . .

Effects of a Gamma-Aminobutyric Acid Agonist on the

Median Eminence Accumulation of LH-Releasing Hormone

Induced by Progesterone (Experiment 7).............61

Effects of Baclofen on Naloxone's Enhancement of

Luteinizing Hormone Release and Catecholamine

Activity in Estradiol-Primed Rats (Experiment 8a).....64 
CHAPTER

Effects of Nalmefene on the Blockade of the Luteinizing Hormone Surge Produced by Baclofen (Experiment $8 b) \ldots \ldots 68$

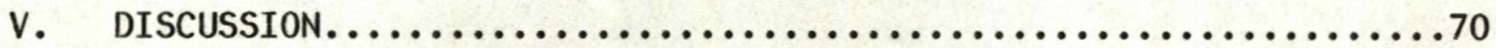

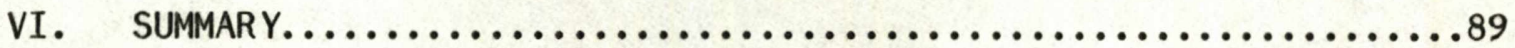

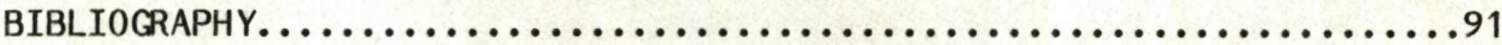

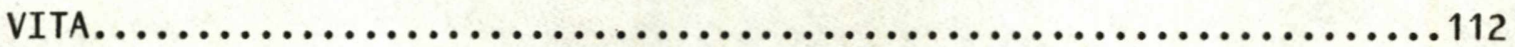




\section{LIST OF TABLES}

TABLE

PAGE

I. Effects of FLA-63 on the concentrations of LH in plasma and

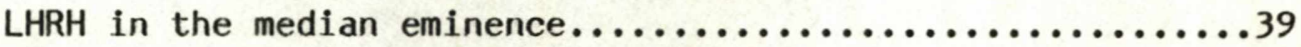

II. Effects of SKF 64139 , LY78335, and FLA-63 on catecholamine concentrations in the medial preoptic nucleus...........40

III. Effects of estradiol benzoate and progesterone (EB + Prog.) on the localized depletion of DA induced by aMT in the MPO$\mathrm{AH}$ and $\mathrm{MBH}$ .44

IV. Effect of naloxone on LH concentrations in ovarian hormonetreated female rats............................. 45

V. Effects of morphine and morphine plus naloxone on LH concentrations in ovarian hormone-treated female rats......49

VI. Effects of baclofen and muscimol on the EB plus Prog.-induced

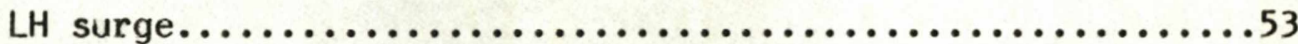

VII. Effects of 5-aminovalerate on baclofen's blockade of the

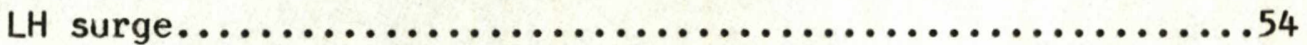

VIII. Effects of bicuculline and 5-amino-valerate on phenobarbital's blockade of the LH surge............................. 55

IX. Effects of baclofen and muscimol on LH release induced by

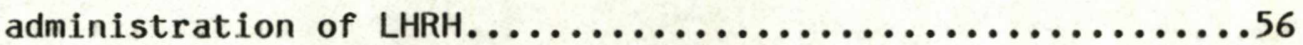

X. Effects of GABA agonists on LH release in ovariectomized

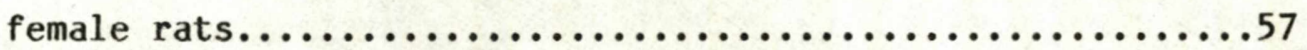


TABLE

XI. Effects of baclofen on the progesterone induced rise in

LH levels in estradiol primed rats.................62

XII. Effects of baclofen on the progesterone induced accumulation of LHRH concentrations in estradiol-primed rats.........63

XIII. Effects of baclofen on naloxone induced LH release in estradiol primed rats........................64

XIV. Effects of baclofen on naloxone's enhancement of NE depletion induced by aMT in the MBH of estradiol-

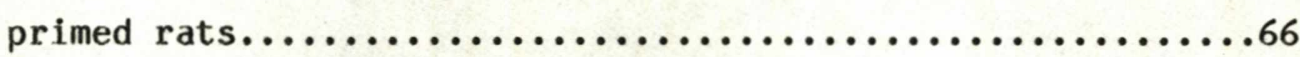

XV. Effects of baclofen on naloxone's enhancement of EPI

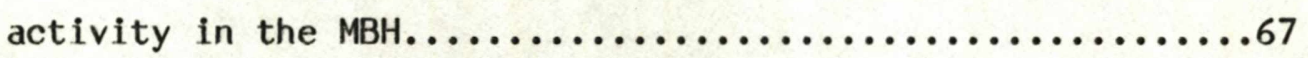

XVI. Effects of baclofen on naloxone's enhancement of DA

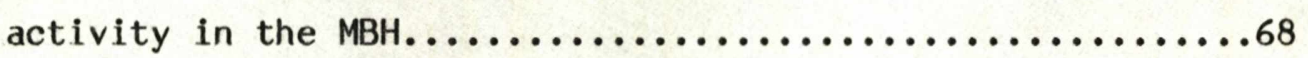

XVII. Effects of nalmefene on baclofen's blockade of the ovarian

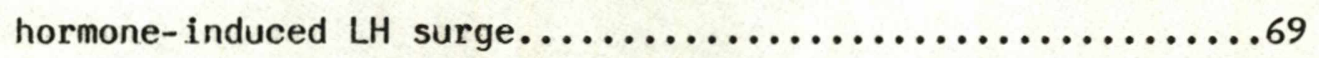




\section{LIST OF FIGURES}

FIGURE

PAGE

1. Effects of SKF 64139 on plasma LH and median eminence LHRH concentrations.

2. Effects of LY78335 on plasma LH and median eminence LHRH

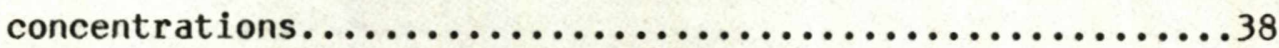

3. Effects of estradiol plus progesterone (EB+Prog.) treatment on the depletion of EPI in the MPO-AH and MBH after

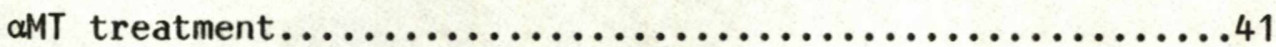

4. Effects of estradiol plus progesterone (EB+Prog.) treatment on the depletion of NE in the MPO-AH and MBH after aMT treatment

5. Effects of naloxone (NAL) or saline (SAL) on the depletion of NE after $\alpha M T$ in estradiol-primed rats..............46

6. Effects of naloxone on the depletion of EPI after aMT .....47

7. Effects of naloxone on the depletion of DA after $\alpha M T \ldots \ldots \ldots 48$

8. Effects of morphine (MOR) and naloxone (NAL) on the depletion of NE after aMT in animals are treated with estradiol plus progesterone (PROG) $\ldots \ldots \ldots \ldots \ldots \ldots \ldots$.......

9. Effects of morphine and naloxone on the depletion of EPI

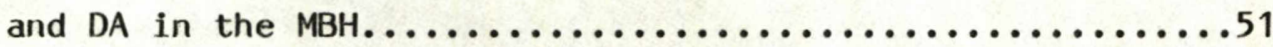

10. Effects of baclofen and muscimol on the depletion of NE produced by $\alpha M T$ in the $P O A$ and $M B H$. 
11. Effects of baclofen and muscimol on the depletion of EPI produced by $\alpha \mathrm{MT}$ in the $\mathrm{POA}$ and $\mathrm{MBH} \ldots \ldots \ldots \ldots \ldots \ldots \ldots$

12. Effects of baclofen and muscimol on the depletion of DA

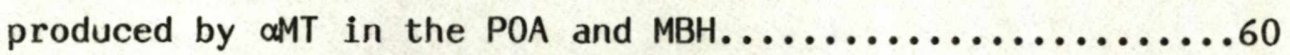




\section{CHAPTER I}

\section{REVIEW OF THE LITERATURE}

\section{A. Introduction}

The estrous cycle of the female rat is characterized by the secretion of both ovarian (estrogen, progesterone) and adenohypophyseal (luteinizing hormone, follicle stimulating hormone, prolactin) hormones which are released in a specific pattern. Plasma concentrations of luteinizing hormone (LH) and prolactin are maintained at low levels during diestrus day 1 and $2(1,2)$. This tonic inhibition is interrupted on proestrus by an afternoon surge in plasma levels of LH, follicle stimulating hormone, and prolactin $(1,2,3)$. These changes in anterior pituitary secretion are the result of the negative (inhibitory) and positive (stimulatory) feedback effects of estradiol and progesterone (4). The feedback actions of the ovarian hormones could take place either in the brain or the pituitary $(4,5)$.

\section{B. Regulation of 내 secretion by ovarian hormones}

Circulating levels of estradiol and progesterone fluctuate during the estrous cycle (2). Progesterone, secreted by the corpora lutea, rises during estrus and diestrus I and decreases during diestrus II. Estradiol secretion also begins to increase on diestrus I and II. Such concentrations of estradiol act synergistcally with progesterone to provide the tonic inhibition of $\mathrm{LH}$ during diestrus $(21,22)$. The acute increase in LH release following ovariectomy and the ability of estradiol to suppress it, support such a tonic inhibitory role for estradiol 
during diestrus (57). Estradiol concentrations continue to rise continuously before peaking on proestrus morning $(2,3)$. That such high levels of estradiol are essential for the occurrence of the preovulatory LH surge is suggested by studies in which an estrogen antagonist (23) or estradiol antiserum $(24,25)$ prevented the proestrous LH surge.

Estradiol thus appears to be indispensible for the proestrus LH surge to occur, however, progesterone may not be since antiserum to progesterone failed to block ovulation (24). However, progesterone does play an important role, in combination with estradiol, to augment the proestrus surge of LH $(22,25)$.

Administration of ovarian hormones to ovariectomized rats can mimic the inhibitory and stimulatory actions seen during the estrous cycle. Following ovariectomy, plasma LH rises and is secreted in a pulsatile fashion $(7,8)$, most probably a consequence of pulsatile LHRH release (18). Estradiol administration rapidly suppresses pulsatile LH release in ovariectomized rats $(9,10)$ thus providing a reliable model of estradiol negative feedback effects. Ovariectomized rats treated with estradiol exhibit daily afternoon surges of $\mathrm{LH}(10,11)$ and progesterone administration to such rats markedly stimulates the LH surge (12). These stimulatory effects of the ovarian hormones have provided a model of ovarian hormone positive feedback.

LHRH is the primary neural hormone regulating anterior pituitary LH release (13). LHRH cell bodies are concentrated in the diagonal band of Broca, septal nucleus, and preoptic area $(14,15)$ and project fibers to 
the median eminence that terminate on blood vessels of the portal system of the pituitary $(16,17)$.

LHRH appears to undergo fluctuations in rates of release during the course of the estrous cycle (18) with greatest amounts of LHRH released on proestrus $(18,19)$. In fact, LHRH release during proestrus has recently been observed to of biphasic (18), with, an initial "priming" pulse followed 2-3 hours later (1600--1730 hours) by a much larger secretion of LHRH. This priming action of LHRH significantly enhances the responsiveness of pituitary gonadotropes. Thus, a smaller quantity of LHRH may be required to initiate the LH surge $(4,20)$ and LHRH release is then coordinated with enhanced pituitary responsiveness $(4,20)$.

LHRH release appears to be responsive to changes in ovarian hormone concentrations during the estrous cycle. Estradiol increases LHRH release, both in vivo and in vitro $(46,58)$. In addition, progesterone appears to have positive effects on LHRH synthesis and release $(53,54$, 55).

After release of LHRH into the pituitary portal system, LHRH interbinds to specific, high affinity membrane receptors to stimulate LH release from anterior pituitary gonadotroph cells (225). Ovarian hormone manipulation of LHRH may account, at lease in part, for the effects of these hormones on LH release. In support of this, the increase in plasma LH levels observed after ovariectomy may be the result of an enhanced output of LHRH into the portal system $(26,27)$. Moreover, the administration of estradiol, which suppresses pituitary LH secretion, 
also depresses levels of LHRH in portal plasma of ovariectomized rats (26).

C. Locus of Action of Ovarian Hormones in Regulation of 내 secretion:

1. Sites of negative feedback

The inhibitiory effects of estradiol on $\mathrm{LH}$ release are believed to occur in both the pituitary and the brain, especially the medial basal hypothalamus (MBH) (5). Results from several lines of investigation support the MBH as a site of estradiol's negative feedback: (1) estrogen and/or progesterone bind to and are taken up by diencephalic cells, including cells in the MBH (38), (2) implants of estradiol into the MBH depress LH release $(27,32)$, (3) MBH lesions block estrogen's inhibition of LH in ovariectomized female rats (30), (4) electrical stimulation of the MBH depresses episodic LH release (31), and (5) damage to the MBH from bilateral knife cuts suppresses pulsatile LH release (35). These observations suggest, therefore, that at least a part of estradiol's inhibitory effects on LH release may occur in the $\mathrm{MBH}$.

Although the importance of progesterone in providing tonic inhibition of LH release during the estrous cycle has been established (22), the site of progesterone's inhibitory effects is not clear. Implants of progesterone into the MBH (29) or peripheral administration of the hormone (36) causes inhibition of LH release.

Estradiol appears to also exert part of its negative feedback effect on the pituitary gland. The response of the pituitary gland to release LH following LHRH administration is acutely enhanced by ovariec- 
tomy (33). Moreover, estradiol reduces pituitary responsiveness to LHRH in ovariectomized rats $(37,39)$.

In contrast to a report of enhanced LHRH neurosecretion accompanying the post-ovariectomy increase in LH (26), other investigators (18, 40) have failed to demonstrate any increase in portal plasma LHRH levels after ovariectomy. These results would suggest that estradiol produces its inhibitory effects on LH by acting on the pituitary gland. In further support of the anterior pituitary as the primary site of estradiol's negative feedback effects, a recent report (41) observed that a dose of estradiol that inhibits LH release, stimulates estrogen receptor translocation in the pituitary gland but not in the $\mathrm{MBH}$. These results suggest that estradiol exerts its inhibitory effects on LH secretion by acting in the brain but perhaps mainly in the anterior pituitary.

\section{Sites of positive feedback}

The majority of experimental evidence supports the concept that the stimulatory effects of estradiol on LH release are exerted both in the brain and at the level of the pituitary gland (5). Within the brain, the preoptic area ( $P O A)$ appears to be the most sensitive area to estradiol's effects. Estradiol is taken up by neurons in the POA (38) and electrochemical excitation of (42) or implantation of estradiol into $(43,44)$ the POA stimulates $\mathrm{LH}$ release. In addition, damage to the POA by knife cuts reduces gonadotropin secretion (45). Estradiol's stimulatory effects on LH secretion may be due to stimulation of LHRH release (46). LHRH levels in the portal blood are enhanced on the afternoon of proestrous $(18,19)$ and this has been attributed to an effect of 
increased estradiol concentrations (46). Moreover, estradiol stimulates the release of LHRH in vitro from the MBH of ovariectomized rats (58).

A portion of estradiol's positive feedback effects may occur in the pituitary gland (5). Estrogen increases the responsiveness of the pituitary to LHRH after pituitary stalk section (47) and also increases responsiveness of pituitary cells to LHRH in vitro (48). However, the possibility that the enhanced pituitary responsiveness is due to increasd LHRH release and to augmented "priming" actions of LHRH can not be excluded (26).

The stimulatory effects of progesterone may also occur in the brain or pituitary. Progesterone (probably in combination with estradiol) stimulates LH secretion on the afternoon of proestrous $(12,52)$. Implants of progesterone into the MBH at 1000 hours on proestrous leads to ovulation (51). Administration of progesterone to ovariectomized rats primed with estradiol increases the concentration of LHRH in the MBH (53) and enhances the secretion of LHRH into the pituitary portal system (54). In addition, in estradiol--primed rats, progesterone stimulates the release of LHRH both in vivo and in vitro $(55,56)$.

Stimulatory effects of progesterone have also been demonstrated in the POA. Implantation of progesterone into the POA-anterior hypothalamic area (226) elevates LH release in estrogen-primed, ovariectomized rats. Thus, progesterone appears to act in both the MBH and POA to induce LH release. Progesterone may also produce part of its stimulatory effects on $\mathrm{LH}$ release by an action on the anterior pituitary gland (5). Progesterone enhances the responsiveness of the pituitary gland to 
LHRH $(49,50)$. However, the possibility can not be excluded that enhanced pituitary responsiveness by progesterone to LHRH may be due to increased LHRH release or augmented "priming" action of LHRH (26).

\section{Mechanism of Action of Ovarian Hormones}

The mechanism of action of the ovarian hormones in producing their feedback effects may be by direct interaction with nerve cell membranes or by indirect actions at the level of the genome (59). An indirect mechanism of action of the ovarian steroids at the genomic level would involve an interaction of the hormone with its receptor to alter RNA synthesis and gene transcription (60). Steroid hormones diffuse freely into cells and are retained due to binding to receptor sites found only in target cells (61). This hormone-receptor complex then migrates to the nucleus and binds there to nuclear acceptor sites (61). The nuclear acceptor sites are composed largely of chromatin, a mixture of DNA and DNA-nonhistone protein complexes $(61,62)$. After binding to the nuclear acceptor complex, the hormone is capable of altering RNA synthesis $(61,62)$.

The possibility that the ovarian hormones may alter genomic function to produce their feedback effects is supported by observations that these hormones affect the levels of specific enzyme and neurotransmitter receptor proteins in the brain (63). Estrogen receptors have been demonstrated in the brain, especially concentrated in areas thought to be involved in the regulation of $\mathrm{LH}$ secretion, e.g. the POA and MBH (38, 64). Estrogen treatment can alter the levels of enzymes, such as choline acetyltransferase, acetylcholinesterase, glutamic acid decarboxy- 
lase, tyrosine hydroxylase, and type A monoamine oxidase that regulate neurotransmitter biosynthesis and degradation $(59,63)$. Estrogen has also been shown to be able to induce progestin receptors in the POA (65) and to increase the number of muscarinic cholinergic, B--adrenergic, and serotonin type 1 receptors (63). However, whether these effects of estradiol are the result of genomic action and what role they play in ovarian hormone feedback remains undetermined.

Other lines of evidence do lend support to the concept that a portion of ovarian hormone feedback action is at the genomic level. The effect of estradiol in inducing hypothalamic progestin receptors is blocked by the protein synthesis inhibitor, anisomycin (63). Moreover, microapplication of anisomycin to ventral medial hypothalamus prevents the activation of feminine sexual behavior induced by estradiol and progesterone (65). Estradiol activated RNA polymerase II in the hypothalamus (60) and recent evidence indicates that estradiol--induced receptor translocation in the pituitary and POA can be correlated to estradiol's negative and positive feedback effects, respectively (41).

Estradiol may produce a portion or all of its feedback actions by mechanisms other than classical receptor mechanisms. Estradiol could have direct effects on all membranes of LHRH neurons, catecholamine neurons, or pituitary gonadotrope cells and thereby regulate gonadotropin secretion. In support of this concept, estradiol induces Ca++ dependent action potentials (66) and stimulates prolactin release (67) from cloned pituitary cells. Estradiol also stereospecifically hyperpolarizes POA and $M B H$ neurons by a direct membrane effect (68) and although the iden- 
tity of the neurotransmitter/neuropeptide contained in these neurons is unknown, some of the neurons may contain LHRH (69). Thus, estradiol may produce its negative and positive feedback effects by either direct effects in the brain or on the pituitary and/or indirect effects mediated at a genomic level in these tissues.

\section{E. Role of Catecholamines in Regulation of LH Secretion}

\section{General considerations}

The catecholamines, dopamine, norepinephrine, and epinephrine are synthesized from the amino acid tyrosine (70). An active transport mechanism transports tyrosine into the nerve terminal where the enzyme tyrosine hydroxylase converts tyrosine to 3,4--dihydroxyphenylalanine (DOPA), the formation of which appears to be the rate limiting step in catecholamine biosynthesis (71). Tyrosine hydroxylase is a stereospecific enzyme that requires a tetrahydropterine cofactor, in addition to $\mathrm{Fe}++$ and molecular $0_{2}(70)$. Alpha methyl--p--tyrosine, a competitive inhibitor of tyrosine, is an effective inhibitor of this enzymatic step. A carboxyl group is removed from DOPA by the enzyme L-aromatic amino acid decarboxylase, a non--specific enzyme requiring pyridoxal phosphate (72), to form dopamine (DA). DA is then transported, via a Mg++--ATP dependent process, into storage granules where it is stored until conversion to norepinephrine (NE) (70). DA is converted to NE by the enzyme dopamine--B--hydroxylase (DBH) in an enzymatic process requiring ascorbate and molecular oxygen. DBH is a $\mathrm{Cu}++--$ containing protein and copper chelating agents, e.g. FLA--63, are very effective 
inhibitors of this enzyme (70). NE in the brain and adrenal medulla is subsequently methylated by the enzyme phenylethanolamine-- N--methyl transferase (PNMT) to form epinephrine (EPI) in a reaction that uses Sadenosyl methionine as a methyl donor (73). Several competitive inhibitors of PNMT including SK \& F 64139 and LY 78335 effectively inhibit EPI synthesis and consequently lower EPI concentrations in the brain tissue (74).

Following calcium--dependent release of either DA, NE, or EPI into the synaptic cleft, the catecholamine acts on specific receptors located on the effector cells. Multiple receptors on which the catecholamines act to produce their effects have been implicated for DA (D1 \& D2) (75), and NE and EPI (alpha 1, alpha 2, beta 1, beta 2), (76,77). In addition to these post--synaptic receptors, abundant evidence indicates the presence of pre--synaptic receptors on catecholamine neurons that are involved in regulation of neurotransmitter release (78).

Pre--synaptic receptors involved in regulation of neurotransmitter release could include autoreceptors for the transmitter the neuron released, in addition to receptors for NE, DA, EPI, serotonin, angiotensin II, opioid peptides, acetylcholine, and prostaglandins (78).

The majority of NE, DA, or EPI released by nerve impulses is taken back up into the nerve terminals by an active re--uptake process (79). After re--uptake, catecholamines are degraded by two main enzymes, monoamine oxidase (MAO) and catechol--methyltransferase (COMT). Most of the release of NE and EPI that escapes re-uptake is metabolized by COMT to noremetanephrine and metanephrine, respectively (80). Normetanephrine 
and metanephrine are converted by MAO to 3-methoxy-4-hydroxy-mandelic acid (VMA), the major metabolite of catecholamines excreted in the urine (70). MAO and COMT, in addition to aldehyde reductase and dehydrogenase, converts NE to 3,4 dihydroxyphenylglycol, 3,4 dihydroxyphenylethylglycol, and 3-methoxy-4-hydroxy-phenylglycol (80). DA also be converted to 3,4-dihydroxyphenylacetic acid by MAO and aldehyde dehydrogenase before being metylated by COMT to homovanillic acid (80).

The anatomical pathways of the catecholaminergic systems have been extensively analyzed $(81,82)$. The noradrenergic system can be divided into the dorsal tegmental pathway and the ventral tegmental pathway (81). The dorsal tegmental pathway arises from cell bodies of the locus coeruleus (A6) (83) and projects primarily to the cerebral cortex, hippocampus, hypothalamus, and cerebellum (81). The ventral tegmental pathway originates from $A 1,2,5,7$ cell groups and innervates the hypothalamus, thal amus, brainstem (81).

The adrenergic systems have been termed $C 1$ and $C 2$ and are similar in many respects to cell groups $A 1$ and $A 2$ of the noradrenergic system. Cell bodies of the adrenergic system appear to originate in the lateral reticular nucleus (C1) and rostral medulla near the nucleus of the solitary tract (C2) (84). Adrenergic projections have been observed in the hypothalamus, thalamus, lower brainstem and intermediolateral cell column of the spinal cord (84).

The dopaminergic systems of the brain can be divided into nigrostriatal, mesocortical, incertohypothalamic, periventricular, and tuberohypophyseal pathways. The dopaminergic pathways provide DA to a variety 
of brain regions including the striatum, isocortex, allocortex, median eminence and pituitary, septum, and dorsal and pariventricular hypothalamic areas (82).

2. Catecholamine Involvement in Episodic LH release

Available evidence indicates an inhibitory role for DA in episodic LH secretion in the rat (85). DA and DA agonists such as apomorphine reduce $\mathrm{LH}$ release in ovariectomized rats $(86,87,88)$. The inability of DA antagonists such as pimozide to affect LH release (87) has prompted the suggestion that $D A$ is not a major regulator of steady state pulsatile LH release (85).

In the rat, there appears to be a dual noradrenergic regulation of pulsatile LH release, i.e. both inhibitory and excitatory components have been described (85). Infusion of NE or clonidine intraventricularly to ovariectomized rats suppresses episodic LH release $(88,89)$. However, an excitatory noradrenergic system may also participate in regulating pulsatile LH release. Reduction of hypothalamic NE levels $(86,87)$ or blockade of NE receptors $(90)$ inhibits episodic LH release. The physiological significance of such a dual system in regulating episodic LH release in ovariectomized rats remains to be established ( 85 , 91). However, administration of estradiol decreases the turnover of NE in the $\mathrm{POA}$ and $\mathrm{MBH}$ of ovariectomized rats, concomitant with a reduction of circulating LH levels $(105,106,110)$. Thus, disturbance of a stimulatory noradrenergic influence on LHRH release may produce estradiol's inhibitory effect on LH release. EPI appears to play little role in 
regulating episodic LH release (92). Inhibition of EPI synthesis (92) or infusion of the catecholamine intraventricularly (88) were without effect on LH release suggesting that EPI is not involved in controlling pulsatile LH release.

3. Catecholamine Involvement in the Preovulatory or ovarian Hormone--Induced LH surge

Catecholamines were initially implicated in the regulation of LH release following observations that dibenamine, an adrenergic blocking agent, suppressed copulation--induced ovulation (93). Subsequent studies demonstrated that dibenamine and reserpine, depletors of monoamines from nerve terminals, blocked ovulation in normal cycling rats $(94,95)$. Reserpine's inhibitory effect could be reversed by administering MAO inhibitors to prevent catecholamine metabolism (96).

Research over the last dozen years has solidified the involvement of catecholamines in the regulation of gonadotropin secretion and suggested that NE is the primary mediator of ovarian hormone positive feedback effects. Interruption of NE synthesis with inhibitors of tyrosine hydroxylase or DBH inhibited preovulatory LH surges (97) and surges of LH induced by treatment of ovariectomized rats with estradiol and progesterone (98). The aforementioned inhibitory effects are reversed by injections of dihydoxyphenylserine (DOPS), a NE precursor (98). Prevention of noradrenergic effects by receptor blockade with phenoxybenzamine or haloperidol also abolishes proestrus or ovarian hormone-induced LH surges $(98,99)$. In addition, infusion of NE intraventricularly to pro- 
estrous rats or ovariectomized rats primed with ovarian hormones stimulates LH release $(100,101)$ and NE is capable of promoting LHRH release both in vivo (102) and in vitro (103). More recently, ovarian hormone treatments that produce an LH surge have been shown to enhance the turnover of $\mathrm{NE}$ in the $\mathrm{POA}$ and $\mathrm{MBH}$ of ovariectomized rats $(104,105,106)$. Taken together, these findings provide support for the hypothesis that an increased noradrenergic neurotransmission underlies the stimulatory feedback effects of estradiol and progesterone on LHRH and $\mathrm{LH}$ release.

Whereas a stimulatory role for NE in gonadotropin secretion seems clear, the role of DA continues to be controversial. DA and the DA agonist apomorphine elevate LH concentrations when injected intraventricularly to cycling rats or ovarian hormone primed ovarectomized rats $(102,107)$ and elicits LHRH release from median eminence fragments in vitro (103). Moreover, DA turnover has been observed to be elevated on the afternoon of proestrus in the median eminence and arcuate nucleus (108). In contrast, DA and apomorphine reduce LH release in ovariectomized rats $(85,88)$ or do not affect LH release under a variety of endocrinological manipulations $(88,100,1109)$. The inconsistency of effects found with DA has resulted in the failure to define a specific role, if any, for this catecholamine in the regulation of gonadotropin release, using the female rat as a model.

In contrast to $\mathrm{NE}$, the role of central EPI systems in mediating ovarian hormone feedback had been, until recently, overlooked. Although EPI systems appear to play little role in episodic LH release $(88,92)$, 
several early reports revealed a possible stimulatory role in cycling animals. Intraventricular infusion of EPI elicits ovulation in estrogen--primed rabbits (111) and proestrus pentobarbital--treated rats (100). In addition, EPI stimulates LH release after intraventricular administration in ovariectomized rats primed with ovarian hormones (88, 101). However, the low concentration of EPI compared to NE in the brain (112) and the non-specificity of drugs available to differentiate adrenergic effects from noradrenergic ones, prompted many investigators to discount the role of EPI in controlling LH secretion. In recent years, the development of specific PNMT inhibitors $(113,114)$ provided a needed tool to define the involvement of EPI in ovarian hormone feedback.

Recent studies have demonstrated that selective inhibition of EPI synthesis prevents preovulatory (116) and ovarian hormone--induced LH surges $(92,115)$. Thus, both NE and EPI may be involved in the stimulatory (positive) feedback effects of the ovarian hormones. A major goal of this research is to define the possible sites and mechanisms of action of the ovarian hormones on EPI systems and the relationship of these effects to ovarian hormone positive feedback.

\section{Local Modulation of Catecholamine Activity}

The mechanisms by which the ovarian hormones alter catecholamine activity to produce their stimulatory effects on gonadotropin secretion are not well understood. Although estradiol and progesterone may affect catecholamine systems directly, several lines of evidence suggest that the ovarian hormone--catecholamine interaction may be indirect (117). 
Estradiol and progesterone are taken up avidly in areas that receive ascending catecholaminergic innervation $(38,614,118)$ and it is in these areas that the ovarian hormones seem to produce their effects on catecholamine turnover and on LH release. In addition, the changes in catecholamine turnover produced by estradiol and progesterone are usually confined to a few discrete regions $(108,110)$. These observations suggest that the ovarian hormones may effect the activity of intrahypothalamic systems that could exert discrete control over catecholamine release.

F. Role of Neuromodulatory Systems in 0varian Hormone Feedback

1. The Endogenous Opioid Peptides--general considerations The endogenous opioid peptides can be separated into three main groups: the enkephalins, peptides similar to beta-endorphin, and peptides related to dynorphin (120). Different genes appear to code for the three groups of peptides. Pre--proopiomelanocortin (POMC) is an inactive prohormone of which enzymatic cleavage produces several hormones including B--endophin, ACTH, and melanocyte stimulating hormone (121). Preproenkephalin is the 263 amino acid precursor for the enkephalin peptides containing four copies of Met--enkephalin, one Leu--enkephalin peptide sequence, and two sequences of C-terminally extended peptides, Met5--enkephalyl--Arg--Gly and Met5--enkephalyl--Arg--Phe $(122,123)$. Pre--prodynorphin containing 256 amino acids, is the precursor for dynorphin A, dynorphin B, and alpha--neo--endorphin (124).

The central distribution of the opioid peptides has only recently been revealed. The distribution of the enkephalins, presently the best 
characterized of the opioid peptides, includes cell bodies in the (1) telencephalon (caudate nucleus, nucleus accumbens, nucleus interstitialis of the stria terminalis (NIST), amygdala) with projections to, most importantly, the globus pallidus, but also to the amygdala and NIST; the diencephalon, mainly the hypothalamus, with projections to areas including the median eminence, the supraoptic nucleus, and neurohypophysis; (3) the brain stem and spinal cord, with cell bodies and fibers in a variety of areas including substantial grisea centralis, interpeduncular nucleus, dorsal

tegmental nucleus, raphe area, nucleus of the solitary tract, dorsal horn and intermediolateral horn (125).

Cell bodies containing beta--endorphin appear to be concentrated almost exclusively in the arcuate nucleus of the MBH (126). Fibers originating from this area extend to the lateral septum and nucleus accumbens and are abundant in many nuclei of the hypothalamus (126). Other fibers project prominently to such brain stem sites as the periaqueductal grey, the nucleus of the solitary tract, and the locus coeruleus (126).

The distribution of dynorphin and related peptides is less well established. Dynorphin A has been found in substantial amounts in the posterior pituitary (127) and seems to be concentrated in supraoptic and paraventricular nuclei (128) of the hypothalamus and the dorsal horn of the spinal cord (129).

The opioid peptides produce their biological effects through interactions with a heterogenous population of receptors (130). The opioid 
receptors, termed $\mathrm{mu}$, delta, sigma, kappa and epsilon, appear to bind different opiate and opioid peptides with varying degrees of specificity (131). Beta--endorphin seems to have equal affinity for mu and delta subtypes with little specificity for kappa receptors (131). The enkephalins, however, have much greater affinity for delta sites than mu, with little specificity for kappa sites. Recent evidence indicates that the dynorphin peptides may be the endogenous ligand for the kappa receptor subtype (132).

2. Endogenous Opioid Peptides and Ovarian Hormone Positive

Feedback

The endogenous opioid neuropeptides, such as the dynorphins, betaendorphin, or met--enkephalin, are possibly involved in ovarian hormone feedback as neuromodulators of catecholamine activity for several reasons. First, neurons containing these peptides are located in estradiol target areas, including the POA and $\mathrm{MBH}(128,133,134)$. In fact, a recent study observed that beta--endorphin neurons in the arcuate nucleus also accumulate estrogen (146) suggesting that these neurons are sites of estradiol action. The POA and MBH are also densely innervated by catecholamines $(81,82)$. Secondly, the alkaloid opiate agonist, morphine, and the endogenous opioid neuropeptides reduce both central and peripheral NE release $(135,136)$, most likely an action due to activation of inhibitory presynaptic receptors (137). Thirdly, morphine and the opioid peptides have profound neuroendocrine effects. Morphine and the opioid peptides depress the proestrous surge of LHRH and LH (138), block ovulation $(139,140)$, and prevent in ovariectomized rats the 
surge of LH produced by treatment with ovarian hormones (141). In addition, the specific opioid receptor antagonist, naloxone, blocks these effects $(138,140,141,142)$ and elevates LH when administered alone $(141,143,144,145)$. Moreover, morphine suppresses NE turnover enhanced by ovarian hormone priming (14). Recent pharmacological evidence suggests that this effect of naloxone to increase LH release may be due to activation of the stimulatory NE and/or EPI systems $(141,145)$. Thus, it is conceivable that ovarian hormones may alter the activity of an endogenous opioid neuropeptide system that regulates catecholaminergic neurotransmission. A second major focus of the present research will investigate the role of endogenous opioid peptides in modulating ovarian hormone effects on NE and EPI activity.

\section{Gamma Aminobutyric Acid (GABA)--General Considerations}

Gamma-aminobutyric acid (GABA) is the primary inhibitory neurotransmitter in the brain (148). GABA acid is synthesized in the brain from glutamic acid catalyzed by the enzyme glutamic acid decarboxylase (GAD), with the coenzyme pyridoxal phosphate required $(148,149)$. GABA Acid is further metabolized to succinic semialdehyde by the enzyme GABA: 2--oxoglutamate aminotransferase (GABA--T), in a reaction also requiring pyrodoxal phosphate (149). Succinic semialdehyde is converted to succinic acid by the enzyme succinic semialdehyde dehydrogenase.

GABA acid has been reported to have a specific distribution in mammalian brain $(150,151,152)$. The distribution of GABA, determined by both biochemical and immunohistochemical methods, seems to be highest in hypothalamic (peri--and para ventricular, arcuate, preoptic, and 
anterior hypothalamic) nuclei, as well as the substantia nigra and globus pallidus $(150,151,152)$.

Electrophysiological analysis of GABA effects has revealed two different mechanisms of actions (149). GABA receptor activation can lead to hyperpolarization of the target neuron, a result due to an enhanced chloride ion inhibition, GABA is also capable of pre--synaptically inhibiting nerve terminals by depolarization (149), an effect associated with an increased C1- ion conductance out of the neuron.

Results from biochemical, electrophysiological, and pharmacological studies have demonstrated the heterogeneity of central GABA receptors (154). Classical GABA A receptors appear to be linked to choride ion channels as stimulation of the GABA A receptor increases conductance leading to hyperpolarization (153). In contrast, GABA B receptors are not associated with chloride ion channels (154) but more possibly linked to voltage sensitive calcium channels in which activation depresses calcium conductance. GABA A and GABA B receptors may also be classified by pharmacological properties. Although GABA is a potent agonist at both sites, muscimol, isoguvacine, and Thip are active only at GABA A sites and inactive, or only weakly active at GABA B sites $(154,158)$. Para--chloro--phenyl GABA (baclofen) is a potent agonist at GABA B sites and is inactive at GABA A receptors $(159,160,161)$. GABA receptors also display differential sensitivity to antagonists. GABA A sites are antagonized by bicuculline (162) whereas GABA B receptors are insensitive to bicuculline antagonism $(159,160)$. Although a pure GABA B anta- 
gonist has not been identified, 5--aminovalerate may have some, albeit weak, GABA B antagonistic effects $(163,164)$.

4. GABA and Ovarian Hormone Feedback

GABA is also a candidate for a neuromodulatory role in ovarian hormone feedback. The reasons for suspecting $G A B A$ are very similar to ones for the endogenous opioid neuropeptides. GABA is densely concentrated in many hypothalamic regions, especially the medial basal area (150, 151,152) were GABAergic fibers are mixed with monoaminergic and LHRH systems $(165,166)$. Furthermore, GABA and GABA agonists, such as baclofen, reduce the evoked release of $3 \mathrm{H}--\mathrm{NE}$, both centrally and peripherally $(159,163,167,168)$. However, the evidence is somewhat conflicting on the influence of GABA on LH release. For example, GABA stimulates LH release in anesthetized male rats (169) but is without effect in unanesthetized male rats (170). Intraventricular administration of GABA increases $\mathrm{LH}$ levels in ovariectomized and ovariectomized, ovarian hormone primed $(171,172)$. However, more recent studies have been able to demonstrate an inhibitory influence of GABA and the GABA agonist, muscimol, on $\mathrm{LH}$ release $(173,174,175)$. In these studies, intraventricular administration of GABA or muscimol reduces LH and suppresses POA NE turnover in ovariectomized or ovariectomized, ovarian hormone--primed female rats $(173,174,175)$. Moreover, muscimol implanted locally into the POA decreases LH (175), and an estradiol treatment that reduced $\mathrm{LH}$ levels stimulated GABA turnover in the POA (174). Interestingly, a recent report noted that GABAergic neurons in the POA can accumulate delete estradiol (176) suggesting that estradiol 
may affect GABA transmission in the PDA. Thus, it has been proposed that estradiol may produce its negative feedback effects by enhancing POA GABA turnover which would, in turn, suppress stimulatory noradrenergic inputs to LHRH neurons $(173,174,175)$.

Other lines of evidence also support an ovarian hormone--GABA interaction. The activity enzyme mediating GABA synthesis, GAD, is increased to estradiol treatment $(177,178)$ and intraventricular injection of GABA blocks ovulation in immature rats (179). Evidence presently available strongly suggests a role for GABAergic neurons in ovarian hormone negative feed-back. A third major portion of the present research will examine the role of GABAergic neurons in modulating the stimulatory effects of the ovarian hormones on LH and on hypothalamic catecholamines. 
This research tests the interrelated hypotheses that the ovarian hormones produce their positive feedback effects on LH secretion through activation of noradrenergic and adrenergic systems in specific hypothalamic regions. Furthermore, the ovarian hormones may alter the activity of opioid neuropeptide and GABA systems to produce these alterations in catecholamine neurotransmission and gonadotropin secretion.

The specific objectives of these studies are to:

1) test whether selective catecholamine synthesis inhibitors prevent the ovarian hormone--induced accumulation and decline of LHRH in the median eminence.

2) examine whether an ovarian hormone regimen that elicits an LH surge enhances the activity of NE and EPI neurons in discrete regions of the hypothalamus.

3) test whether the opiate antagonist, naloxone, enhances the activity of NE and EPI neurons in discrete regions of the hypothalamus.

4) test whether the opiate agonist, morphine, which blocks the LH surge, depresses the activity of NE and EPI neurons in discrete regions of the hypothalamus.

5) investigate the effects of the GABA A agonist, muscimol, the GABA B agonist, baclofen, and the GABA antagonist, bicuculline and 5--aminovaleric acid on LH release. 
6) test whether the GABA agonists depress the activity of NE and EPI neurons in discrete regions of the hypothalamus.

7) test the effects of GABA agonists on the rise of LHRH induced by progesterone.

8)a) examine whether the GABA agonist, baclofen, reverses the enhancement of LH release and catecholamine activity produced by naloxone.

b) test whether the opiate antagonist, nalmefene, prevents the blockade of the LH surge produced by baclofen. 


\section{A. Routine Animal Care}

Adult, Sprague--Dawley albino female rats (Harlan Industries, Inc. Indianapolis) were used in the experiments, approximately 60 days of age at the beginning of each experiment. Animals were housed in groups of five and maintained on a $14 \mathrm{~h}$ light:10 h dark schedule (lights on 0500-1900) with water and food ad libitum. All rats were ovariectomized and allowed two--three weeks recovery.

\section{B. Brain Microdissection}

The microdissection technique is based on that described by Palkovits (180). After decapitation, brains are removed quickly and frozen on powdered dry ice. Three hundred micrometer thick coronal sections were cut at -4 degrees $C$ on a microtome cryostat. Brain sections were frozen onto microscope slides. Individual brain nuclei were then removed from the sections with stainless steel cannulae while viewed with a dissecting stereomicroscope. Generally, the appearance of brain ventricles, tracts, and recognizable nuclei were relied upon to guide the dissection. The dissected tissue was placed into the appropriate medium (0.1 $\mathrm{N} \mathrm{HClO}_{4}$ for catecholamines; $1 \mathrm{~N} \mathrm{HCl}$ for LHRH) and homogenized by sonication. Aliquots were removed for protein determination (181). The supernatent was then used for neurochemical analysis. 
C. Regional dissection of the hypothalamus

After decapitation, brains were removed rapidly and frozen on powdered dry ice. Two discrete brain regions were then dissected: 1) medial preoptic--anterior hypothalamic area (POA) and 2) medial basal hypothalamus $(\mathrm{MBH})$. The POA fragment is bordered by the optic chiasm rostrally and supraoptic commissures caudally, the anterior commissure dorsally, and extendes approximately $1 \mathrm{~mm}$ lateral to the midline on either side. The MBH fragment was bounded by the rostral--caudal extent of the median eminence, the infundibular sulcus laterally, and extended approximately $1 \mathrm{~mm}$ dorsally. These areas were weighed, homogenized in 1 $\mathrm{ml}$ of cold $0.1 \mathrm{~N} \mathrm{HClO}_{4}$, and centrifuged at 10,000 rpm for 30 minutes. Aliquots of sixty microliters were assayed for catecholamines with a sensitive radioenzymatic assay $(182,183,184)$.

\section{The alpha--Methyl Tyrosine Method}

As an index of catecholaminergic activity, the studies measured the depletion of hypothalamic catecholamines one hour after administration of the catecholamine synthesis inhibitor alpha-methyl tyrosine (aMT). The extent of catechoamine depletion after aMT administration depends largely upon the rate of nerve impulse flow (185). For example, after mid-thoracic spinal transection, the ability of aMT to reduce NE concentrations caudal to the transection is lost, suggesting that intact neuronal activity is essential for aMT to reduce NE levels (185). This method has since been used to study the effects of drugs on catecholamine function. A more pronounced decline after aMT indicates an 
"increased release" of transmitterr from nerve terminals, while a smaller decline reflects a relatively low state of activity. The aMT method, like all non-steady state methods, carries the limitation that synthesis blockade, with subsequent increases in transmitter levels, may affect the normal activity of the system (186). Although the method is limited to a lesser extent in that it may not provide a true turnover rate per se (186), any differences between two groups in the degree of depletion reflect differences in turnover (185). Thus, this approach is most appropriate for comparing the effects of different experimental conditions on catecholamine function.

\section{E. Analytical Methods}

1. Catecholamines: Concentrations of catecholamines were determined by radioenzymatic assay $(182,183)$. This assay used a partially purified preparation of catechol-0-methyltransferase to induce catecholamine methylation with radiolabeled S-adenosyl-L-methionine acting as the methyl donor. The resulting methylated catecholamines were purified by solvent extraction and isolated by thin layer chromatography. The 0-methylated compounds were then counted by liquid scintillation (184). The sensitivity of the assay is approximately equal to $5 \mathrm{pg}$ for the three catecholamines.

\section{Radioimmunoassay:}

Luteinizing Hormone. In each study, trunk blood was collected after decapitation and centrifuged at $2000 \mathrm{rpm}$ for 20 minutes. Serum was separated and stored at -85 degrees C. LH and prolactin were 
measured by double antibody radioimmunoassays, using NIADDK/NICHD National Hormone Pituitary Program reagents and procedures. Log logit data transformation was used for data calculation (178). The inter--and intraassay coefficients of variation for LH were $13.5 \%$ and $6 \%$, respectively.

LH--Releasing Hormone. LHRH was measured by the double antibody radioimmunoassay of Nett, et. al. (188), using the R--42 antiserum. Synthetic LHRH (Peninsula Laboratories) was used for reference standard and for iodination. Monoiodinated LHRH was prepared by a modification of the chloramine T method (189). Intraassay coefficients of variation ranged from $1 \%$ to $7 \%$, and the sensitivity of the assay was approximately $0.5 \mathrm{pg} /$ tube.

F. Hormone and Drug Treatments

Experiment 1: Effects of PNMT and DBH inhibitors on the LH and LHRH surges induced by ovarian hormones

In this study, as in other studies of the project that investigated the positive feedback effects of the ovarian hormones, stimulatory sequential ovarian hormone priming was used. In each study, ovariectomized female rats received sc injections of estradiol benzoate (EB; 50 micrograms at $1000 \mathrm{~h}$ ) followed by progesterone (P; $2.5 \mathrm{mg}) 48 \mathrm{~h}$ later. Henceforth this shall be simply referred to as EB--P priming.

In each study of experiment 1 , the animals received the EB--P priming. Beginning $1 \mathrm{~h}$ before the progesterone injections, animals received ip injections of one of the following 1) the EPI synthesis inhibitor 
SKF $64139(50 \mathrm{mg} / \mathrm{kg}), 2)$ the DBH inhibitor FLA-63 (40 mg/kg), or 3) the EPI synthesis inhibitor LY $78335(50 \mathrm{mg} / \mathrm{kg})$. The EPI synthesis inhibitors were dissolved in saline while FLA-63 was dissolved in $1 \mathrm{~N}$ $\mathrm{HC1}$, buffered to $\mathrm{pH} 6.8$ and diluted in saline. In each experiment, appropriate saline vehicle controls were conducted simultaneously. Selected animals were killed by decapitation at various times after progesterone treatment in order to encompass the changes in tissue LHRH and plasma LH concentrations. Plasma LH and median eminence LHRH were measured by radioimmunoassay. To varify the effectiveness of the catecholamine synthesis inhibitors, concentrations of NE, EPI, and DA were determined in the POA.

Experiment 2: Effects of ovarian hormones on catecholamine activity in the hypothalamus.

This study tested whether hypothalamic catecholamine neurons are activated by an ovarian hormone treatment that induces an LH surge. Ovariectomized rats received sequential oil or EB-P priming and were sacrificed either $3 \mathrm{~h}$ after progesterone (or oil) or $6 \mathrm{~h}$ after progesterone treatment. The period $3 \mathrm{~h}$ after progesterone corresponds to the approximate time during which LHRH levels are increased in the median eminence. The period $6 \mathrm{~h}$ after progesterone corresponds to the time of the LH surge. One hour before decapitation, half of the animals in each group were given ip injections of saline, and half received the catecholamine synthesis inhibitor alpha-methyl tyrosine methyl ester HC1 (400 $\mathrm{mg} / \mathrm{kg}$ base; $\mathrm{aMT})$. Concentrations of NE, EPI, and DA in the POA and MBH 
were determined by radioenzymatic assay.

Experiment 3: Effects of naloxone on 내 release and catecholamine turnover in the POA and MBH of estradiol--primed rats.

This experiment was designed to test whether naloxone, an opiate antagonist, mimics the effects of progesterone in increasing LH release and catecholamine turnover in rats primed with estradiol. In this experiment, rats were primed with EB at 1000h. Fifty hours later $(1200 \mathrm{~h})$, animals received ip injections of either saline vehicle or naloxone $\mathrm{HC1}(10 \mathrm{mg} / \mathrm{kg})$ and were sacrificed $1 \mathrm{~h}$ later. In order to assess catecholamine activity, one half of the animals in each group were given aMT $(400 \mathrm{mg} / \mathrm{kg})$ simultaneously with the naloxone or saline. Plasma LH was determined by radioimmunoassay and catecholamine concentrations in $\mathrm{POA}$ and $\mathrm{MBH}$ were measured with radioenzymatic assay.

Experiment 4: Effects of morphine on LH release and on catecholamine turnover in the $\mathrm{POA}$ and $\mathrm{MBH}$ of EB-P primed rats.

This experiment tested whether the opiate agonist, morphine which blocks the LH surge, will also prevent the stimulation of catecholamine turnover induced by estradiol and progesterone. Animals received the EB-P priming and were sacrificed $3 \mathrm{~h}$ later. One hour prior to decapitation, groups of progesterone treated animals received either saline, morphine HC1 $(10 \mathrm{mg} / \mathrm{kg})$, or morphine plus naloxone HC1 $(5 \mathrm{mg} / \mathrm{kg})$. At the same time, half of the animals in each group received aMT. Doseages of opiate drugs used in Experiments 3 and 4 were chosen on the basis of those doses known to affect LH release. Plasma LH was determined by 
radioimmunoassay and catecholamine concentrationsin POA and $\mathrm{MBH}$ were measured with a radioenzymatic assay.

Experiment 5: Effects of GABA agonists and antagonists on 내 secretion in ovariectomized and ovariectomized, ovarian hormone-primed rats.

The first study of Experiment 5 was designed to test the effects of GABA agonists and antagonists on the surge of LH induced by the ovarian hormones. Animals received sequential oil or EB-P injections. Concomitant with the progesterone injections, animals were given ip injections of either saline vehicle, the barbiturate, phenobarbital $(50 \mathrm{mg} / \mathrm{kg})$, the selective GABA B agonist, baclofen $(10 \mathrm{mg} / \mathrm{kg})$, or the GABA A agonist, muscimol $(2 \mathrm{mg} / \mathrm{kg})$. Additional animals in each group also received the postsynaptic GABA A antagonist, bicuculline $(1 \mathrm{mg} / \mathrm{kg})$ or the putative GABA B antagonist, 5 aminovaleric acid $(10-150 \mathrm{mg} / \mathrm{kg})$, simultaneously. In order to ensure maximal duration of drug action, half of the animals in each group received a second injection at $1400 \mathrm{~h}$ of their respective agonist or agonist plus antagonist.

A second study tested whether the GABA agonists, baclofen or muscimol, directly affect the anterior pituitary gland. Rats were given the stimulatory EB-P priming. Beginning with the progesterone injections, the animals received simultaneous ip injections of either saline vehicle, baclofen $(10 \mathrm{mg} / \mathrm{kg})$, or muscimol $(2 \mathrm{mg} / \mathrm{kg})$. Two hours after progesterone $(1200 \mathrm{~h})$, animals received either saline vehicle or $100 \mathrm{ng}$ synthetic LHRH subcutaneously and were sacrificed 15 minutes later.

A third study was performed to examine the effects of the GABA ago- 
nists on LH release in ovariectomized, hormonally untreated rats. In this experiment, ovariectomized rats received at $1200 \mathrm{~h}$ ip injections of either saline vehicle, baclofen $(10$ or $20 \mathrm{mg} / \mathrm{kg})$, or muscimol (2 mg/ kg). Additional agonist treated animals were also given bicuculline (1-4 mg/kg) simultaneously. Animals were sacrificed by decapitation one hour after drug treatment. LH was determined by radioimmunoassay.

Experiment 6: Effects of GABA agonists on catecholamine turnover in the $\mathrm{POA}$ and $\mathrm{MBH}$ of rats treated with ovarian hormones.

Experiment 6 was designed to test whether GABA agonists alter hypothalamic catecholamine activity in rats pretreated with ovarian hormones. In this study, ovariectomized rats received the stimulatory EB-P priming, and were sacrificed $3 \mathrm{~h}$ after progesterone. Concomitant with the progesterone injections, animals received ip injections of either baclofen $(10 \mathrm{mg} / \mathrm{kg})$, muscimol $(2 \mathrm{mg} / \mathrm{kg})$, or saline vehicle. To assess effects on catecholamine activity, one hour before decapitation, half of the animals in each group received aMT $(400 \mathrm{mg} / \mathrm{kg})$. Plasma LH was determined by radioimmunoassay and catecholamine concentrations in POA and MBH were measured with a radioenzymatic assay.

Experiment 7: Effects of a GABA agonists on the median eminence accumulation of LHRH induced by progesterone.

This study was designed to test whether the $\mathrm{CABA}_{B}$ agonist, baclofen, can prevent the ovarian hormone stimulation of LHRH concentrations in the median eminence. Animals received the stimulatory EB-P priming. 
Concomitantly with the progesterone injections, animals received ip injections of either baclofen $(10 \mathrm{mg} / \mathrm{kg})$, or saline vehicle. Animals were sacrificed either $1,2,3,4$, or 6 hours after progesterone in order to encompass the changes in tissue LHRH and plasma LH concentrations. Animals sacrificed $6 \mathrm{~h}$ after progesterone received a second injection of their respective drug or saline treatment at $1400 \mathrm{~h}$. LHRH and LH were measured by radioimmunoassay.

Experiment 8a: Effects of baclofen on naloxone's enhancement of LH

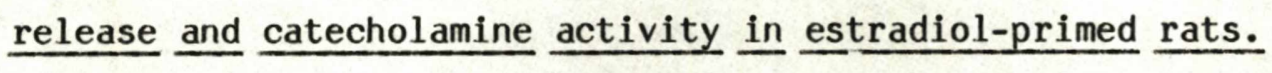

Experiment 8b: Effects of nalmefene on the blockade of the 내 surge produced by baclofen.

Two studies examined the interactions between GABA agonists and opiate antagonists and their relationship to $\mathrm{LH}$ release and catecholamine activity.

In the first study, ovariectomized rats received sc injections of EB followed fifty hours later $(1200 \mathrm{~h})$ by ip injections of either saline vehicle or naloxone $\mathrm{HC1}(10 \mathrm{mg} / \mathrm{kg})$. Simultaneously, one half of the animals in each group received saline or aMT and were sacrificed one hour later. In order to assess the effects of baclofen on naloxoneinduced catecholamine turnover, 30 minutes before naloxone, EB primed animals were given either baclofen or saline.

A second experiment was designed to test whether the opiate antagonist, nalmefene, prevents the blockade of the EB-P priming effect. At 
the time of the progesterone administration, animals received ip injections of either saline, baclofen $(10 \mathrm{mg} / \mathrm{kg})$, nalmefene $(10 \mathrm{mg} / \mathrm{kg})$, or baclofenplus nalmefene. To assure maximal duration of drug action, all animals received at $1400 \mathrm{~h}$ a second injection of their respective drug or drug plus antagonist treatment. All animals were sacrificed $6 \mathrm{~h}$ after progesterone $(1600 \mathrm{~h})$. LH was measured by radioimmunoassay and catecholamine concentrations in the MBH were determined with a radioenzymatic assay.

\section{G. Statistical Analysis}

Single factor or two-factor analysis of variance and Newman--Keuls tests were applied to determine levels of significance in changes in LH and LHRH secretion and catecholamine concentrations after experimental drug treatment (187). 
CHAPTER IV

RESULTS

Experiment 1: Effects of PNMT and DBH inhibitors on LH and LHRH surges induced by ovarian hormones.

As depicted in Figs. 1 and 2, the administration of progesterone at $1000 \mathrm{~h}$ to estrogen-pretreated rats significantly increased LHRH concentrations in the median eminence at $1300 \mathrm{~h}$. This elevation was followed by a significant decline at $1400 \mathrm{~h}$, and the levels did not change significantly thereafter. As reported previously (190), peak LHRH concentrations occurred before the highest levels of LH. Pretreatment with the catecholamine synthesis inhibitors blocked or delayed the LH surge, but had differential effects on the changes in median eminence LHRH. Figure 1 shows that the EPI synthesis inhibitor SKF 64139 partially blocked the rise of LHRH seen at $1300 \mathrm{~h}$. In these animals, LHRH concentrations increased significantly, but the magnitude of the effect was significantly less than that in the controls. LHRH concentrations were similar in the two groups at 1400 and $1600 \mathrm{~h}$.

In a second experiment, the highest levels of $\mathrm{LH}$ were observed in the controls at $1400 \mathrm{~h}$. Pretreatment with LY 78335, another EPI synthesis inhibitor, appeared to delay the LH surge by $2 \mathrm{~h}$, at which time LH concentrations were significantly higher than controls. LY 78335treated animals also showed a similar delay in the elevation of LHRH after progesterone treatment. 
Pretreatment with FLA-63, which inhibits both NE and EPI synthesis, also abolished the ovarian hormone-induced LH surge, but in contrast to the effects of SKF 64139 , completely prevented the rise of LHRH in the median eminence (Table 1). In this study, control animals showed significant increases in median eminence LHRH levels at 1400 and $1630 \mathrm{~h}$ compared to $1300 \mathrm{~h}$ valves. However, after treatment with FLA-63, LHRH levels failed to increase and progressively decreased from 1300 to 1630 h.

Thus, the LH surge can be prevented by inhibiting to synthesis of NE or EPI but the synthesis of both NE and EPI must be prevented to block the increase in LHRH concentrations in the ME. 


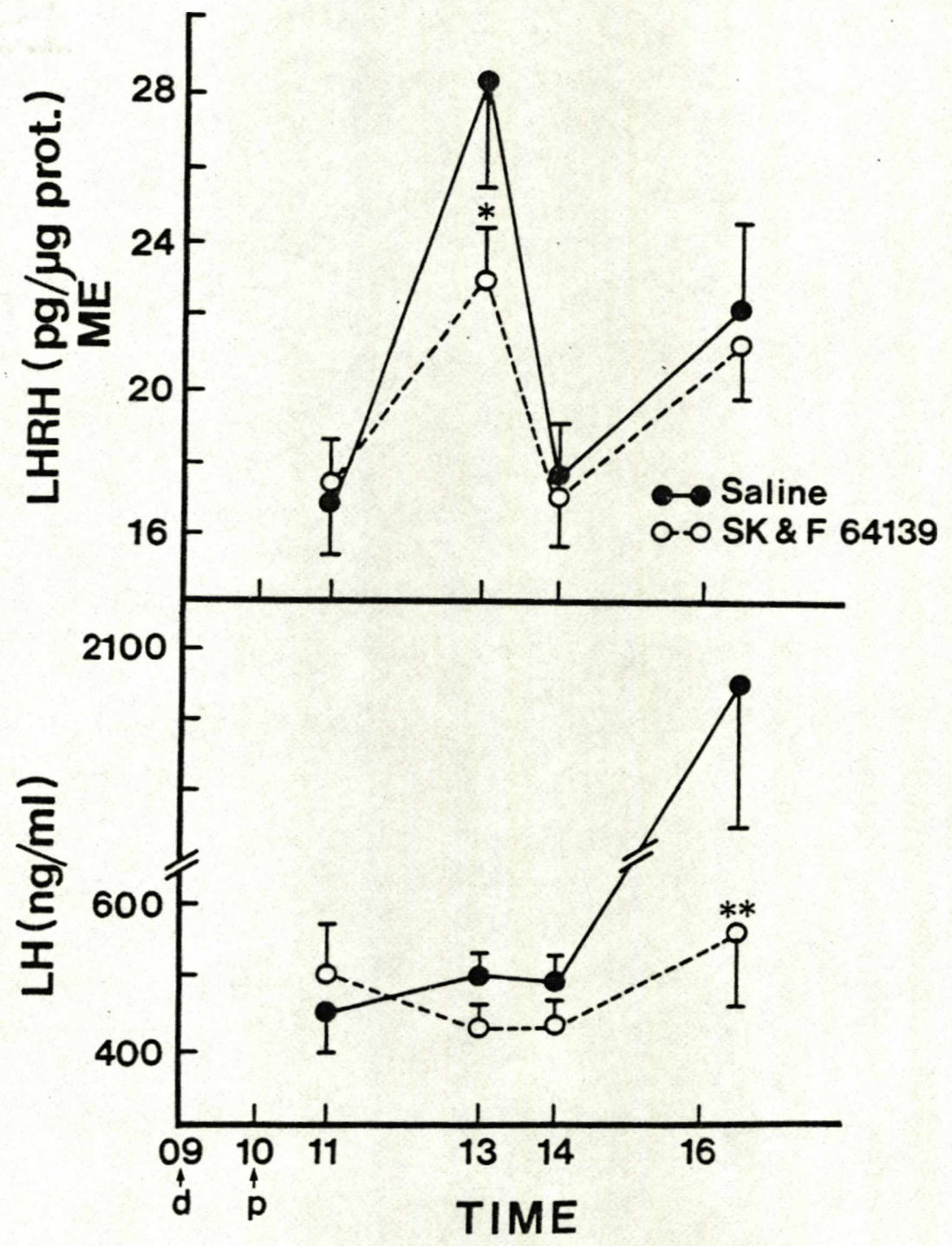

Figure 1. Effects of SKF 64139 on plasma LH and median eminence LHRH concentrations. d, Time of drug administration; $p$, time of progesterone administration. ${ }^{*} P<0.05 ; * * P<0.01$ ( $v s$. saline-treated controls, based on analyses of variance and Newman-Keuls tests). 

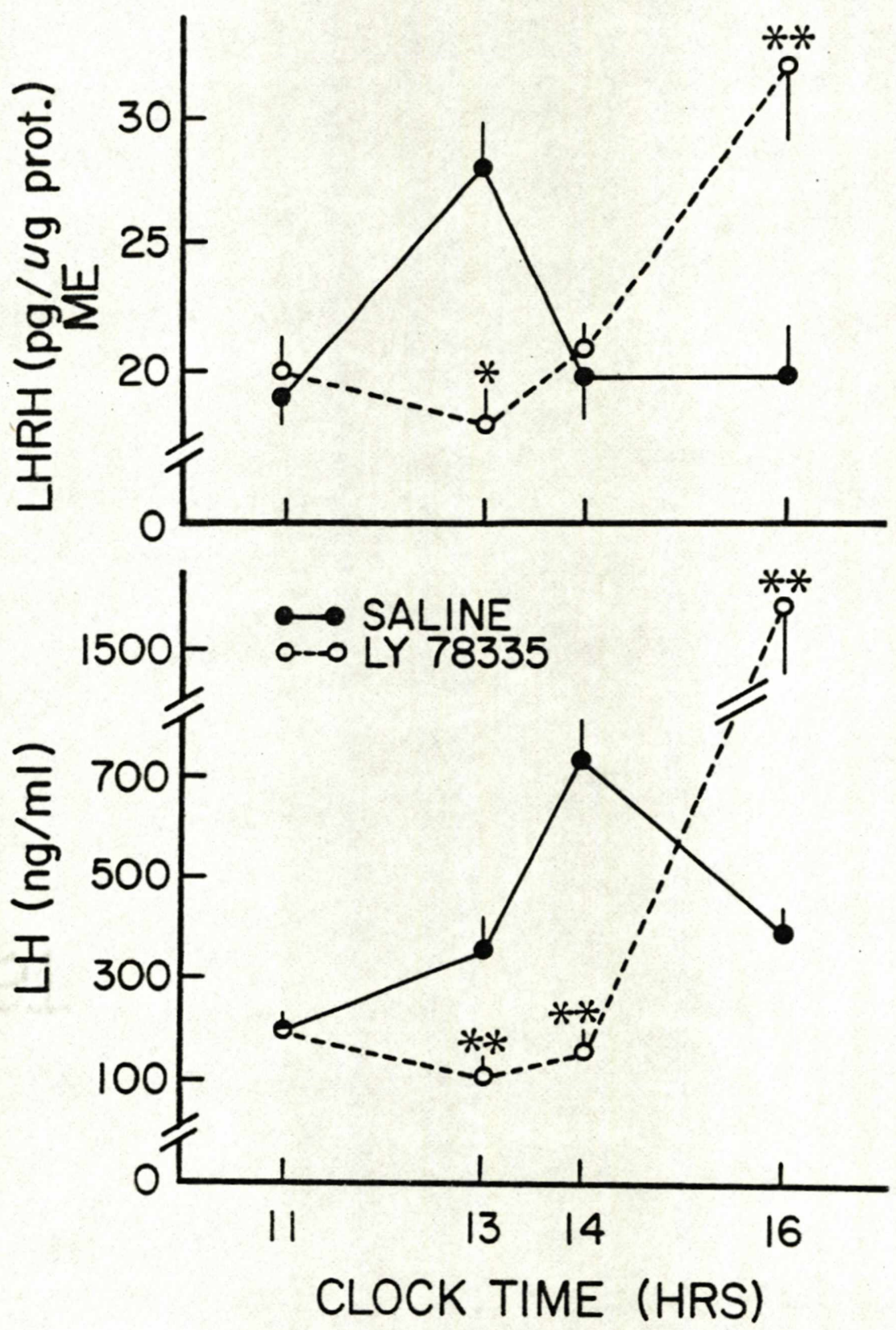

Figure 2. Effects of LY78335 on plasma LH and median eminence LHRH concentrations. Timing of injections is described in Fig. 1. * $P<$ $0.05,{ }^{*}, P<0.01$ (vs. saline-treated controls, based on analyses of variance and Newman-Keuls tests). 
TABLE I

EFFECTS OF FLA-63 ON THE CONCENTRATIONS OF LH IN PLASMA (A) AND LHRH IN THE MEDIAN EMINENCE (B)

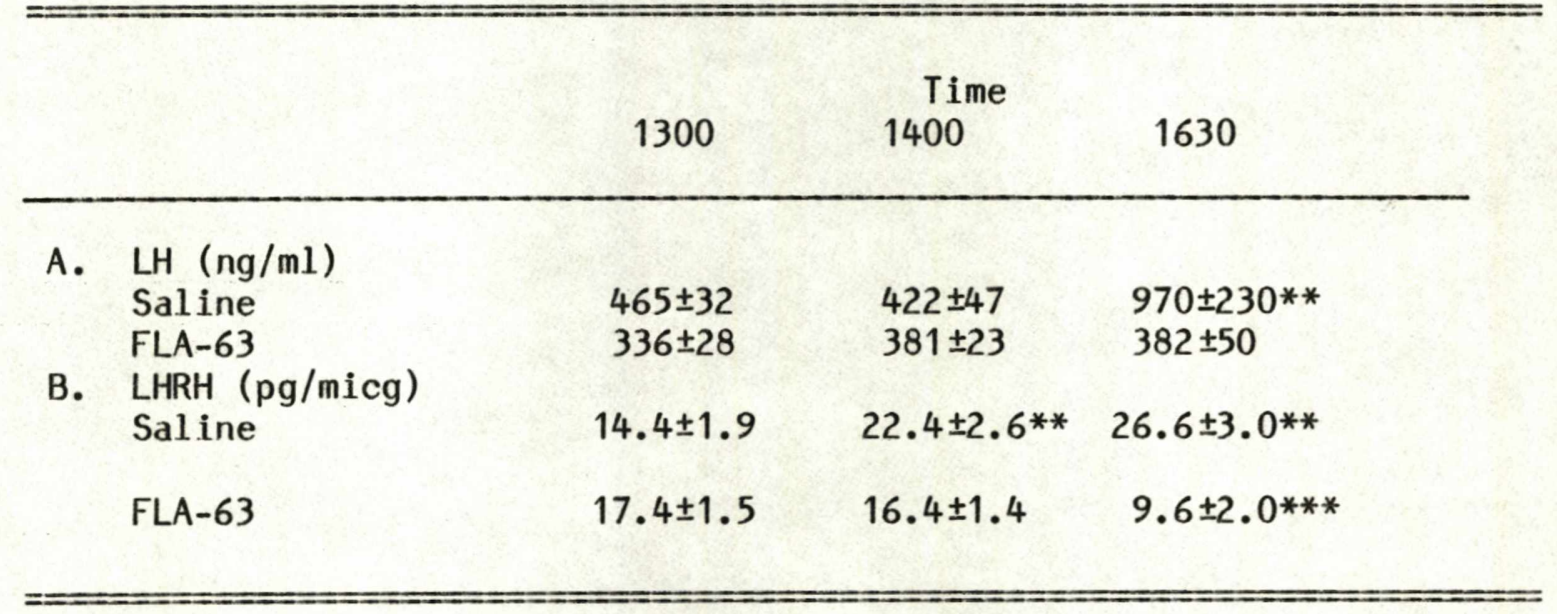

Values are the mean \pm SEM $(n=10)$.

*P<p. 01 vs. all others, based on analysis of variance and Newman-Keuls tests.

**P<0.01 vs. saline-treated group at $1300 \mathrm{~h}$

$* * * P<0.01$ vs. saline treated group at $1630 ; P<0.05$ vs. FLA 1300-treated group.

Table 2 illustrates the effectiveness of the catecholamine synthesis inhibitors in reducing NE and/or EPI concentrations in the medial preoptic nucleus. The DBH inhibitor FLA-63 significantly decreased both NE and EPI concentrations and significantly increased DA levels. Both SKF 64139 and LY 78334 decreased preoptic levels of EPI but had no effect on NE or DA. 
TABLE II

\section{EFFECTS OF SKF 64139, LY 78335, AND FLA-63 ON CATECHOLAMINE CONCENTRATIONS IN THE MEDIAL PREOPTIC NUCLEUS}

\begin{tabular}{|c|c|c|c|c|}
\hline \multirow{2}{*}{ Amine - } & \multicolumn{4}{|c|}{ Treatment } \\
\hline & Saline & FLA-63 & SKF 64139 & LY 78335 \\
\hline $\begin{array}{l}\text { NE } \\
\text { EPI }\end{array}$ & $\begin{array}{l}30.2 \pm 1.7 \\
0.48 \pm 0.04\end{array}$ & $\begin{array}{r}8.8 \pm 1.2^{*} \\
0.22 \pm 0.04\end{array}$ & $\begin{array}{c}25 \pm 1.6 \\
0.28 \pm 0.03\end{array}$ & $\begin{array}{l}30.5 \pm 1.7 \\
0.33 \pm 0.02 *\end{array}$ \\
\hline$D A$ & $1.6 \pm 0.2$ & $6.5 \pm 0.6^{*}$ & $1.2 \pm 0.09$ & $1.7 \pm 0.1$ \\
\hline
\end{tabular}

Values are the mean \pm SEM, expressed as picograms per microgram protein $(n=25-26)$. *P $<0.01$ based on analyses of variance and Newman-Keuls tests.

Experiment 2: Effects of ovarian hormones on catecholamine activity in the hypothalamus.

Results from this study revealed that the estrogen plus progesterone treatment that produces an LH surge, differentially affected the steady state concentrations and extent of depletion of NE and EPI in the POA and MBH. As shown in Fig. 3, the aMT-induced decline of EPI was significantly enhanced at $1300 \mathrm{~h}$ and at $1600 \mathrm{~h}$ in the MBH after progesterone treatment. There were no significant decreases in EPI in the POA after aMT administration in rats treated with oil, or estradiol and progesterone. The ovarian hormones also produced small, 


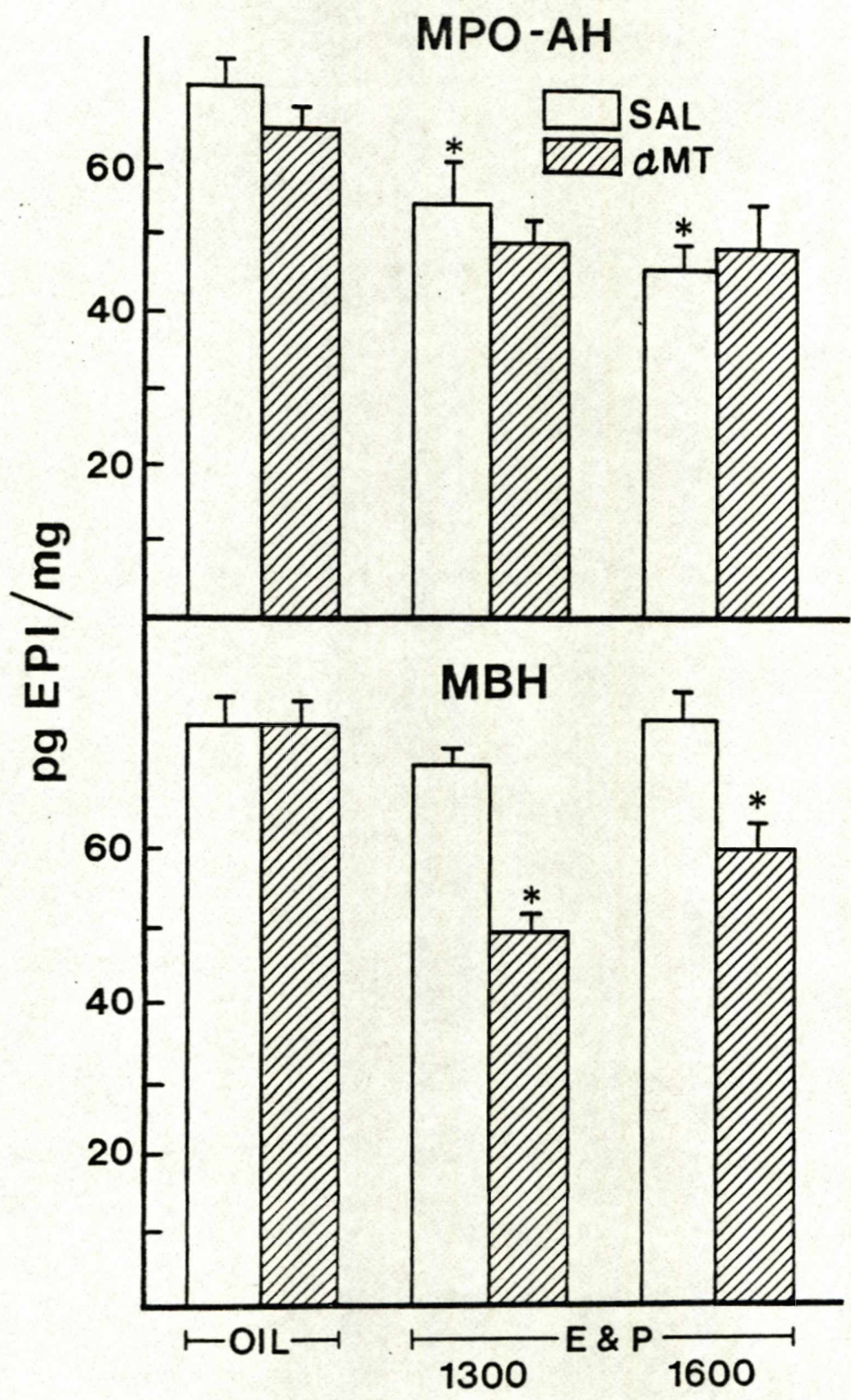

Figure 3. Effects of estradiol plus progesterone $(E+P)$ treatment on the depletion of EPI in the MPO-AH and MBH after $\alpha M T$ treatment. *, $(M P 0-A H), P<0.05$ vs. oil-saline $(S A L)$-treated group; ${ }^{*},(M B H), P<0.05$ vs. saline-treated group. 
but significant, decreases in steady state EPI concentrations in the POA.

Estradiol plus progesterone increased the magnitude of the aMT-induced depletion of NE in both hypothalamic regions at $1300 \mathrm{~h}$ (Fig. 4). The turnover of $\mathrm{NE}$ was reduced to the oil vehicle levels at $1600 \mathrm{~h}$ in these areas. Figure 4 also shows that basal, steady state concentrations of NE were significantly decreased by the ovarian hormones.

The levels and aMT-induced decline of DA were not affected in either region by estrogen plus progesterone treatment (Table 3 ). 


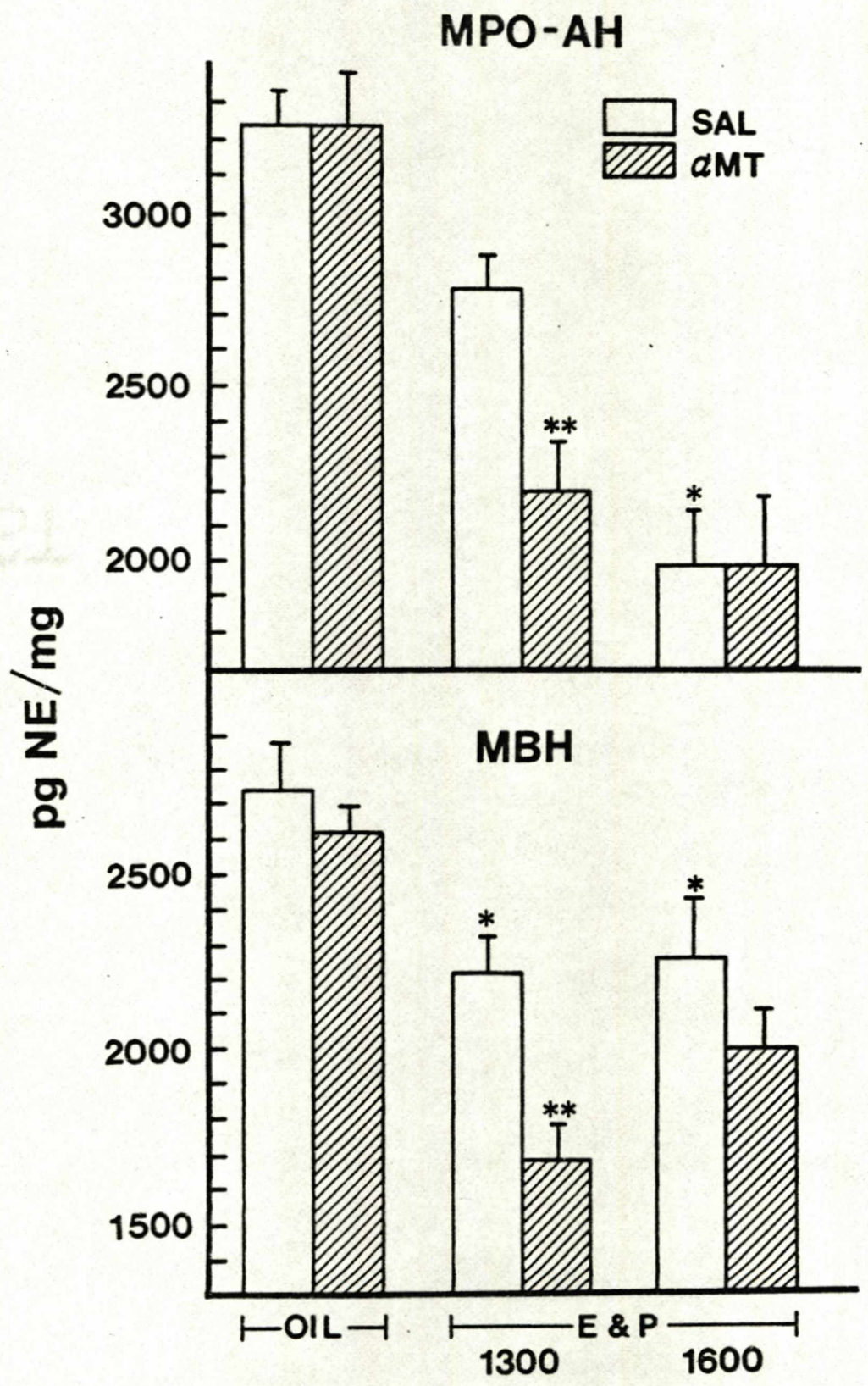

Figure 4. Effects of estradiol plus progesterone $(E+P)$ treatment on the depletion of NE in the MPO-AH and MBH after aMT treatment. *, $P<0.05$ vs. oil-saline (SAL)-treated group; $* * P<0.01$ vs. saline-treated group. 
TABLE III

EFFECTS OF ESTRADIOL BENZOATE AND PROGESTERONE (EB \& P) ON THE LOCALIZED DEPLETION OF DA INDUCED BY $\alpha M T$

IN THE POA AND MBH

\begin{tabular}{llllll}
\hline \multirow{2}{*}{ Treatment } & \multicolumn{2}{c}{ POA } & & \multicolumn{2}{c}{ MBH } \\
\cline { 2 - 3 } \cline { 5 - 6 } & Saline & $\alpha M T$ & & Saline & $\alpha M T$ \\
& & & & & \\
Oil & & & & & \\
**EB \& P, 1300 h & $241 \pm \pm 22$ & $172 \pm 36$ & & $637 \pm 45$ & $436 \pm 21$ \\
**EB \& P, 1600 h & $306 \pm 57$ & $170 \pm 28^{*}$ & & $526 \pm 35$ & $385 \pm 25 *$ \\
\hline \hline
\end{tabular}

Values are the mean \pm SEM, expressed as picograms per mg $(n=9-10)$. *P<0.05 vs. saline-treated group, based on analyses of variance and Newman-Keuls tests.

*P<0.01 vs. saline-treated group, based on analyses of variance and Newman-Keuls tests.

Experiment 3: Effects of naloxone on 내 release and catecholamine turnover in the $\mathrm{POA}$ and $\mathrm{MBH}$ of estradiol-primed rats.

Naloxone administration to EB-pretreated rats significantly increased circulating LH concentrations one hour later, as compared to saline controls (Table 4). 
TABLE IV

EFFECT OF NALOXONE ON LH CONCENTRATIONS IN OVARIAN HORMONE-TREATED RATS

\begin{tabular}{ll}
\hline \multicolumn{1}{c}{ Group } & LH, ng/ml \\
\hline & \\
EB + saline & $335 \pm 52$ \\
E + naloxone & $608 \pm 43 *$
\end{tabular}

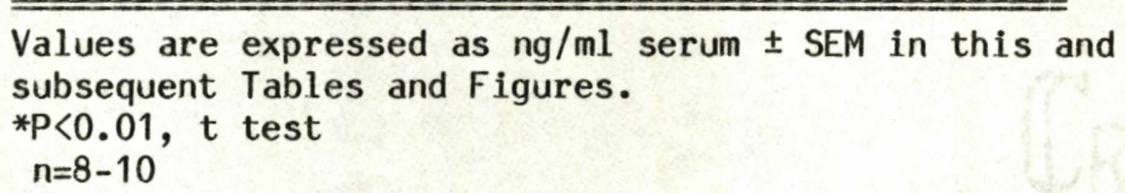

Figures 5 and 6 present the effects of naloxone on the aMT-induced decline of NE and EPI, respectively, in the two diencephalic regions. In the EB-saline controls, there were no significant declines in either catecholamine levels $1 \mathrm{~h}$ after aMT, suggesting a low level of activity in these regions.

However, the administration of aMT significantly increased the depletion of NE in both the POA and $\mathrm{MBH}$ and also increased the decline of EPI in the MBH of EB-naloxone treated rats, suggesting increased catecholamine activity. Naloxone did not alter the effects of aMT on EPI or DA depletion in the POA (figs. 2, 3), but produced a small, significant enhancement of DA depletion in the MBH (fig. 7).

Experiment 4: Effects of morphine on 내 release and catecholamine turnover in the $\mathrm{POA}$ and $\mathrm{MBH}$ of $\mathrm{EB}$-progesterone treated rats.

Table 5 shows that morphine decresed LH levels in EB-P treated rats. 


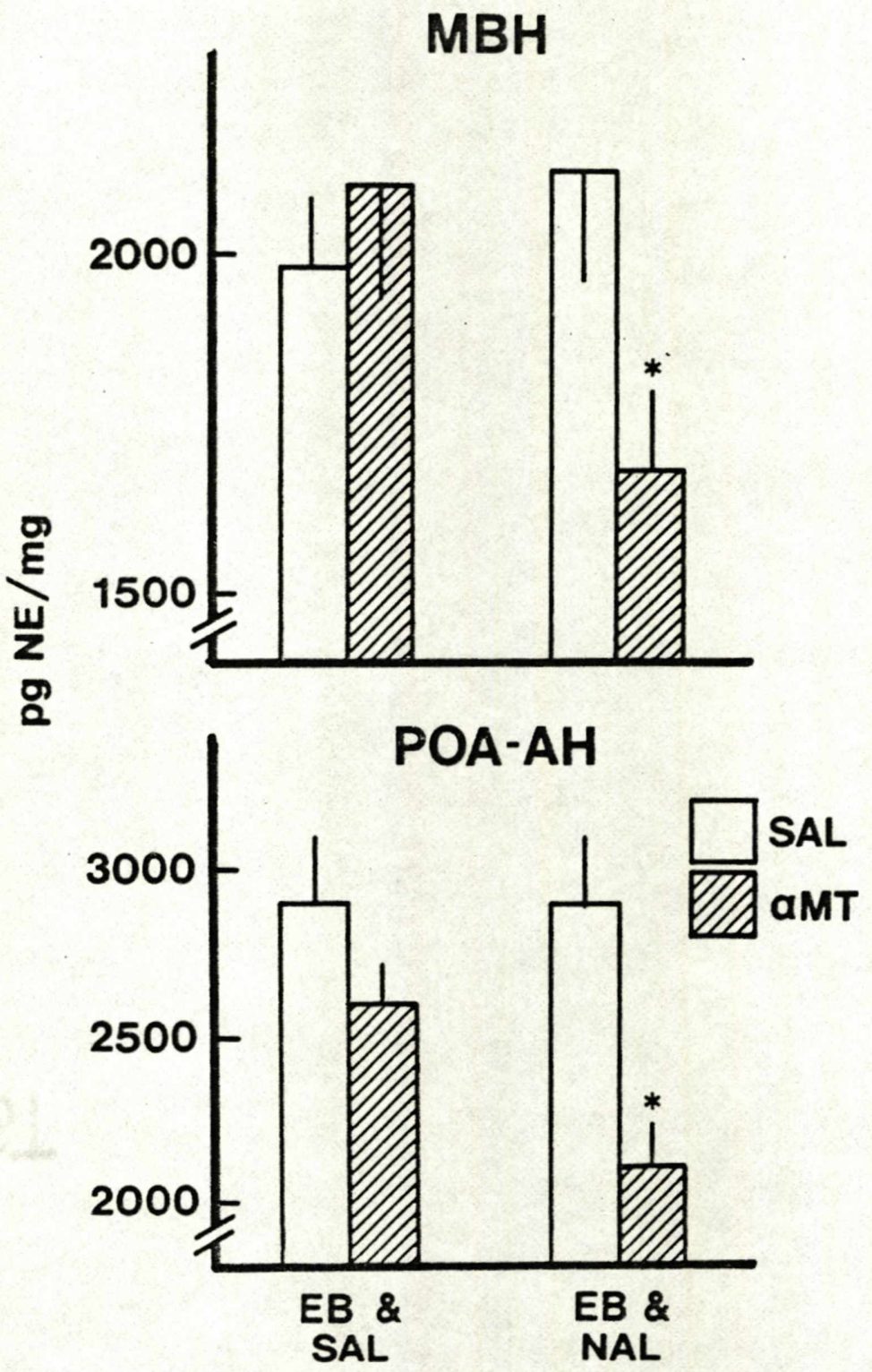

Figure 5. Effects of naloxone (NAL) or saline (SAL) on the depletion of NE after $M T$ in estradiol-primed rats. Statistical analysis (based on 2 -factor analysis of variance and Newman-Keuls tests). MBH: $* P<0.05$ vs. respective saline, $P<0.05$ vs. $E B$ and $S A L-a M T$. $P O A-A H:{ }^{*} P<0.01$ vs. respective saline, $P<0.05$ vs. $E B$ and $S A L-\alpha M T$. 


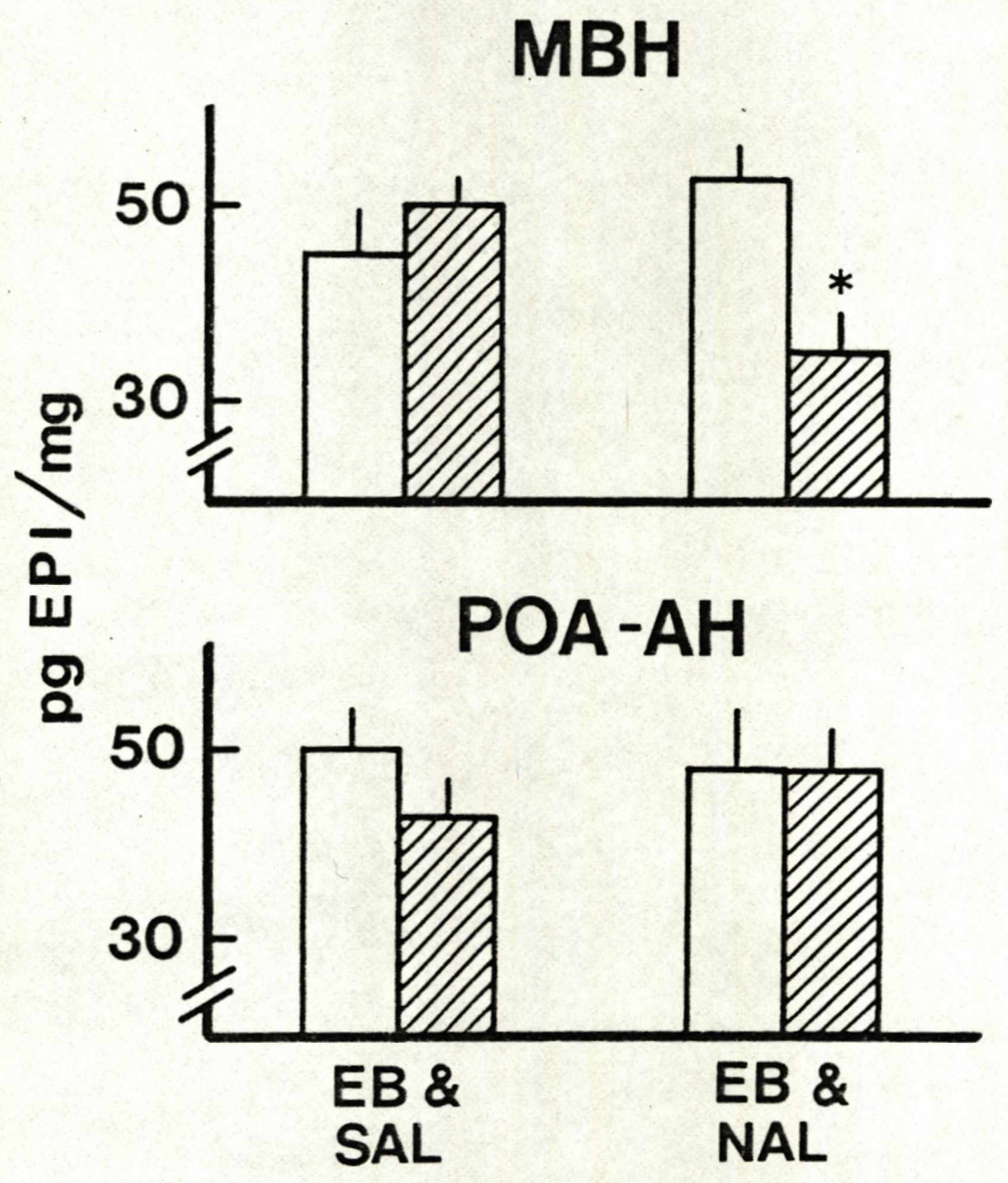

Figure 6. Effects of naloxone on the depletion of EPI after aMT. Abbreviation, coding and statistical analysis as in figure $5 . \quad * P<0.05$ vs. respective saline and vs. EB and SAL-aMT. 


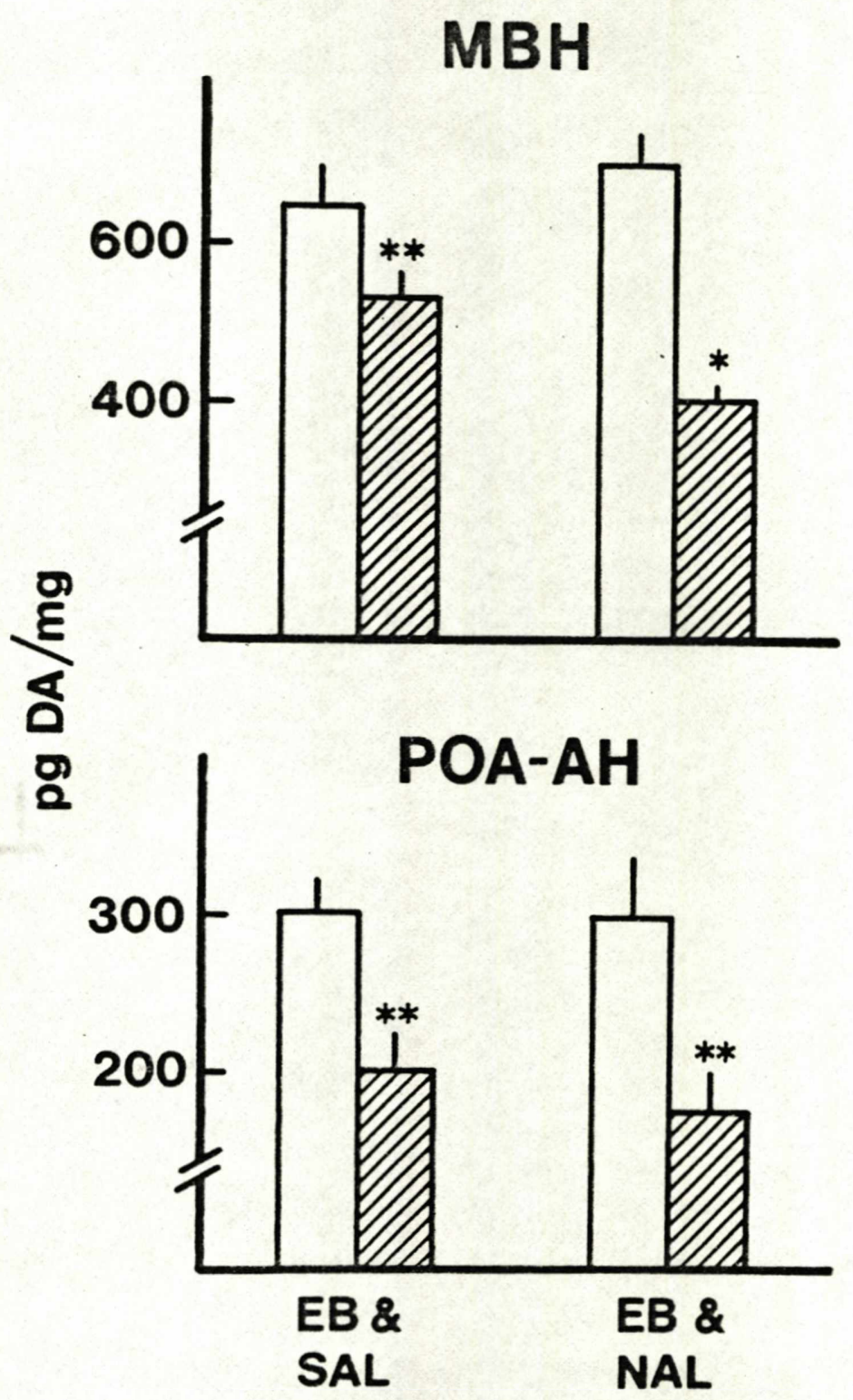

Figure 7. Effects of naloxone on the depletion of DA after aMT Abbreviations, coding and statistical analysis as in figure 5. MBH: **P 0.01 vs. respective saline; ${ }^{*} P<0.01$ vs. respective saline and $P<0.05$ vs. EB and SAL-aHT. POA-QMT. POA-AH: **P<0.01 vs. respective saline. 


\section{TABLE V}

EFFECTS OF MORPHINE AND MORPHINE PLUS NALOXONE ON LH CONCENTRATIONS IN OVARIAN HORMONE-TREATED

\section{FEMALE RATS}

\begin{tabular}{ll}
\hline Group & LH, ng/ml + SEM \\
\hline & \\
\hline EB + progesterone + saline & $309 \pm 84^{* *}$ \\
EB + progesterone + morphine & $123 \pm 34$ \\
EB + progesterone + morphine + naloxone & $343 \pm 62^{* *}$ \\
\end{tabular}

**P<0.01 vs. EB + progesterone + morphine, based on analysis of variance and Newman-Keuls tests.

The catecholamine synthesis inhibitor, $\alpha-M T$, produced significant depletions of NE in the POA and MBH (fig. 8) and of EPI in the MBH (fig. 9) in controls treated with estradiol and progesterone. Figures 8 and 9 show that administration of morphine to such animals reduced $\mathrm{NE}$ and EPI depletion by aMT in these areas, and also diminished the decrease in MBH DA after ${ }^{M M T}$, suggesting decreased catecholamine turnover in these regions.

Steady-state concentrations of catecholamines were not altered by morphine with the exception of $N E$ in the POA. In this region, morphine-treated rats showed significantly decreased NE concentrations compared to the progesterone-saline group. NE levels were not decreased further by $\alpha M T$. Addition of naloxone at least partially antagonized 


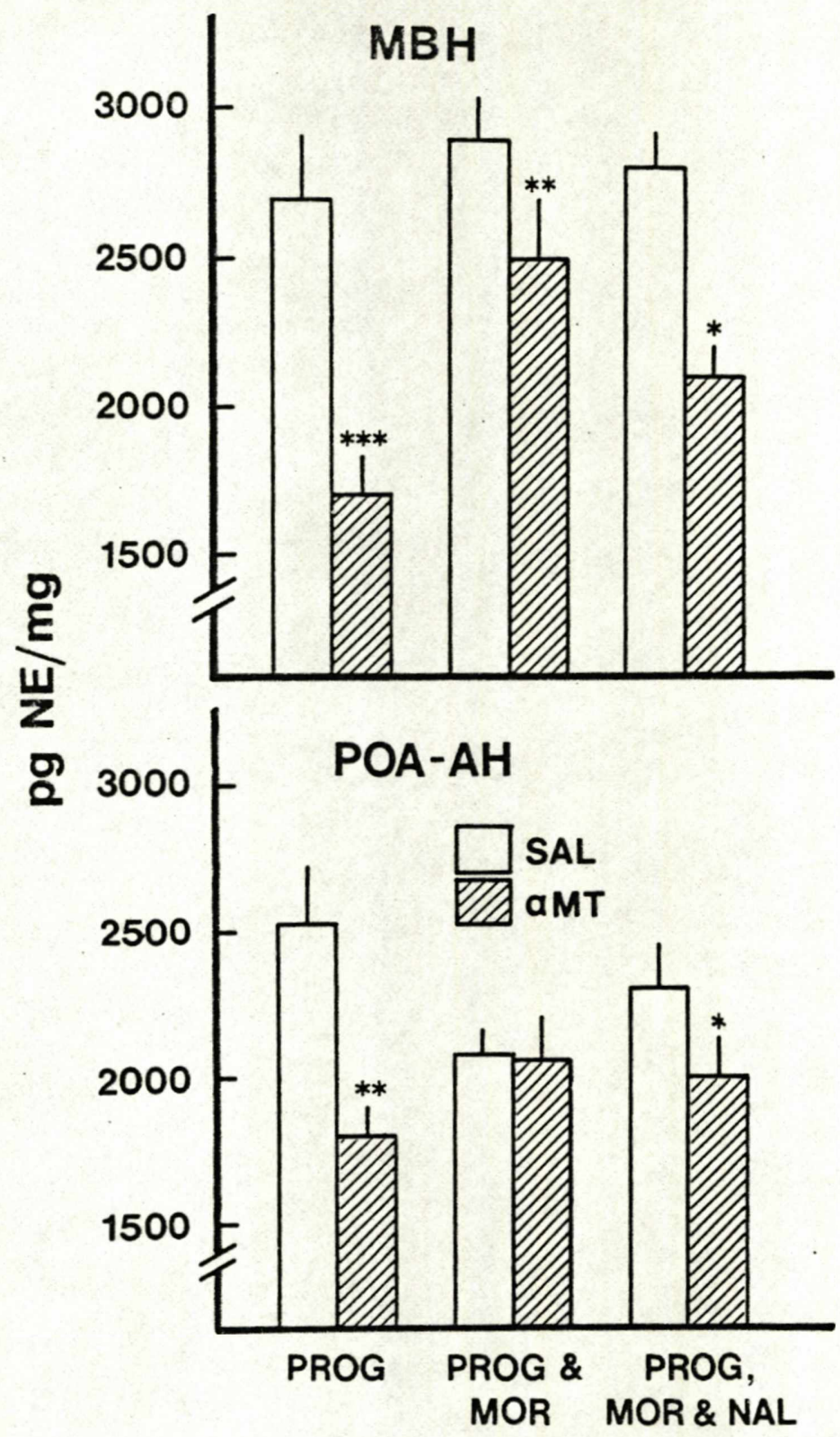

Figure 8. Effects of morphine (MOR) and naloxone (NAL) on the depletion of NE after aMT in animals pretreated with estradiol plus progesterone $(P R O G)$. Statistical analysis as in figure 5. $\mathrm{MBH}$ : ***P<0.01 vs. respective saline; **P<0.01 vs. PROG-aMT; *P 0.01 vs. respective saline, *P 0.05 vs. respective saline. 

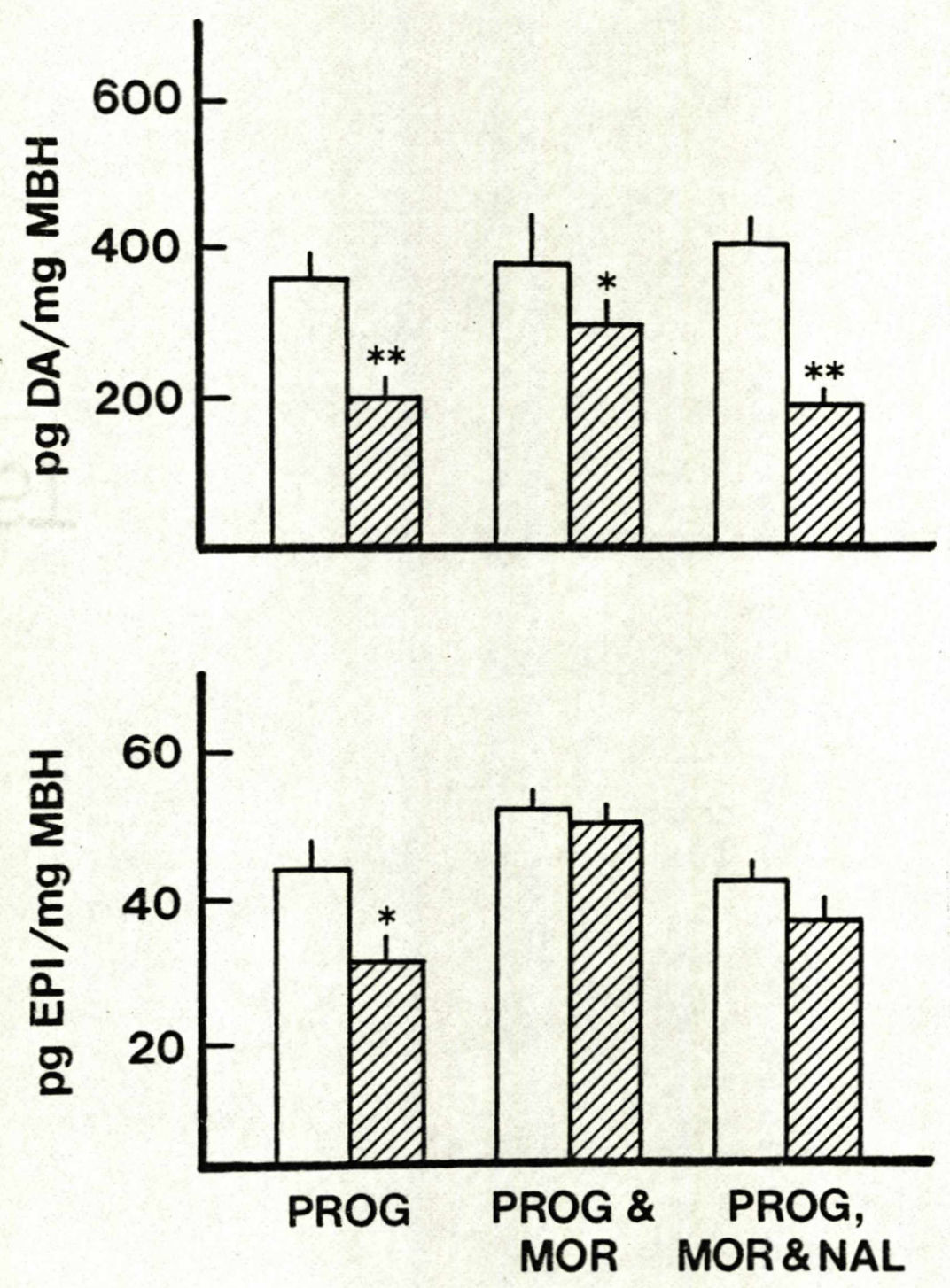

Fig. 9. Effects of morphine and naloxone on the depletion of EPI and DA in the $\mathrm{MBH}$. Abbreviations, coding, and statistical analys is as in figure 5. EPI results: ${ }^{*} P<0.05$ vs. respective saline; $D A$ results: ${ }^{*} P<0.01$ vs. respective saline; ${ }^{*} P 0.05$ vs. PROG- $M M T$ and PROG, MOR and NAL- CMT . 
these inhibitory effects of morphine. Neither progesterone nor the opiate drugs altered EPI or DA depletion in the POA.

Experiment 5: Effects of GABA agonists and antagonists on 느 secretion in ovariectomized and ovariectomized, ovarian hormone-primed rats.

As presented in Table 6, administration of progesterone at $1000 \mathrm{~h}$ to EB-primed rats markedly stimulated serum LH concentrations. Treatment of steroid-primed rats at $1000 \mathrm{~h}$ and $1400 \mathrm{~h}$ with either baclofen or muscimol prevented the rise in serum LH levels. The GABA A antagonist, bicuculline, failed to antagonize the inhibitory effects of baclofen but reduced the effect pf muscimol on LH release. The putative GABA B antagonist, 5-aminovalerate, failed to antagonize baclofen's inhibitory effect on the LH surge (Table 7). A single injection of baclofen given with progesterone, also significantly reduced, but did not totally prevent, the LH surge produced by the ovarian hormone regimen, while a single injection of muscimol was less effective. 
TABLE VI

EFFECTS OF BACLOFEN AND MUSCIMOL ON THE EB PLUS P-INDUCED LH SURGE

\begin{tabular}{|c|c|c|}
\hline Hormone Treatment & $\mathrm{LH}$ (ng/ml) & $\mathbf{n}$ \\
\hline 0il and saline & $400 \pm 27 * *$ & 24 \\
\hline$E B+P+$ Saline & $2202 \pm 273$ & 25 \\
\hline \multicolumn{3}{|l|}{$E B+P+B a c l o f e n$} \\
\hline$(10 \mathrm{mg} / \mathrm{kg} \times 1)$ & $1163 \pm 229 * *$ & 10 \\
\hline$(10 \mathrm{mg} / \mathrm{kg} \times 2)$ & $129 \pm 28 * *$ & 13 \\
\hline + bicuculline* & $250 \pm 28 * *$ & 7 \\
\hline \multicolumn{3}{|c|}{$E B$ and $P$ and muscimol } \\
\hline$(2 \mathrm{mg} / \mathrm{kg} \times 1)$ & $1673 \pm 98$ & 8 \\
\hline$(2 \mathrm{mg} / \mathrm{kg} \times 2)$ & $145 \pm 14^{* *}$ & 14 \\
\hline + bicuculline非 & $808 \pm 170 * *$ & 12 \\
\hline
\end{tabular}

Ovariectomized rats received EB followed $48 \mathrm{~h}$ later by $P$ (injections at $1000 \mathrm{~h})$. Drug injections were given at $1000 \mathrm{~h}(\mathrm{x} 1$ or at $1000 \mathrm{~h}(\mathrm{x} 2)$. *Baclofen $(10 \mathrm{mg} / \mathrm{kg})$ plus bicuculline $(1 \mathrm{mg} / \mathrm{kg})$ at $1000 \mathrm{~h}$ and $1400 \mathrm{~h}$.

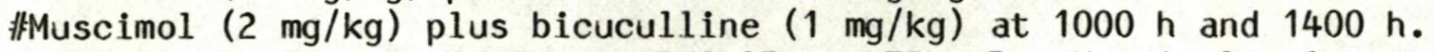
$* * P<0.01$ vs. $E B+P+$ Saline. $* P<0.05$ vs. $E B+P+$ Muscimol $\times 2$. 


\section{TABLE VII}

EFFECTS OF 5-AMINOVALERATE (5AV) ON BACLOFEN'S BLOCKADE OF THE LH SURGE

$\mathrm{EB}+$ Progesterone (Prog.)

$\mathrm{EB}+$ Prog. + baclofen $(10 \mathrm{mg} / \mathrm{kg})$

$\mathrm{EB}+$ Prog. + baclofen + 5AV $(10 \mathrm{mg} / \mathrm{kg})$

$\mathrm{EB}+$ Prog. + baclofen + 5AV (25 mg/kg)

$\mathrm{EB}+$ Prog. + baclofen + $5 \mathrm{AV}$ ( $50 \mathrm{mg} / \mathrm{kg})$

$\mathrm{EB}+$ Prog. + baclofen + $5 \mathrm{AV}$ (75 mg/kg)

$\mathrm{EB}+$ Prog. + baclofen + 5AV (125 mg/ kg)

$\mathrm{EB}+$ Prog. + baclofen + 5AV (150 mg/kg)

*P $<0.01$ vs. $E B+$ Prog.

$n=5-7$

Table 8 shows that phenobarbital administration to rats primed with the ovarian hormones blocks the LH surge. Concurrent injections of bicuculline with phenobarbital, and by itself at $1400 \mathrm{~h}$, failed to reverse the barbiturate's effect. 
TABLE VIII

EFFECTS OF BICUCULLINE AND 5-AMINOVALERATE ON (5AV)

PHENOBARBITAL'S BLOCKADE OF LH SURGE

\begin{tabular}{|c|c|}
\hline Treatment & $\mathrm{LH}(\mathrm{ng} / \mathrm{ml})$ \\
\hline $\begin{array}{l}\mathrm{EB}+\text { Progesterone } \\
\mathrm{EB}+\text { Prog. + Phenobarbital (Pb) (50 mg/kg) } \\
\mathrm{EB}+\text { Prog. + Pb + bicuculline }(2 \mathrm{mg} / \mathrm{kg}) \\
\mathrm{EB}+\text { Prog. + Pb + bicuculline }(4 \mathrm{mg} / \mathrm{kg}) \\
\mathrm{EB}+\text { Prog. }+\mathrm{Pb}+5 \mathrm{AV}(75 \mathrm{mg} / \mathrm{kg}) \\
\mathrm{EB}+\text { Prog. + Pb }+5 A V(150 \mathrm{mg} / \mathrm{kg})\end{array}$ & $\begin{array}{l}3799 \pm 1280 \\
223 \pm 21^{*} \\
177 \pm 22^{*} \\
182 \pm 18^{*} \\
205 \pm 39^{*} \\
144 \pm 6^{*}\end{array}$ \\
\hline
\end{tabular}

*P $<0.01$ vs. $E B+$ Prog

$n=5-7$

Table 9 shows that a $100 \mathrm{mg}$ dose of synthetic LHRH produced a dramatic rise in plasma $\mathrm{LH}$ concentrations within 15 minutes.

Administration of baclofen and muscimol, in doses that blocked the progesterone-induced rise of $\mathrm{LH}$, failed to affect this increase. 
TABLE IX

EFFECTS OF BACLOFEN AND MUSCIMOL ON LH RELEASE INDUCED

BY ADMINISTRATION OF LHRH

\begin{tabular}{cc}
\hline Treatment & LH (ng/ml) \\
\hline & \\
\hline EB + Progesterone (Prog.) + Saline & $377 \pm 16$ \\
EB + Prog. + LHRH & $3342 \pm 332^{* *}$ \\
EB + Prog. + LHRH + Baclofen & $3378 \pm 538^{* *}$ \\
EB + Prog. + LHRH + Muscimol & $3967 \pm 372^{* *}$ \\
\hline
\end{tabular}

**P $<0.01$ vs. $E B+P+$ saline $n=5-7$

In a third study, baclofen and muscimol, in doses that blocked the LH surge, did not significantly depress basal LH release in ovariectomized, hormonally untreated rats (Table 10). A two-fold higher dose of baclofen tended to depress LH levels, but the effect did not quite reach statistical significance. Bicuculline did not block and tended to somewhat enhance baclofen's suppression of basal LH release. 
TABLE $X$

EFFECTS OF GABA AGONISTS ON LH RELEASE IN OVARIECTOMIZED RATS

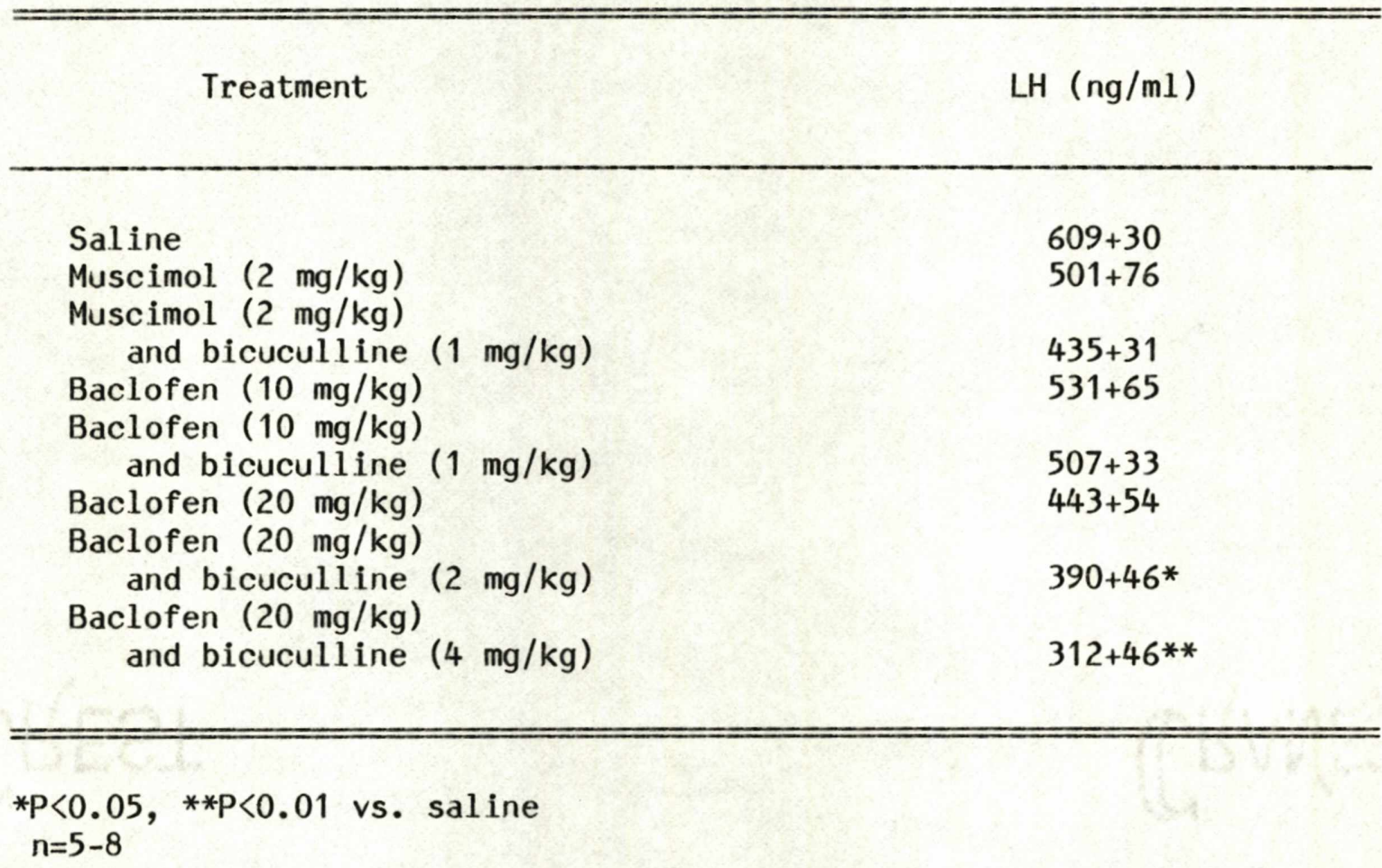

Experiment 6: Effects of GABA agonists on catecholamine turnover in the $\mathrm{POA}$ and $\mathrm{MBH}$ of rats treated with ovarian hormones.

The synthesis inhibitor, aMT, produced significant depletion of NE, EPI, and DA in the MBH (Fig. 10, 11, 12) and of NE in the POA (Fig. 10) in control animals treated with EB followed by progesterone. Administration of baclofen or muscimol significantly decreased steady state concentrations of NE and EPI in these regions. In addition, aMT did not significantly reduce NE and EPI after baclofen and muscimol pretreatment 


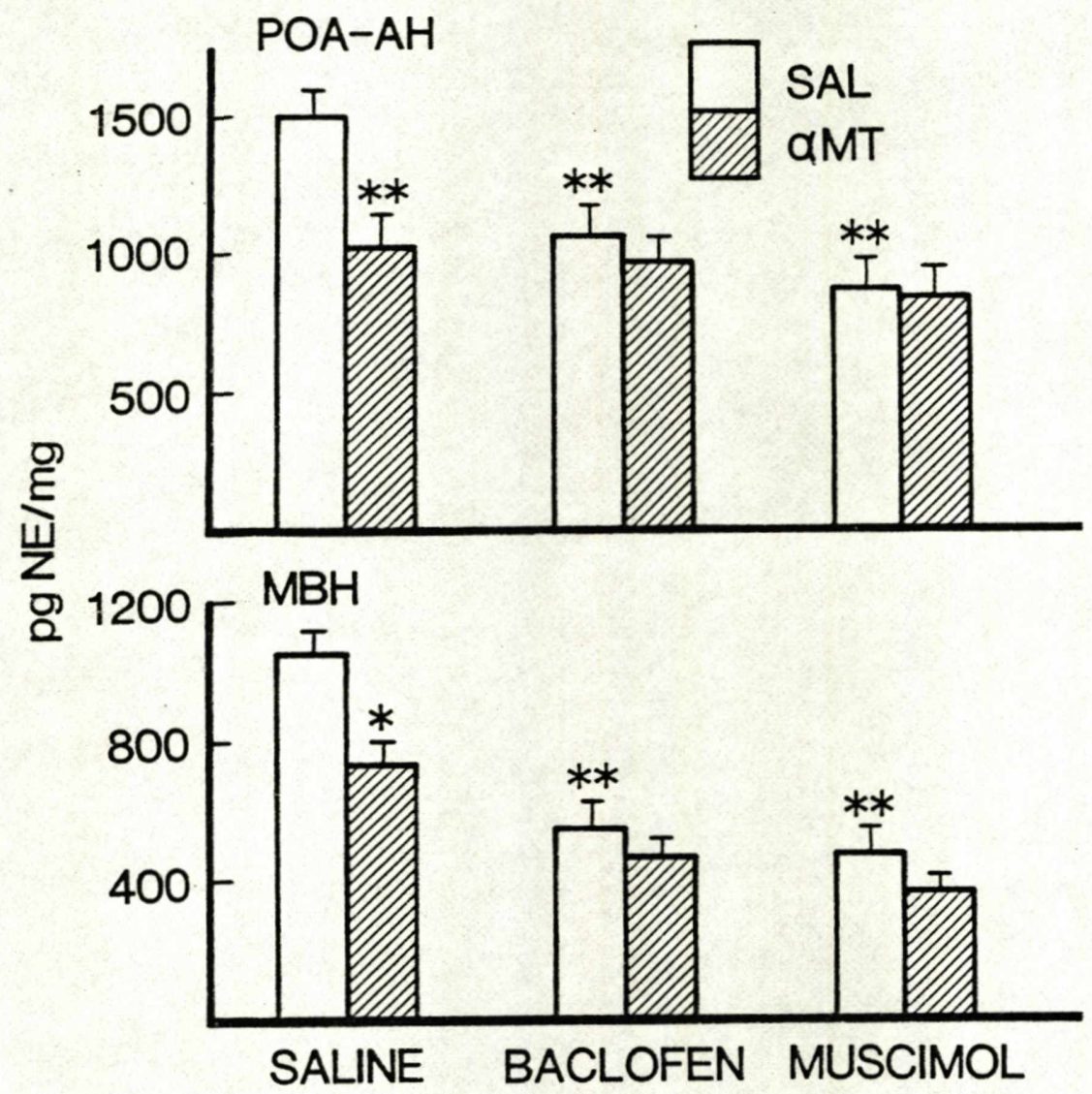

Figure 10. Effects of baclofen and muscimol on the depletion of norepinephrine (NE) produced by $\alpha M T$ in the POA-AH and $M B H$. $* P<0.05, * * P<0.01$ vs. SALINE (SAL) 


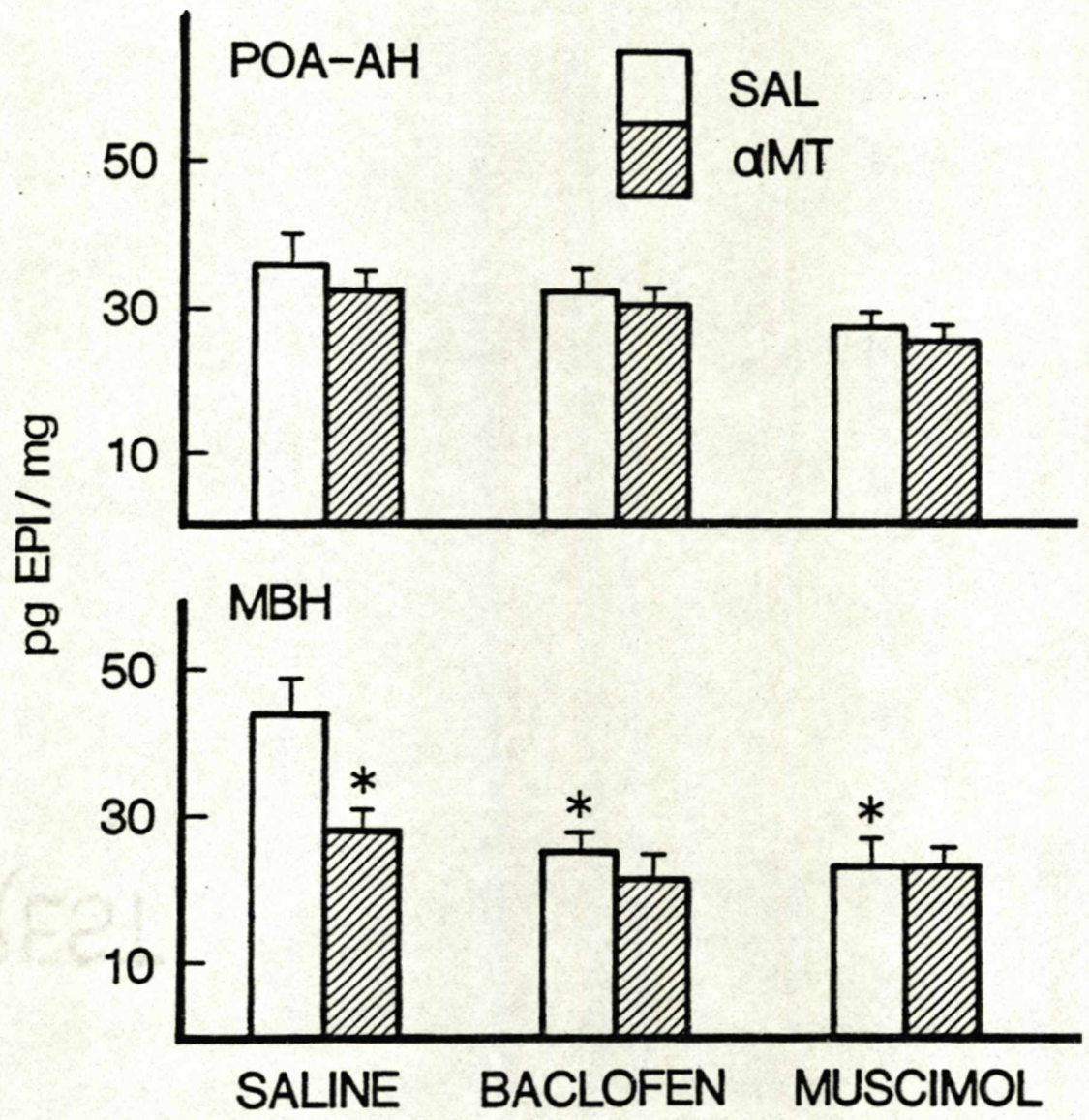

Figure 11. Effects of baclofen and muscimol on the depletion of epinephrine (EPI) produced by $a M T$ in the $P O A-A H$ and $M B H$. *P<0.05 vs. SALINE (SAL) 


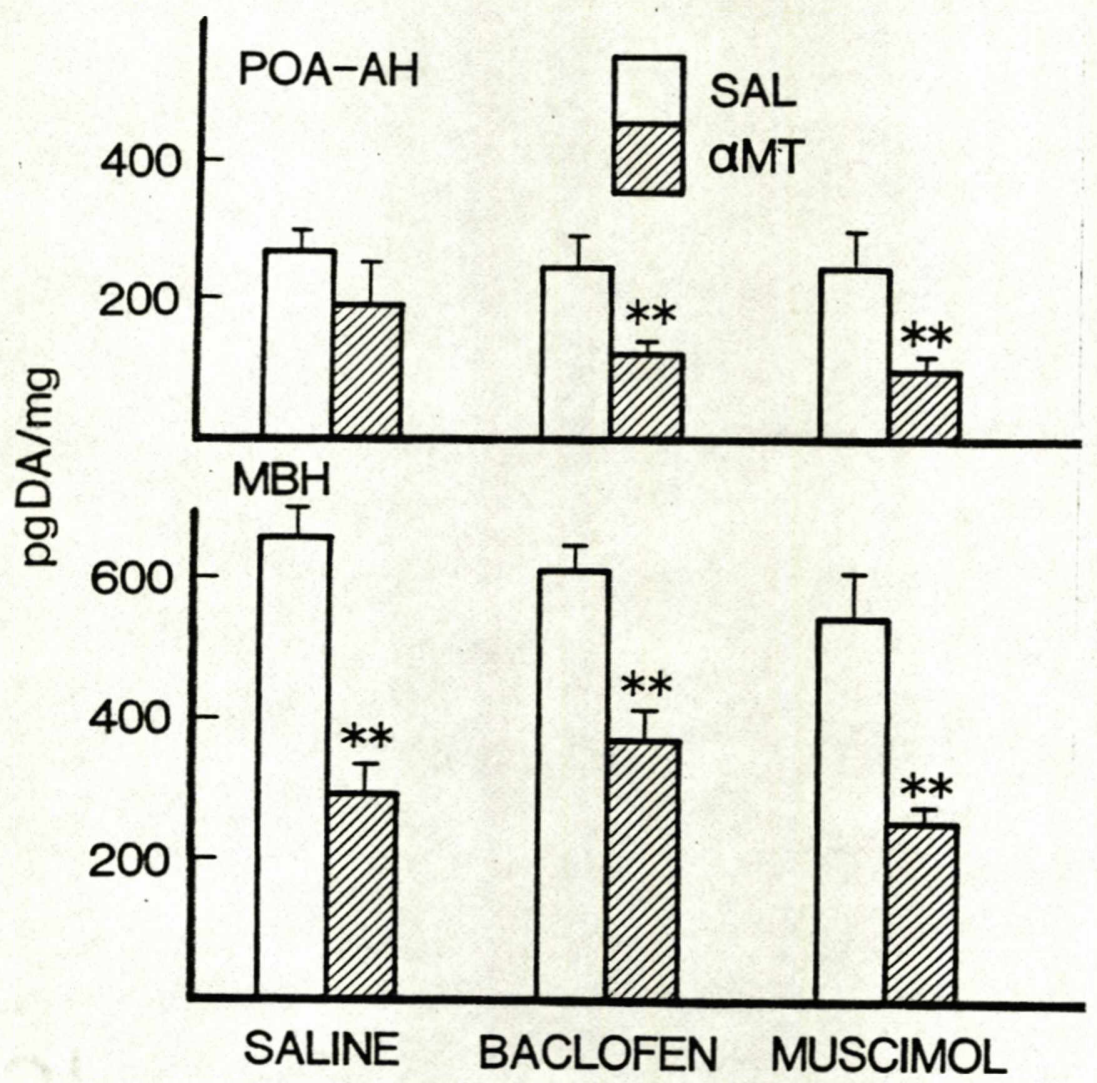

Figure 12. Effects of baclofen and muscimol on the depletion of dopamine (DA) produced by aMT in the $\mathrm{POA}-\mathrm{AH}$ and $\mathrm{MBH}$. **P<0.01 vs. respective SAL. 
(Fig. $10 \& 11$ ), suggesting decreased catecholaminergic activity in these areas. These drugs did not alter the concentrations or depletion of DA in either the MBH or POA (Fig. 12).

Experiment 7: Effects of the GABAB agonist baclofen on the median eminence accumulation of LHRH induced by progesterone.

As illustrated in Table 11, administration of progesterone at 1000 $h$ to estradiol-primed animals significantly elevated plasma LH levels at $1400 \mathrm{~h}$ and $1600 \mathrm{~h}$. Treatment of ovarian hormone-primed rats with the GABA B agonist, baclofen, drastically reduced $\mathrm{LH}$ concentrations at these time periods. 
TABLE XI

EFFECTS OF BACLOFEN ON THE PROGESTERONE-INDUCED RISE

IN LH LEVELS IN ESTRADIOL-PRIMED RATS

\begin{tabular}{lcc}
\hline & & LH $(\mathrm{ng} / \mathrm{ml})$ \\
Time & Saline & Baclofen \\
\hline & & \\
$1100 \mathrm{~h}$ & $222 \pm 26$ & $190 \pm 40$ \\
$1200 \mathrm{~h}$ & $187 \pm 39$ & $227 \pm 54$ \\
$1300 \mathrm{~h}$ & $240 \pm 62$ & $113 \pm 19$ \\
$1400 \mathrm{~h}$ & $938 \pm 62^{* *}$ & $208 \pm 55^{*}$ \\
$1600 \mathrm{~h}$ & $2873 \pm 599^{* *}$ & $72 \pm 8^{*}$ \\
& & \\
\hline \hline
\end{tabular}

$* * P<0.01$ vs. 1100,1200 , and $1300 \mathrm{~h}$ saline values

$* \mathrm{P}<0.01$ vs. respective saline

$n=7-9$

Administration of progesterone at $1000 \mathrm{~h}$ to estradiol treated rats, produced significant elevations in median eminence LHRH concentrations at $1100 \mathrm{~h}$. LHRH concentrations declined significantly at $1200 \mathrm{~h}$ and $1300 \mathrm{~h}$. In rats pretreated with baclofen, the ovarian hormone priming again resulted in an increase in LHRH levels at $1100 \mathrm{~h}$ but levels did not change significantly thereafter. In fact, concentrations of LHRH were significantly higher at $1400 \mathrm{~h}$. 
TABLE XII

EFFECTS OF BACLOVEN ON THE PROGESTERONE-INDUCED ACCUMULATION IN LHRH CONCENTRATIONS IN THE MEDIAN EMINENCE OF ESTRADIOL-PRIMED RATS

\begin{tabular}{lll}
\hline & & LHRH (pg/microgram protein - ME) \\
Time & Saline & Baclofen \\
\hline & & \\
$1000 \mathrm{~h}$ & $29 \pm 2$ & $49 \pm 5$ \\
$1100 \mathrm{~h}$ & $42 \pm 3^{*}$ & $34 \pm 9$ \\
$1200 \mathrm{~h}$ & $38 \pm 5$ & $35 \pm 5$ \\
$1300 \mathrm{~h}$ & $30 \pm 3^{* *}$ & $37 \pm 6^{* * *}$ \\
$1400 \mathrm{~h}$ & $21 \pm 3^{* *}$ & $33 \pm 5$ \\
$1600 \mathrm{~h}$ & $28 \pm 2^{*}$ & \\
\hline
\end{tabular}

$* \mathrm{P}<0.01$ vs. $1000 \mathrm{~h}$ saline control

**P<0.01 vs. $1100 \mathrm{~h}$ saline control

**P $<0.05$ vs. respective saline control $n=7-9$ 
Experiment 8a: Effects of baclofen on naloxone's enhancement of 내 release and catecholamine activity in estradiol-promed rats.

In the first study of Experiment 8, administration of naloxone to estradiol-primed rats significantly elevated serum LH levels (Table 13). Pretreatment, 30 minutes before naloxone, with baclofen failed to affect the increase in LH release elicited by naloxone.

TABLE XIII

EFFECTS OF BACLOFEN ON NALOXONE'S ENHANCEMENT OF LH RELEASE

Treatment

$\mathrm{LH}(\mathrm{ng} / \mathrm{ml})$

$E B+$ Saline

$E B+$ Naloxone $(10 \mathrm{mg} / \mathrm{kg})+$ Saline

$123 \pm 12$

$\mathrm{EB}+$ Naloxone + Baclofen $(10 \mathrm{mg} / \mathrm{kg})$

$277 \pm 32 * *$

$223 \pm 35 *$

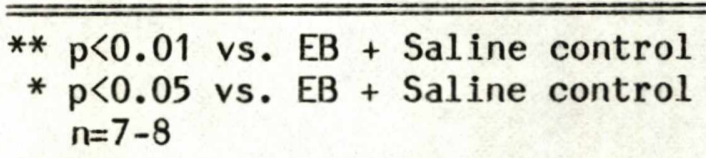


Tables 14-16 present the effects of naloxone on catecholamine depletion induced by aMT in the MBH. In the EB-saline controls, there was no significant decline in either NE or EPI after aMT, suggesting a low level of activity in these areas (Table 14 and 15). However, administration of naloxone significantly potentiated the depletion of $\mathrm{NE}$ and EPI in the MBH, suggesting increased catecholamine turnover (Table 14 and 15). Pretreatment with baclofen failed to prevent naloxone's enhancement of NE or EPI depletion induced by aMT (Table 14, 15). 
TABLE XIV

EFFECTS OF BACLOFEN ON NALOXONE'S ENHANCEMENT OF NE DEPLETION INDUCED BY OMT IN THE MBH OF ESTRADIOL-PRIMED RATS

\begin{tabular}{|c|c|c|}
\hline Treatment & Saline ${ }^{p g}$ & $\begin{array}{l}\text { sue } \\
\qquad \alpha M T\end{array}$ \\
\hline $\begin{array}{l}E B+\text { Saline } \\
E B+\text { Naloxone } \\
E B+\text { Naloxone + Baclofen }\end{array}$ & $\begin{array}{c}776 \pm 155 \\
1408 \pm 187 * \\
1141 \pm 112^{*}\end{array}$ & $\begin{array}{l}481 \pm 111 \\
758 \pm 113^{* *} \\
628 \pm 77^{* *}\end{array}$ \\
\hline
\end{tabular}

$* P<0.05$ vs. EB saline

**P $<0.05$ vs. respective saline

$\mathrm{n}=7-8$ 
TABLE XV

EFFECTS OF BACLOFEN ON NALOXONE'S ENHANCEMENT OF EPI ACTIVITY IN THE MBH

\begin{tabular}{lll}
\hline & \multicolumn{1}{c}{$\mathrm{pg} \mathrm{EPI/mg \text {tissue }}$} \\
Treatment & Saline & $\alpha M T$ \\
& & \\
& & $13 \pm 2$ \\
EB + Saline & $19 \pm 5$ & $26 \pm 5^{*}$ \\
EB + Naloxone & $40 \pm 5^{*}$ & $20 \pm 3^{* *}$ \\
EB + Naloxone & $29 \pm 3$ & \\
\end{tabular}

*P $<0.05$ vs. EB saline

$* * P<0.05$ vs. respective saline $n=7-8$ 
TABLE XVI

EFFECTS OF BACLOFEN ON NALOXONE'S ENHANCEMENT

OF DA ACTIVITY IN THE MBH

\begin{tabular}{lll}
\hline & \multicolumn{1}{c}{$\mathrm{pg} \mathrm{DA/mg \text {tissue }}$} \\
Treatment & Saline & QMT \\
& & \\
& & $163 \pm 42^{* *}$ \\
EB + Saline & $340 \pm 48$ & $205 \pm 21^{* *}$ \\
EB + Naloxone & $475 \pm 70^{*}$ & $168 \pm 22^{* *}$ \\
EB + Naloxone + Baclofen & $650 \pm 43^{*}$ & \\
\hline
\end{tabular}

*P<0.05 vs. EB saline

**P $<0.05$ vs. respective saline

$n=7-8$

Experiment 8b: Effects of nalmefene on the blockade of the LH surge produced by baclofen.

The results from the second study in Experiment 8 are illustrated in Table 17. Administration of progesterone at $1000 \mathrm{~h}$ to estradiol primed rats elicited a significant elevation of serum LH concentrations. Pretreatment of ovarian hormone-primed rats at $1000 \mathrm{~h}$ and $1400 \mathrm{~h}$ with baclofen significantly attenuated the LH surge. Pretreatment with nalmefene at 1000 and $1400 \mathrm{~h}$ did not significantly alter LH concentrations. The concomitant administration of nalmefene with baclofen did not prevent baclofen's inhibitory effect on the ovarian hormone-induced surge of LH. 
TABLE XVII

EFFECTS OF NALMEFENE ON BACLOFEN'S BLOCKADE OF THE LH SURGE

\begin{tabular}{cc}
\hline & \\
Treatment & LH $(\mathrm{ng} / \mathrm{ml})$ \\
\hline & \\
EB + Progesterone (Prog.) & $2921 \pm 372$ \\
EB + Prog. + Baclofen $(10 \mathrm{mg} / \mathrm{kg})$ & $332 \pm 74^{*}$ \\
EB + Prog. + Nalmefene $(10 \mathrm{mg} / \mathrm{kg})$ & $2122 \pm 483$ \\
& $169 \pm 27^{*}$ \\
\hline
\end{tabular}

$* P<0.01$ vs. $E B+$ Progesterone $n=6-8$ 


\section{DISCUSSION}

Experiments 1 and 2 were designed to define more completely the role of the catecholamines, especially EPI in mediating the stimulatory or positive feedback effects of the ovarian hormones on LHRH and LH secretion. Results from these studies suggest that both NE and EPI systems are involved in the effects of estrogen and progesterone in stimulating the accumulation of LHRH in the median eminance and the release of LH from the anterior pituitary.

Inhibition of both NE and EPI synthesis with the DBH inhibitor, FLA-63, completely prevented the LH surge and accumulation of LHRH in the median eminence that occur in the afternoon after progesterone treatment. These results are consistent with earlier work in which administration of another DBH inhibitor, diethyldithiocarbamate, produced similar effects on median eminence LHRH concentrations and pituitary LH release (190). While these earlier results were attributed to blockade of NE synthesis, the present studies indicate that a portion of the inhibitory effect may be due to interference with EPI neurotransmission. Administration of the selective EPI synthesis inhibitor, SKF 64139, partially blocked the progesterone-induced afternoon increase in median eminence LHRH concentrations and prevented the LH surge. Thus, while depletions of both NE and EPI completely prevented the increase in LHRH concentrations, selective depletion of EPI resulted in an increase that was significantly smaller in magnitude than the control LHRH value. These findings indicate that both NE and EPI systems are activated to produce the full accumulation of LHRH, and that under condi- 
tions of reduced EPI neurotransmission, the smaller rise in LHRH concentrations reveals that there is also a contribution of that neurotransmitter system.

The results obtained with the second EPI synthesis inhibitor, LY 78335, also support the conclusion that EPI neurons are involved in ovarian hormone effects on LHRH and LH release. Administration of LY 78335 interfered with progesterone effect to increase the accumulation of LHRH in the median eminence and the pituitary release of $\mathrm{LH}$, that is, the increases in LHRH and LH release were delayed compared with those in the concurrently run controls. Indeed, rats treated with LY 78335 may have shown a rebound phenomenon as levels of LHRH and LH were significantly greater at $1600 \mathrm{~h}$ then the corresponding control values. The two EPI synthesis inhibitors exhibited different patterns of effects on LHRH. This may reflect a shorter duration of neuroendocrine action for LY 78335 than SKF 64139, as suggested previously by the effects of these two drugs on GH secretion (191). However, it is evident from the results of these studies that inhibition of EPI synthesis interferes with the ovarian hormone stimulatory effects on LH and LHRH.

Despite a significant increase in median eminence LHRH concentrations, the administration of SKF 64139 totally prevented the subsequent surge of LH induced by the ovarian hormones. These effects of SKF 64139 are similar to those produced by the barbiturates which also block the LH surge (192) but fail to prevent the increase in LHRH that precedes the preovulatory or ovarian hormone induced LH surge $(193,194)$. The significance of the sequential LHRH increase and decrease that occurs 
several hours after progesterone treatment is unclear. Others have proposed that the rise of LHRH may represent increased synthesis $(190,193)$, while a more recent report observed decreased degradation of LHRH by an endopeptidase at this time (195). The results of this and other studies (190) suggest that the elevation of LHRH in the median eminence is dependent upon catecholamine neurotransmission and appears to be necessary, but not sufficient, for the subsequent LH surge. However, the physiological significance of the decline in LHRH levels that follows the elevation is not clear. It is probable that this decrease is not a release of the neuropeptide into portal blood that triggers the LH surge, because it may occur in the absence of LH release e.g. after blockade by barbiturates or SKF 64139 . The release of LHRH that initiates or maintains the LH surge may occur after the decline and is more likely regulated by both NE and EPI systems.

The pharmacological characterization of neurotransmitters involved in ovarian hormone feedback is limited by the selectivity and specificity of the agents used. In addition to its PNMT-inhibiting actions, SKF 64139 possesses some alpha2-adrenergic blocking effects, but those are unlikely to account for its inhibitory actions on LH and LHRH surges. First, a non-alpha-blocking PNMT inhibitor also prevents ovarian hormone-induced elevation of $\mathrm{LH}$ release (92). The rises in LHRH and LH concentrations were also inhibited by LY 78335, a PNMT inhibitor with little demonstrable alpha-blocking action in vivo (205). Furthermore, PNMT inhibitors do not share the effect of alpha-noradrenergic 
antagonists in disrupting episodic LH release or preventing the elevation of PRL by estradiol (92). The present results also demonstrate a further difference between pharmacological noradrenergic and adrenergic antagonists, as the DBH inhibitor FLA-63 abolished the rise in LHRH and lowered its concentration, while the PNMT inhibitor did not. Therefore, it is more likely that the neuroendocrine effects of LY 78335 and SK \& F 64139 are due to disruption of EPI rather than NE neurotransmission.

Experiment 2 was designed to examine whether an ovarian hormone regimen that elicits an LH surge enhances the activity of NE and EPI neurons in the MBH and POA. This and subsequent studies, in which NE and EPI activity was of importance, employed the alpha methyltyrosine method to determine catecholamine turnover. That is, the degree of depletion of a catecholamine after synthesis inhibition with alpha methyltyrosine was taken as an index of the activity of that neurotransmitter system. The results also support the hypothesis that central EPI neurons participate in the regulation of LH and LHRH release. The depletion of MBH EPI induced by the catecholamine synthesis inhibitor aMT was potentiated by the estrogen plus progesterone regimen that induced an LH surge. It is generally accepted that such enhanced depletion reflects an increased degree of nerve impulse flow in the system (185) and these findings, therefore, suggest that there is increased activity in medial basal hypothalamic EPI nerve terminals during the LH surge induced by the ovarian hormones. Estradiol and progesterone did not alter EPI depletion in the POA. Similarly, an earlier report observed no changes in EPI turnover in the medial preoptic nucleus 
during the proestrus critical period (108). Although the results are in contrast to a recent study reporting increased POA EPI turnover coinciding with the proestrus surge of LH (116) the results of the present studies suggest that EPI may promote the release of LHRH from nerve terminals in the $\mathrm{MBH}$ region. This conclusion is supported by the demonstration that EPI evokes the release of LHRH from the median eminence in vitro (206).

Because the pharmacological studies suggested that both NE and EPI systems may also be activated during the accumulation of LHRH that precedes the LH surge, the depletion of the catecholamines after aMT treatment were assessed at an earlier time point that approximately corresponds to these events, based on the results from Experiment 1 . Consistent with the pharmacological results, EPI depletion was enhanced only in the MBH during the earlier period. In addition, the aMT-induced decline of $\mathrm{NE}$ was maximal at this time in both the POA and MBH. These results are consistent with several investigators who have observed increased $\mathrm{NE}$ turnover in the $\mathrm{MBH}$ and $\mathrm{POA}$ associated with the proestrus or ovarian hormone induced LH surge $(104,105,106,110)$. Moreover, these results are also consistent with previous proposals that there are timedependent increases in hypothalamic catecholaminergic activity that mediate the effects of ovarian hormones on LHRH and LH release (91). The results from Experiments 1 and 2 suggest that the ovarian hormones differentially affect NE and EPI systems in different regions of the hypothalamus. The elevation of NE turnover by the ovarian hormones at $1300 \mathrm{~h}$ in both the $\mathrm{POA}$ and $\mathrm{MBH}$ may possibly reflect the importance of 
NE in the ovarian hormone-induced accumulation of LHRH in the median eminence. In contrast to NE, the estradiol plus progesterone treatment enhanced EPI turnover only in the MBH but at $1600 \mathrm{~h}$ as well as $1300 \mathrm{~h}$. Although both NE and EPI seem to be involved in activating LHRH accumulation at $1300 \mathrm{~h}$, EPI may be the neurotransmitter primarily involved in promoting the release of LHRH at $1600 \mathrm{~h}$ that is directly involved in initiating the $\mathrm{LH}$ surge.

In summary, the results from Experiments 1 and 2 support the hypothesis that both NE and EPI systems have roles in regulating the secretion of LH. These results indicate that 1) activation of both EPI and NE neurons mediates the accumulation of LHRH in the median eminence that precedes the ovarian hormone-induced Lh surge; and 2) EPI and NE systems are also involved in the ovarian hormone-induced LH surge.

The neurochemical mechanisms by which the ovarian hormones modulate noradrenergic and adrenergic systems to regulate $\mathrm{LH}$ secretion is not well understood. The ovarian hormones are apparently not taken up by LHRH cell bodies (207). Even though there does appear to be some degree of uptake into catecholamine cell bodies (208), the ovarian hormones seem to affect catecholamine turnover only in specific regions of the brain (110) such as the POA and MBH, areas that contain catecholamine nerve terminals. Thus, the ovarian hormones may affect some process that locally controls the turnover of these neurotransmitters at the nerve terminals. Experiments 3 and 4 examined the possibility that the endogenous opioid neuropeptides may participate in locally modulating catecholamine turnover. Therefore, Experiments 3 and 4 were designed to 
test whether the opiate antagonist, naloxone, and the opiate agonist, morphine, which have well defined effects on gonadotropin secretion, alter the activity of NE and EPI neurons in the hypothalamus of ovarian hormone treated rats. The results of these studies provide support for the hypothesis that opiate effects on LH secretion are mediated by alterations in catecholamine neurotransmission. In Experiment 3, administration of the opiate antagonist, naloxone, increased LH levels, potentiated the decline of $\mathrm{NE}$ in the $\mathrm{POA}$ and $\mathrm{MBH}$, and enhanced the depletion of EPI in the MBH after aMT. These findings suggest that naloxone enhances activity in noradrenergic and adrenergic systems that innervate the POA and $\mathrm{MBH}$. This conclusion is strengthened by the results of previous pharmacological studies demonstrating thatnaloxoneinduced LH release is prevented by noradrenergic and/or adrenergic synthesis inhibitors $(145,147)$. The catecholamine systems that are activated by the removal of opiate inhibition may, in turn, enhance the release of LHRH $(92,190)$.

It is possible that naloxone increases NE and EPI activity by antagonizing the inhibitory influence of an endogenous opioid neuropeptide. Opiate alkaloids and neuropeptides depress the release of NE from cortical, cerebellar, and hypothalamic slices in vitro $(136,137)$, and the results of Experiment 4 demonstrate that the opiate agonist, morphine, may reduce NE and EPI release in discrete hypothalamic regions as well. The administration of morphine to ovariectomized rats primed with ovarian hormones decreased $\mathrm{LH}$, and also reduced the depletion of NE in the $P O A$ and $M B H$ and of EPI in the MBH, after $\alpha M T$, suggesting reduction of 
catecholamine activity during the depression of $\mathrm{LH}$ release. Morphine also decreased steady-state concentrations of NE in the POA, an effect possibly reflecting a decrease in synthesis. This effect was prevented in most cases by the coadministration of naloxone, implicating opiate receptor involvement in the effect of morphine. Previous studies have shown that morphine prevents the ovarian hormone-induced accumulation of LHRH in the median eminence (141) as well as the release of LHRH into pituitary portal blood on proestrus afternoon (138). These results indicate that one possible mechanism by which the opiates disrupt LH secretion may be through inhibition of hypothalamic noradrenergic and adrenergic systems that regulate LHRH synthesis and/or release.

In Experiment 4, morphine also decreased the aMT induced depletion of DA in the MBH. A number of studies have also shown that morphine and endogenous opioid peptides such as beta-endorphin reduce the turnover of DA in the median eminence and diminish the release of tuberoinfundibular DA into hypophysial portal circulation (209). Although confusion remains as to the role of these changes in $\mathrm{LH}$ secretion, there is more evidence linking them to the release of prolactin by morphine (209).

It is interesting to note the similar neuroendocrine and neurochemical actions of naloxone and progesterone. Both stimulate LH release in ovariectomized, estrogen-primed rats and these effects are dependent upon catecholaminergic neurotransmission $(141,145,147)$. Moreover, both progesterone and naloxone stimulate the aMT-induced depletion of EPI in the MBH, but not $\mathrm{POA}$, and of $\mathrm{NE}$ in the $\mathrm{POA}$ and $\mathrm{MBH}$. These observations are therefore consistent with the hypothesis that one 
aspect of ovarian hormone positive feedback may involve removal of the inhibitory influence of an endogenous opioid system over catecholamine release. Similarly, morphine may stimulate the opioid receptors for such a system that are located on NE and EPI nerve terminals.

Progesterone and naloxone differ, however, in the time course of these effects. Progesterone may require several hours to stimulate LH release if the hormone is acting via classic steroid receptor mechanisms, involving genomic expression, that result in depression of activity of an endogenous opioid neuropeptide system, and subsequent stimulation of catecholamine release. Presumably, the opiate antagonist, naloxone, stimulates $\mathrm{LH}$ and catecholamine release with shorter latentcy because this drug directly reduces endogenous opioid neurotranmission, bypassing the steroid receptor system.

A number of recent studies have attempted to define what changes, if any, occur in brain, pituitary, and plasma beta-endorphin concentrations in naturally cycling animals and if these pools of beta-endorphin are responsive to ovarian hormone treatment. An initial report noted that median eminence beta-endorphin concentrations increase while arcuate levels of beta-endorphin decrease on proestrous afternoon (196). However, hypothalamic beta-endorphin concentrations do not appear to differ from diestrus to proestrus (197) and a more detailed analysis of beta-endorphin content in hypothalamic nuclei during the estrous cycle revealed a significant increase in arcuate beta-endorphin levels during proestrus (198). 
Thus, attempts to relate changes in beta-endorphin concentrations in the hypothalamus with pituitary function have been inconclusive and require further investigation.

Beta-endorphin levels appear to vary in hypophyseal portal blood during the menstrual cycle (199), being high during the follicular and luteal phase and virtually undetectable at menstruation or after long term ovariectomy. These results would suggest that when ovarian hormone concentrations are low, such as after ovariectomy or during menstruation, hypothalamic beta-endorphin release is correspondingly low (199). These results are interesting in view of other reports noting naloxone's inability to stimulate LH release at times when ovarian hormone concentrations are low, such as after gonadectomy (200), during the early follicular phase of the menstrual cycle in normal women $(201,202)$, or in post-menopausal women (203). Conversely, the opiate peptide FK 33-824 fails to inhibit LH release one week after gonadectomy (200). Thus, a great deal of evidence exists to support a physiological relationship between the ovarian hormones and the endogenous opioid peptides in the regulation of the pituitary gonadotropin secretion.

In summary, the results from Experiment 3 and 4 support the hypothesis that the ovarian hormones produce their stimulatory feedback effects on LH secretion by altering the activity of an inhibitory endogenous opioid neuropeptide system which, in turn, regulates the release of NE and EPI. These catecholamines are then able to stimulate LHRH, and subsequently, the LH surge. 
A scenario, virtually identical to the hypothesis discussed above, has, in fact, been recently reported (91). This proposed role for the opioid neuropeptides is complemented by a very similar role in the negative feedback effects of estradiol in female rats (211) and testosterone in male rats (210). In both of these cases it is evisioned that the hormone (either estradiol or testosterone) activates an endogenous opioid peptide system that, in turn, inhibits LH secretion $(210,211)$. In the model employed in these studies, progesterone may act to physiologically reverse these negative feedback effects of estradiol in order to trigger the preovulatory release of LH.

Few studies have addressed the issue of which endogenous opioid peptide(s) the ovarian hormones interact with to regulate LH release. The evidence presently available suggests that beta-endorphin and/or dynorphin peptide may mediate these ovarian hormone effects. Although met-enkephalin levels are responsive to chronic estrogen treatment (212) in male rats, hypothalamic concentrations of met-enkephalin do not appear to fluctuate during the estrous cycle (213). Perhaps more importantly, antisera against beta-endorphin, and to a lesser extent, antisera against dynorphin 1-13 increase $L H$ release when injected into the MBH of immature female rats (214). In contrast, antiserum against metenkephalin do not affect LH release in this model (214). A role for dynorphin in the control of LH release is further supported by the finding that bremazocine, a benzomorphan compound selective for kappa receptors, is more potent than morphine as an inhibitor of LH release (215). Therefore, an opioid peptide of the beta-endorphin and/or dynorphin 
family may mediate ovarian hormone effects on gonadotropin secretion. However, only more intensive research of all the opioid neuropeptides, including met-enkephalin, will clearly answer this important question.

As has been detailed in the Introduction of this dissertation, GABA may also be considered a candidate for a neuromodulatory role in locally controlling hypothalamic catecholamine activity and pituitary LH secretion. Therefore, Experiments 5 and 6 were designed to examine the effects of GABA agonists and antagonists on LH secretion under a variety of endocrine conditions and also to test whether CABA agonists depress activity of NE and EPI neurons after synthesis inhibition in discrete regions of the hypothalamus. The results of Experiment 5 and 6 raise the possibility that a GABA system exists in the hypothalamus capable of inhibiting adenohypophyseal LH secretion, perhaps by depressing activity in central NE and EPI neurons. Administration of the GABA agonists, baclofen and muscimol, prevented the $\mathrm{LH}$ surge in rats induced by the sequential pretreatment of estradiol plus progesterone. Maximal inhibition was reached when a second injection of baclofen or muscimol was given $4 \mathrm{~h}$ after the first. The effect of the GABA agonists to disrupt the LH surge appears to occur in the brain, as neither baclofen nor muscimol affected the release of $\mathrm{LH}$ in response to administration of synthetic LHRH.

Baclofen and muscimol also tended to depress LH levels in ovariectomized, hormonally untreated rats, an effect that is more pronounced following central administration of GABA or muscimol (175). It is unclear why the GABA antagonist, bicuculline, potentiated this effect, 
although it is possible that under these circumstances, a stimulatory GABA component may be unmasked (172).

The barbiturate, phenobarbital, has a well known inhibitory effect on the LH surge $(192,193,194)$. Because phenobarbital appears to enhance the binding of GABA to its receptor and also enhances $\mathrm{Cl}$ ion conductance, it was possible that the barbiturate effect on LH was mediated by GABA systems. This, however, appears not to be the case as the GABA antagonist, bicuculline, did not prevent phenobarbital's blockade of the LH surge. Barbiturates may therefore directly affect catecholamine transmission to disrupt LH release (193, 194).

The results from Experiment 6 provide further evidence as to possible sites and mechanisms of action of this inhibitory GABA effect on LH release. As demonstrated in Experiment 2 and 5 aMT produced significant decreases of NE in the POA and of NE, EPI, and DA in the MBH of animals pretreated with estradiol followed by progesterone. Administration of the GABA agonists, baclofen and muscimol, produced similar effects on catecholamine activity as both GABA agonists significantly reduced steady state levels and blunted the aMT-induced decline of NE in the POA and of both NE and EPI in the MBH. In contrast, the GABA agonist did not affect the levels or depletion of DA in the MBH. These results suggest that noradrenergic and adrenergic neurotransmission in these areas was reduced by GABA stimulation, while DA activity was unaffected. Previous reports and the results from Experiments 1-4 have demonstrated the importance of NE and EPI activity for the ovarian hormone-induced rise in median eminence LHRH and the subsequent LH surge 
(91, 190). GABA systems may therefore disrupt LH release by depressing activity in the NE and EPI nerve terminals innervating the $\mathrm{POA}$ and $\mathrm{MBH}$ that regulate these events.

Several lines of evidence support such a role for GABA. GABA depresses $N E$ release in brain and from peripheral nerves via actions at a receptor subtype different from classical postsynaptic receptor (167, 168). Pharmacological characterization of this GABA B receptor reveals that 1) baclofen is a potent agonist at this receptor subtype, but not at the postsynaptic GABA A receptor (168); 2) muscimol also possesses some GABA $B$ as well as GABA A activity $(154,161) ; 3)$ the GABA $B$ is insensitive to antagonism by bicuculine $(159,160)$. The actions of these drugs on the GABA B receptor therefore closely parallel their actions on $\mathrm{LH}$ release. Interestingly, bicuculline, in a dose known to antagonize GABA A receptors (160), failed to block the inhibitory effect of muscimol on LH release. This raises the possibility that some GABA A effects may contribute to muscimol's depression of LH release. In other studies, the selective GABA A agonist, Thip (4,5,6,7-tetrahydroisoxazole (5,5-6) pyridin-3-ol) either failed to block or had inconsistent effects on $\mathrm{LH}$ release, providing further support for GABA B mediation of baclofen and muscimol effects on LH secretion and catecholamine activity.

In contrast to the GABA A-mediated opening of chloride ion channels in postsynaptic membranes (149), B receptors have recently been linked to inhibition of calcium influx in presynaptic nerve terminals (155, 156, 157). This mechanism, therefore, could possibly account for the lowering by baclofen and muscimol of NE and EPI concentrations as well 
as the blockade of the $\alpha M T$-induced depletion of these catecholamines observed in Experiment 6. The activity of tyrosine hydroxylase, the rate limiting enzyme in catecholamine synthesis, is increased by calcium in noradrenergic neurons (216), and activation of GABA B receptors by baclofen and muscimol to effectively diminish calcium conductance could thus reduce nerotransmitter synthesis and decrease steady state levels of the catecholamines. Moreover, it is well established that increased intracellular calcium is essential for the release of catecholamines and other neurotransmitters (217). The depression of calcium influx by stimulation of GABA B receptors might therefore reduce NE and EPI release and consequently, the decline of these catecholamines after inhibition of synthesis, an effect that depends on the release of catecholamine release $(185)$.

The hypothesis of GABA B receptors located on NE and EPI nerve terminals also receives support from the recent demonstration that a subpopulation of GABA B receptors is associated with cortical noradrenergic nerve terminals (21B). The regional and neurochemical specificity of the effects of GABA agonists on catecholamine activity in Experiment 6 is consistent with Experiments 2-4 which found that NE in both the POA and $\mathrm{MBH}$ is responsive to treatments with ovarian hormones and opiate drugs, while the EPI systems are affected only in the MBH. The absence of an effect of baclofen on MBH DA activity has also been observed previously (219).

GABAergic suppression of central NE activity has also been demonstrated using ovariectomized rats $(173,174)$, and on the basis of such 
effects it has been proposed that such a localized control mechanism may contribute to the inhibitory effects of estrogen on LH release (173, 174). Although few studies have correlated ovarian hormonal effects on LH with changes in central GABA activity, a recent report (175) found that an estrogen treatment that reduced $\mathrm{LH}$ also increased GABA turnover while decreasing NE turnover in the medial preoptic area. Moreover, the GABA synthetic enzyme, GAD, is responsive to estradiol treatment (178) and hyperprolactinemia, which suppresses both LH release and NE activity (220), also increased GAD activity (177) and GABA turnover (221). It is interesting, in view of these reports, to note that some GABA neurons in the preoptic area accumulate estradiol (176). In summary, the results from Experiments 5 and 6 support that the hypothesis that estradiol and progesterone affect activity in intrahypothalamic GABA systems that regulate ascending catecholamine input to LHRH neurosecretory cells to affect LH release. Experiment 7 was designed to examine whether a GABA agonist, which blocks the LH surge, also prevents the accumulation of LHRH in the median eminence induced by administration of stiulatory estradiol plus progesterone regimen.

As observed in Experiment 1, and reported previously (190), administration of progesterone to estradiol-primed rats elicits a significant increase in median eminence LHRH concentrations at $1100 \mathrm{~h}$. LHRH concentrations decreased significantly at 1300 and $1400 \mathrm{~h}$ and did not change significantly thereafter. Treatment of ovarian hormone-primed rats with baclofen, in a dose that markedly suppressed the LH surge, had a dif- 
ferent pattern of effects on LHRH levels. Levels of LHRH were increased at the $1100 \mathrm{~h}$ time point but did not change significantly thereafter. In fact, LHRH concentrations were higher at every time point in baclofen-treated rats as compared to control animals although only the $1400 \mathrm{~h}$ time point reached statistical significance. Thus, it appears that baclofen allows progesterone to stimulate LHRH accumulation in the median eminence, yet prevents the subsequent decline in LHRH levels. The result that in baclofen-treated rats LHRH did not decrease significantly after peaking at $1100 \mathrm{~h}$, and that levels at $1400 \mathrm{~h}$ were significantly higher than controls, may possibly reflect a decrease in LHRH release. An effect of baclofen to decrease LHRH release would be consistent with the evidence presently available that baclofen reduces calcium conductance in presynaptic nerve terminals $(155,156,157)$ andsuch a mechanism has been suggested to account for baclofen's depression of monoamine release in the brain $(154,168)$ and periphery $(159,164,167)$.

Experiment 8 was designed to test whether baclofen reverses the stimulatory effects of naloxone on LH release and catecholamine activity and also to examine whether nalmefene prevents the blockade of the LH surge produced by baclofen. The results from Experiment 8 provide preliminary evidence for parallel, independent modulation of LH secretion and hypothalamic catecholamine activity by GABA and opioid peptides. In the first study of Experiment 8, pretreatment of estradiol-primed rats with baclofen failed to prevent the enhancement of 
LH by naloxone. In addition, the GABA agonist failed to reverse naloxone's enhancement of NE or EPI depletion in the MBH induced by aMT. These results therefore suggest that the effects of naloxone on LH release and catecholamine activity are not due to interruption of opioid-GABA links. That is, opioid neuropeptides do not appear to stimulate the activity of central GABAergic neurons in order to affect hypothalamic catecholamine activity and pituitary LH release.

Experiment $8 \mathrm{~b}$ was designed to test whether the long acting opiate antagonist, nalmefene, could, when administered simultaneously with baclofen, reverse the GABA agonist's blockade of the LH surge. In this study, treatment with nalmefene could not prevent the blockade by baclofen of the ovarian hormone-induced LH surge. These results thus suggest that baclofen does not disrupt LH secretion by enhancing an opioid peptide inhibitory influence over LH release. Moreover, further preliminary evidence is then provided in support of two parallel yet independent intrahypothalamic systems that regulate gonadotropin secretion and hypothalamic catecholamine activity.

The mechanisms through which NE and EPI act in mediating ovarian hormone effects on LHRH and LH release have been partially characterized. The majority of studies have implicated alpha-adrenergic (but not beta-adrenergic) receptors in NE and EPI actions (97, 222). Several recent studies suggest that these alpha-receptors may be of the alpha 1 type, presumably post synaptic $(89,116,222)$. For example, phenylephrine (alpha 1 agonist) and clonidine (alpha 2 agonist) both 
increase $\mathrm{LH}$ release in ovariectomized rats primed with estrogen and progesterone (89). The preovulatory (116) or estrogen-induced LH surge (222) is blocked by the alpha 1 antagonists prazosin and phenoxybenzamine (116). Although both alpha 1 and alpha 2 receptors seem to be involved, these results provide preliminary support for a primary role for alpha 1-adrenergic receptors in the stimulation by noraderenrgic and adrenergic systems of LHRH and LH.

The ovarian hormones may regulate monoamine neurotransmission through mechanisms other than those affecting synthesis and release. For example, minor effects of ethinyloestradiol to decrease NE re-uptake in the hindbrain have been reported (223). Also, enzymes involved in monoamine degradation, such as type A monoamine oxidase, appear to be responsive to ovarian hormone treatment (224). Ovarian hormones may also modulate monoamine neurotransmission postsynpatically, e.g. by affecting the quantity or affinity of neurotransmitter receptors (59). However, although ovarian hormones effects on neurtransmitter re-uptake, degradation, and receptor quantity may participate in the regulation of reproductive function, these mechanisms do not account for discrete effects of estradiol and progesterone to affect monoamine turnover only in specific regions of the brain. For this reason, it has been proposed that the ovarian hormones may affect the activity of neuroregulatory substances in the hypothalamus that modulate catechoamine activity and anterior pituitary LH secretion. 
SUMMARY

Previous research has demonstrated the importance of monoaminergic neurons in mediating the stimulatory feedback effects of the ovarian hormones on hypothalamic LHRH concentrations and adenohypohyseal LH secretion. Results from Experiments 1 and 2 strongly suggest that brain epinephrine, in addition to norepinephrine, may mediate a portion of ovarian hormone effects on LHRH and LH.

The stimulatory feedback effects of estradiol and progesterone appear to be exerted, at least in part, through activation of POA and MBH noradrenergic and MBH adrenergic systems. These neuro-chemical changes then seem to facilitate LHRH, and subsequently LH, release.

The neurochemical mechanisms have not been established for these discrete ovarian hormone feedback actions on NE and EPI neurotransmission. Because estradiol and progesterone appear to alter NE and EPI turnover primarily in areas containing the nerve terminals for these neurotransmitters, the possibility that the ovarian hormones affect that activity of neuromodulatory substances was addressed. Results from Experiments 3-7 support the concept that the ovarian hormones produce their positive feedback effects, in part by reducing activity in hypothalamic opioid neuropeptide and GABA neurons which, in turn, disinhibit stimulatory NE and EPI inputs to LHRH neurons. This facilitation of LHRH release would allow the subsequent LH surge to occur.

Results from Experiment 8 provide preliminary evidence that these regulatory effects of opiates and GABA are actions of parallel, 
independent systems controlling catecholamine activity and anterior pituitary LH release. 
BIBLIOGRAPHY 


\section{BIBLIOGRAPHY}

1. Gay, V.L.; Midgley, A.R.; Niswender, G.D. (1970) Patterns of gonadotrophin secretion associated with ovulation. Fed. Proc. 29(6): 1880.

2. Smith, M.S.; Freeman, M.E.; Niell, J.D. (1975) The Control of progesterone secretion during the estrous cycle and early pseudopregnancy in the rat: Prolactin, gonadotropin and steroid levels associated with rescue of the corpus luteum of pseudopregnancy. Endocrinology 96:219.

3. Butcher, R.L.; Collins, W.E.; Fugo, M.W. (1974) Plasma concentrations of LH, FSH, prolactin, porgesterone, and estradiol-17B throughout the 5-day estrous cycle of the rat. Endocrinology 107:892.

4. Fink, G. (1979) Feedback actions of target hormones on hypothalamus and pituitary with special reference of gonadal steroids. Ann. Rev. Physiol. 41:571.

5. Goodman, R.L.; Knobil, E. (1981) The sites of action of ovarian steroids in the regulation of LH secretion. Neuroendocrinology $32: 57$.

6. Kalra, S.P.; Kalra, P.S. (1974) Temporal inter-relationships among circulating levels of estradiol, progesterone, and LH during the rat estrous cycle: Effects of exogenous progesterone. Endocrinology 95: 1711 .

7. Gallo, R.V. (1980) Neuroendocrine regulation of pulsatile luteinizing hromone release in the rat. Neuroendocrinology 30:122.

8. Gay, V.L.; Sheth, N.A. (1972) Evidence for a periodic release of $\mathrm{LH}$ in castrated male and female rats. Endocrinology 90:158.

9. Kalra, P.S.; Fawcett, C.P.; Krulich, L.; McCann, S.M. (1973) The effects of gonadal steroids on plasma gonadotrpins and prolactin in the rat. Endocrinology 92:1256.

10. Legan, S.J.; Coon, G.A.; Karsch, F.J. (1975) Role of estrogen an initiator of daily LH surges in the ovariectomized rat. Endocrinology 96:50.

11. Caligaris, L; Astrada, J.J.; Taleisnik, S. (1971) Release of luteinzing hormone induced by estrogen injection into ovariectomized rats. Endocrinology 88:810. 
12. Caligaris, L; Astrada, J.J.; Taleisnik, S. (1971) Biphasic effects of progesterone on the release of gonadotropin in rats. Endocrinology 89:331 (1971).

13. Ibata, Y.; Watanabe, K.; Kinoshita, H.; Kubo, S.; Sano, Y. (1979) The location of LH-RH neurons in the rat hypothalamus and their pathways in the median eminence. Cell Tissue Res. 198:381.

14. McCann, S.M. (1982) Physiology and pharmacology of LHRH and somatostatin. Ann. Rev. Pharmacol. Toxicol. 22:491.

15. Bennett-Clark, C.; Joseph, S.A. (1982) Immunocytochemical distribution of LHRH neurons and processes in the rat hypothalamic and extrahypothalamic location. Cell Tissue Res. 221:493.

16. Hokfelt, T.; Fuxe, F.; Goldstein, M.; Johansson, 0.; Fraser, H.; Jeffcoate, S. (1975) Immunofluorescence mapping of central monoamines and releasing hormone (LRH) systems. In Stumpf, W.E.; Grant, L.D. (eds.) Anantomical Neuroendocrinology, Karger, Basel, p. 281.

17. Kawano, H.; Daikoku, S. (1982) Immunohistochemical demonstration of LHRH neurons and their pathways in the rat hypothalamus. Neuroendocrinolgoy 32:179.

18. Levine, J.E.; Ramirez, V.D. (1982) Luteinzing hormone rleasing hormone release during the rat estrous cycle and after ovariectomy as estimated with push-pull cannulae. Endocrinology 11:1439.

19. Sarkar, D.K.; Chiappa, S.A.; Fink, G. (1976) Gonadotropin releasing hormone surge in pro-oestrous rats. Nature 264:461.

20. Aiyer, M.S.; Chiappa, S.A.; Fink, G. (1974) A primary effect of luteinzing hormone releasing factor on the anterior pituitary gland of the female rat. J. Endocrinol. 62:573.

21. McCann, S.M. (1962) Effect of progesterone on plasma luteinzing hormone activity. Am. J. Physiol. 202:601.

22. Goodman, R.L. (1978) A quantitavie analysis of the physiological role of estradiol and progesterone in the control of tonic and surge secretion of luteinizing hormone in the rat. Endocrinology 102: 142.

23. Shirley, B; Wolinsky, J.; Schwartz, N.B. (1968) Effects of a single injection of and estrogen antagonist on the estrous cycle of the rat. Endocrinology 82:959. 
24. Ferin, M; Tempure, A.; Zimmering, P.A.; Vande, U.; Bliele, R.L. (1969) Effect of antibodies to 17B-estradiol and progesterone on the estrous cycle of the rat. Endocrinology 85:1070.

25. Niell, J.D.: Freeman, M.E.; Tillson, S.A. (1971) Control of the proestrus surge of prolactin and luteinizing hormone secretion by estrogens in the rat. Endocrinology 89:1448.

26. Sarker, D.K.; Fink, G. (1980) Luteinzing hormone releasing factor in pituitary stalk plasma from long--term ovariectomized rats: effects of steroids. J. Endocr. 86:511.

27. Blake, C.A.; Norman, R.L.; Sawyer, C.H. (1974) Localization of the inhibitory actions of estrogen and nicotine on release of luteinizing hormone in rats. Endocrinology 16:22.

28. Kalra, P.A.; McCann, S.M. (1975) The stimulatory effect of gonadotropin rlease of implants of estrdiol or progesterone in certain sites in the central nervous system. Neuroendocrinology 19:289.

29. Smith, E.R.; Davidson, J.M. (1974) Location of feedback receptors; effects of intracranially implanted steroids on plasma LH and LRF response. Endocrinology 95:1566.

30. Bishop, W.; Fawcett, C.P.; Krulich, L.; McCann, S.M. (1972) Acute and chronic effects of hypothalamic lesions on the release of FSH, $\mathrm{LH}$ and prolactin in intact and castrated rats. Endocrinology $91: 643$.

31. Gallo, R.V. and 0sland, R.B. (1976) Electrical stimualtion of the arcuate nucleus in ovariectomized rats inhibits episodic luteinizing hormone (LH) release but excites $L H$ release after estrogen priming. Endocrinology 99:659.

32. Ramirez, V.D.; Abrams, R.M.; McCann, S.M. (1964) Effects of estradiol implants in the hypothalamo--hypophysial region of the rat on the secretion of luteinizing hormone. Endocrinology 75:243.

33. Cooper, K.J.; Fawcett, C.P.; McCann, S.M. (1974) Augmentation of pituitary responsiveness to luteinizing hormone/follicle stimulating hormone-releasing factor (LH--RF) as a result of acute ovariectomy in the four-day cyclic rat. Endocrinology 96:1123.

34. DeKoning, J.; van Dieten, J. AMJ; van Rees, G.P. (1976) Inhibitory and augmentative effects of estradiol on LH--RH induced release of $\mathrm{LH}$ by anterior pituitary glands from intact female rats in vitro. Mol. Cell. Endocrinol. 5:321. 
35. Blake, C.A.; Sawyer, C.H. (1974) Effects of hypothalamic differentiation on the pulsatile rhythm in plasma concentrations of luteinizing hormone in ovariectomized rats. Endocrinology 95:730.

36. Blake, C.A. (1973) A medial basal hypothalamic site of synergistic action of estrogen and progesterone on the inhibition of pituitary luteinizing hormone release. Endocrinology 101:1130.

37. Negro-Vilar, A.; Orias, R.; McCann, S.M. (1973) Evidence for a pituitary site of action for the acute inhibition of LH release by estrogen in the rat. Endocrinology 92:1680.

38. Stumpf, W.E.; Sar, M.; Keefer, D.A. (1975) Atlas of estrogen target cells in rat brain, in: Anatomical Neuroendocrinology (W.E. Stumpf and L.D. Grant, eds.) pp.104 (Korger, NY).

39. Shcally, A.V.; Redding, T.W.; Arimura, A. (1973) Effect of sex steroids on pituitary responses to $\mathrm{LH}$ and FSH releasign hormone in vitro. Endocrinolgoy 93:893 (1973).

40. Eskay, R.L.; Mical, R.S.; Porter, J.C. (1977) Relationship between luteinizing hormone releasing hormone concentration in hypophysial portal blood and luteinizing hormone release in intact, castrated, and electrochemically-stimulated rats. Endocrinology $100: 263$.

41. Kelner, K.L.; Pekc, E.J. (1984) Differential sensitivity of estrogen target tissues: implications for estrogen regulation of serum luteinizing hormone. J. Neurosci. Res. 11D: 79.

42. Cramer, 0.M.; Barraclough, L.A. (1971) Effects of electrical stimulation of the preoptic area on plasma LH concentrations in proestrous rats. Endocrinology 88: 1175 .

43. Goodman, R.L. (1978) The site of positive feedback actions of estradiol in the rat. Endocrinology 102:151.

44. Kalra, P.S.; McCann, S.M. (1975) The stimulatory effect on gonadotropin release of implants of estradiol or progesterone in certain sites in the central nervus system. Neuroendocrinology $19: 289$.

45. Hillarp, M.A. (194d) Studies on the localization of hypothalamic centres controlling goladotrophic function of the hypophysis. Acta Endocrinol (Kbh) 2:11.

46. Sarker, D.K.; Fink, G. (197) Effects of gonadal steroids on output of luteinizing hormone releasing factor into pituitary stalk blood in female rat. J. Endocr. 80:303. 
47. Fink, G.; Henderson, S.R. (1977) Site of modulatory action of oestrogen and progesterone on gonadotropin response to luteinizing hormone releasing factor. J. Endocr. 73:165.

48. Drouin, J.; Lagace, L; Labrie, F. (1976) Estradiol-induced increase of $\mathrm{LH}$ responsiveness to $\mathrm{LH}$ releasing hormone (LHRH) in rat anterior pituitary cells in culture. Endocrinologie 99:1477.

49. Fink, G; Henderson, S.R.; Steroids and pituitary responsiveness in female, androgenized female and male rats. J. Endocr. 73:157.

50. Lagace, L.; Massicotte, J.; Labrie, F.D. (1980) Acute stimulatory effects of progesterone on luteinizng hormone and follicle stimulating hormone release in rat anterior pituitary cells in culture. Endocrinology 106:684.

51. Schuiling, G.A.; van Dieten, J.A.M.J.; van Rees, G.R. (1974) Induction and inhibition of ovulation in the rat by intracerebral progesterone implants. Neuroendocrinology 15:38.

52. Brown-Grant, K; Nartolin, F. (1972) Facilitation of luteinizing hormone secretion in the female rat by progesterone. J. Endocrinol. 53:37.

53. Kalra, S.P.; Kalra, P.S. (1979) Dynamic changes in hypothalamic LH-RH levels associated with the ovarian steroid-induced gonadotropin surge. Acta Endorinol 92:1.

54. Lu, K.H.; Yen, S.S.C. (1980) The effect of an antiserum to luteinizing hormone releasing hormone on the progesterone-induced luteinizing hormone surge in ovariectomized, estrogen-primed rats. Endocrinology 106:867.

55. Kim, K.; Ramirez, V.D. (1982) In vitro progesterone stimulates the release of luteinizing hormone-releasing hormone from superfused hypothalamic tissue from ovariectomized estradiol-primed prepubertal rats. Endocrinology 111:750.

56. Levine, DJ.E.; Ramirez, V.D. (1980) In vivo release of luteinizing hormone-releasing hormone estimated with push-pull cannulae from the medial basla hypothalamus of ovariectomized, steroidprimed rats. Endocrinology 107:1782.

57. Ramirez, V.D.; McCann, S.M. Comparison of the regulation of luteinizing hormone (LH) secretion in immature and adult rats. Endocrinology 102:1015. 
58. Drouva, S.V.; Laplante, E.: Gautron, J-P; Kordon, C. (1984) Effects of 17B--Estradiol on LH-RH release from rat mediobasal hypothalamic slices. Neuroendocrinology 38d:152.

59. McEwen, B.S.; Parson, B. (1982) Gonadal steroid action on the brain: neurochemistry and neuropharmacology. Ann. Rev.

Pharmacol. Toxicol. 22:555.

60. Kelner, K.L.; Miller, A.L.; Peck Jr., E.J. (1980) Estrogens and the hypothalamus: nuclear receptor and RNA polymerase activiation. J. Recept. Res. 1:215.

61. Spelsberg, T.C.; Littlefield, B.A.; Seelke, R.; Dani, G.M.; Yoyoda, H.; Boyd-Leinen, D.P.; Thrall, C.; Kon, 0.L. (1983) Role of specific chromosomal proteins and DNA sequences in the nuclear binding sites for steroid receptors. Rectn Prog. Horm. Res. $39: 463$.

62. Gorski, J.; Gannon, F. (19) current models of steroid hormone action: a critique. Ann. Rev. Physiol. 39:425.

63. McEwen, B.S.; Biegnon, K.A.; Fishcette, C.; Luine, V.N.; Parsons, B.; Rainbox, T.C. (1984) Toward a neurochemical basis of steroid hormone action. In: Frontiers in Neuroendocrinology 8:153.

64. Pfaff, D.W.; Keiner, M. (1973) Atlas of estradiol--concentrating cells in the central nervous system of the female rat. J. Conp. Neurol. 151:121.

65. Parsons, B.; McEwen, B.S.; Pfaff, D.W.: A discontinuous schedule of estradiol treatment is sufficient to activate progesterone--facilitated feminine sexual behavior and to increase cytosol progestin receptors in the hypothalamus of the rat. Endocrinolgy 110:613.

66. Dufy, B.; Vincent, J.D.; Fleury, H.; Du Pasquier, P.: Gourdji, KKD.; Tixier-Vidal, A. (1979) Membrane effects of thyrotropin-releasing hormone and estrogen shown by intracellular recording from pituitary cells. Science 204:509.

67. Zyzek, E.; Dufy-Barbe, L.; Dufy, B.; Vincent, J.D. (1981) Short term effect of estrogen on release of prolactin by pituitary cells in culture. Biochem. Biophys. Res. Comm. 102:1151 (1981).

68. Kelly, M.J.; Kuhnt, B.; Wuttke, W.: Hyperpolarization of hypothalamic parvocellular neurons by $17 \mathrm{~B}$--estradiol and their identification through intracellular staining with procior yellow. Exp. Brain Res. 40:440. 
69. Kelly, M.J.; Ronnekleiv, 0.K.; Levine, J.E. (1983) Electrophysiological actions of 17B-estradiol on medial basal hypothalamic luteinizing hormone-releasing hormone neurons in the female guinea pig. Soc. Neurosci. Abst. \#208.15.

70. Cooper, J.R.; Bloom, F.E.; Roth, R.H. (1975) The Biochemical Basis of Neuropharmacology. pp. 120-195 (0xford Press, New York).

71. Levitt, M.; Spector, S.; Sjoerdsma, A.; Udenfriond, S. (1965) Elucidation of the rate limiting step in norepinephrine biosynthesis in the perfused guinea pig heart. J. Pharmacol. Exp. Ther. $201: 669$.

72. Lowenberger, W.; Weissbach, H.; Udenfirend, S. (1962) Aromatic L-amino acid decarboxylase. J. Biol. Chem. 237:89.

73. Pohorecky, L.A.; Zigmond, M.; Karten, H.; Wurtman, R.J. (1969) Enzymatic conversion of norepinephrine to epinephrein by the brain. J. Pharmacol. Esp. Ther. 165: 190.

74. Fuller, R.W. (1982) Pharmacology of brain epinephrein neurons. Ann. Rev. Pharmacol. Toxicol. 22:31.

75. Creese, I.; Sibley, KD.R.; Henblin, MW.; Leff, S.E. (1983) Dopamine receptors in the central nervous system. Adv. Biochem. Psychopharmacol. 36:129.

76. Lords, A.M.; Arnold, A.; McAuliff, J.P.; Luduana, F.P.; Brown, T.G., Jr. (1967) Differentiation of receptor systems activated by sympathomimetic amines. Nature 214:597.

77. Minneman, K.P.; Hogstand, L.R.; Molinoff, P.B. (1979) Simultaneous determination of beta- 1 and beta- 2 adrenergic receptors in tissues containing both receptor subtypes. Mol. Pharmacol. 15:286.

78. Starke, K. (1981) Presynaptic receptors. Ann Rev. Pharmacol. Toxicol. 21:7.

79. Iverson, L.L. (1973) Catecholamine uptake process. Br. Med. Bull. 29:130.

80. Axelrod, J. (1966) Methylation reaction in the formation and metabolism of catecholamines and biogenic amines: The enzymatic conversion of norepinephrine (NE) to epinephrine (3). Pharmacol. Rev. 18:95.

81. Moore, R.Y.; Bloom, R.E. (1979) Central catecholamine neuron systems: anatomy and physiology of the norepinephrine and epinephrine systems. Ann. Rev. Neurosci. 2:113. 
82. Moore, R.Y.; Bloom, R.E. (1978) Central catecholamine neuron systems: anatomy and physiology of the dopamine systems. Ann. Rev. Neurosci. 1:129.

83. Dahlstrom, A.; Fuxe, K. (19) Evidence for the existence of monoamine-containing neurons in the central nervous system. I. Demonstration of monoamines in the cell bodies of brain stem neurons. Acta Physiol. Scand (suppl.) 62 232:1.

84. Hokfelt, T.; Fuxe, D.K.; Goldstein, M.; Johansson, 0. (1976) Immunohistochemical evidence for the existence of adrenaline neurons in the rat brain. Brain Res. 66:235.

85. Gallo, R.W. (1980) Neuroendocrine regulatio of pulsatile luteinizing hormone release in the rat. Neuroendocrinology 30:122.

86. Gnodde, H.P.; Schuiling, G.A. (1976) Involvement of catecholaminergic and cholinergic mechanisms int he pulsatile release of LH in the long-term ovariectomized rat. Neuroendocrinology 20:212.

87. Drouva, S.V.; Gallo, R.V. (1976) Catecholamine involvement in episodic luteinizing hormone release in adult ovariectomized rats. Endocrinology 99:651.

88. Gallo, R.V.; Drouva, S.V. (1979) Effect of intraventricular infusion of catecholamines on luteinizing hormne release in ovariectomized and ovariectomized, steroid-primed rats. Neuroendocrinology 29: 149.

89. Leung, P.C.K.; Arendash, G.W.: Whitmoyer, D.I.; Gorski, R.A.; Sawyer, C.H. (1982) Differential effects of central adrenoreceptor agonists on luteinizing hormone release. Neuroendocrinology 34: 207.

90. Weick, R.F. (1978) Acute effects of adrenergic receptor blocking drugs and neuroleptic agents on pulsatile discharges of luteinizing hormone in the ovariectomized rat. Neuroendocrinology 26:108.

91. Kalra, S.P.; Kalra, P.S. (1983) Neural regulation of luteinizing hormone secretion in the rat. Endocrin. Rev. 4:311.

92. Crowley, W.R.; Terry, L.C.; Johnson, M.D. (1982) Evidence for the involvement of central epinephrein systems in the regulation of luteinizing hormone, prolactin and growth hormone release in female rats. Endcrinology 110: 1102 .

93. Sawyer, C.; Markee, J.E.; Hollinshead, W.H. (1947) Inhibition of ovulation in the rabbit by the adrenergic blocking agent dibenamine. Endocrinology 41:395. 
94. Everett, J.W.; Sawyer, C.H.; Markee, J.E. (1949) A neurogenic timing factor in control of the ovulatory discharge of luteinizing hormone in the cycling rat. Endocrinology 44:234.

95. Barraclough, C.A.; Sawyer, C.H. (1957) Blockade of the release of pituitary ovulatory hormone in the rat by chlorpromazine and reserpine: possible mechanisms of action. Endocrinology $44: 341$.

96. Meyerson, B.J.; Sawyer, C.H. (1968) Monoamines and ovulation in the rat. Endocrinology 83:170.

97. Kalra, S.P.; McCann, S.M. (1974) Effects of drugs modifying catecholamine synthesis on plasma LH and ovulation in the rat. Neuroendocrinology 15:79.

98. Kalra, S.P.; Kalra, S.P.; Krulich, L.; Fawcett, C.P.: McCann, S.M. (1972) Involvement of norepinephrein in transmission of the stimulatory influence of progesterone on gonadotropin release. Endocrinology 90: 1168 .

99. Clifton, D.K.; Sawyer, C.H. (1980) Positive and negative feedback effects of ovarian steroids on luteinizing hormone release in ovariectomized rats following chronic depletion of hypothalamic

100. Rubinstein, L.; Sawyer, C.H. (1970) Role of catecholamines in the release of pituitary ovulating hormone(s) in rat. endocrinology $86: 988$.

101. Vijayan, E.; McCann, S.M. (1978) Re-evaluation of the role of catecholamines in control of gonadotropin and prolactin release. Neuroendocrinology 25: $150 \mathrm{~m}$.

102. Krieg, R.J.; Ching, C.H. (1983) Stimulation of luteinizing hormone releasing hormone (LHRH) secretion by norepinephrein (NE) on steroid- primed or unprimed ovariectomized (ovx) rats. Fed. Proc. 43:976 (1983).

103. Negro-Vilar, A.; Ojeda, S.R.; McCann, S.M. (1979) Catecholaminergic modulation of luteinizing hormone-releasing hormone released by median eminance terminals in vitro. Endocrinology 104:1749.

104. Crowley, W.R.; O'Donohue, T.L.; Waschslict, H.; Jacobowitz, D.M. (1978) Effects of estrogen and progesterone on plasma gonadotropins and on catecholamine levels and turnover in discrete brain nuclei of ovariectomized rats. Brain Res. 154:345.

105. Honma, K.; Wuttke, W. (1980) Norepinephrein and dopamine turnover rates in the medial preoptic area and the medial basal hypothalamus of the rat brain after various endocrinological manipulations. Endocrinology 106:1848. 
106. Wise, P.N.; Rance, D.N.; Barraclough, C.A. (1981) Effects of estradiol and progesterone on catecholamine turnover rates in discrete hypothalamic regions of ovariectomized rats. Endocrinology $108: 2186$.

107. Schneider, P.G.; McCann, S.M. (1970) Mono- and indoleamines and control of LH secretion. Endocrinology 86:1127.

108. Rance, N.; Wase, P.M.; Selmannoff, M.K.; Barraclough, C.A. (1981) Catecholamine turnover rates in discrete hypothalamic areas and associated changes in median eminence luteinizing hormone-releasing hormone and serum gonadotropins on proestrus and diestrus day 1. Endocrinology 108:1795.

109. Krieg, R.J.; Sawyer, C.H. (1976) Effects of intraventricular catecholamines on luteinizing hormone release in ovarectomizedsteroid-primed rats. Endocrinology 99:411.

110. Crowley, W.R. (1982) Effects of ovarian hormones on norepinephrine and dopamine turnover in individual hypothalamic and extrahypothalamic nuclei. Neuroendocrinology 34:381.

111. Sawyer, C.H. (1952) Stimulation of ovulation in the ribbit by the intraventricular injection of epinephrine or norepinephrine.

Anat. Record 112:385.

112. Van Der Gugten, J.; Palkovits, M.; Wiznen, H.L.; Versteeg, D.H.G. (1976) Regional distribution of adrenaline in rat brain. Brain Res. 1076: 171.

113. Pendleton, R.G.; Gessner, G.; Sawyer, J. (1980) Comparison of the effects of SK \& F 29661 and 64139 upon adrenal and cardiac catecholamines. Eur. J. Pharmacol. 68:117.

114. Fuller, R.W.; Perry, K.W. (1977) Lowering of epinephrine concentrations in rat brain by 2,3-dichloro-alpha-methylbenzylamine, on inhibition of norepinephrine- $\mathrm{N}$-methyltransferase. Biochem.

Pharmacol. 26:2087.

115. Crowley, W.R.; Terry, L.C. (1981) Effects of an epinephrein synthesis inhibitor, SKF 64139, on the secretion of luteinizing hormone in ovariectomized female rats. Brain Res. 204:231.

116. Coen, C.W.; Coombs, M.C. (9183) Effects of manipulating catecholamines on the incidence of the preovulatory surge of luteinizing hormone and ovulation in the rat: evidence for a necessary involvement of hypothalamic adrenaline in the normal or "midnight" surge. Neuroscience 10:187. 
117. Kalra, S.P. (1983) Opioid peptides-Inhibitory neuronal systems in regulation of gonadotropin secretion. In McCann, S.M.; Dhindsa, D.S. (eds). Role of peptides and roteins in control of reproduction. Elsevier Biomedical, NY, p.63.

118. Heritage, A.S.; Grant, L.D.; Stumpf, W.E. (1977) 3H-Estradiol in catecholamine neurons of rat brain stem: Combined localization by autoradiography and formaldehyde-induced fluorescence. J. Comp. Neurol. 176:607.

119. Mansky, K.T.; Menstres-Ventura, P. Wuttke, W. (1982) Involvement of GABA in the feedback actions of estradiol on gonadotropin and prolacting release: hypothalamic GABA and catecholamine turnover rates. Brain Res. 231-353.

120. Cox, B.M. (1982) Endogenous opioid peptides: A guide to structures and terminology. Life Sci. 31:1645.

121. Nakanishi, S.; Inoue, A.; Kita, M.; Nakamura, M.; Chang, A.C.Y.; Cohen, S.N.; Numa, I.S. (1979) Nucleotide sequence of cloned cDNA for bovine corticotropin-beta-lipotropin precursor. Nature $278: 423$.

122. Noda, M.; Furatoni, Y.; Takahashi, H.; Toyosata, M.; Hirose, T.; Inayama S.; Nakanishi, S.; Numa, S. (1982) cloning and sequence analysis of cDNA for bovine adrenal preproenkephalin. Nature $295: 202$.

123. Gubler, U.; Seeberg, P.; Hoffman, B.J.; Gage, L.P.; Udenfirend, S. (1982) Molecular cloning establishes proenkephalin as precursor on enkephalin-containing peptides. Nature 295:205.

124. Kakidani, H.; Furatani, Y.; Takahashi, H.; Noda, M.; Morimoto, Y.; Hirose, T.; Asai, M.; Inayami, S.; Nakahashi, S.; Numa, S. (1982) Cloning and sequence analysis of cDNA for porcine beta-neoendorphin/dynorphin precursor. Nature 298:245.

125. Cuello, A.C. (1983) Central distribution of opioid peptides. Br. Med. Bull. 39:11.

126. Bloom, F.E.; Rossier, D..I.; Blattenberg, E.L.F.; Bayon, A.; Frenda, Z.; Hendriksen, S.J.; Siggins, G.R.; Desal, D.; Browne, R. ; Ling, N.; Guillemin, R. (1978) Beta-endorphin: cellular localization, electrophysiological and behavioral effects. Adv. Biochem. Psychopharm. 18:89

127. Goldstein, A.; Chazarossian, V.E. (1980) Immunoreactive dynorphin inpituitary and brain. Proc. Natl. Acad. Sci. USA 77:6207. 
128. Watson, S.J.; Akil, H.; Fischli, N.; Godlstein, A.; ZimmermaN, E.; Nilaver, G.; Van Winersa; Griedanus, T.B. (1982) Dynorphin and vasopressin: Common localization in magnocellular neurons. Science 216:85.

129. Botticelli, L.J.; Cox, B.M.; Goldstein, A. (1981) Immunoreactive dynorphin in mammalian spinal cord and dorsal root ganglia. Proc. Natl. Acad. Sci. USA 78:7783.

130. Pasternak, G.W.; Gintzler, A.R.; Houghten, R.A.; Ling, G.S.F.; Goodman, R.R.; Speigel, K.; Nishimura, S.; Johnson, N.; Recht, L.D. (1983) Biochemical and pharmacological evidence for opioid receptor multiplicity in the central nervous system. Life Sci. 33: 167.

131. Paterson, S.J.; Robson, L.E.; Kosterlitz, H.W. (1983) Classification of opioid receptors. Br. Med. Bull. 39:31.

132. Chawkin, C.; James, I.F.; Goldstein, A. (1982) Dynorphin is a specific endogenous ligand of the kappa opiate receptor. Science 215:413.

133. Sar, M.; Stumpf, W.E.; Miller, R.J.; Chang, K-J.; Cuatrecasas, P. (1978) Immunohistochemical localization of enkephalin in rat brain and spinal cord. J. Comp. Neurol. 182:17.

134. Finley, J.C.W.; Lindstrom, P.; Petrusz, P. (1981) Immunocytochemical localization of beta-endorphin-containing neurons in the rat brain. Neuroendocrinology.

135. Henderson, G.; Hughes, J. (1976) The effects of morphine on the release of noradrenaline from the mouse vas deferens. $\mathrm{Br} . \mathrm{J}$. Pharmacol. 57:551.

136. Taube, H.D.; Borowski, E.; Endo, T.; Starke, S. (1976) Enkephalin: A potential modulator of noradrenaline release in rat brain. Dur. J. Pharmacol. 38:377.

137. Langer, S.Z. (1981) Presynaptic regulation of the release of catecholamines. Pharmacol. Rev. 32:337.

138. Ching, M. (1983) Morphine suppresses the proestrous surge of GnRH in pituitary portal plasma of rats. Endocrinology 112:2209.

139. Barraclough, C.A.; Sawyer, C.H. (1955) Inhibition of a release of pituitary ovulatory hormone in the rat by morphine. Endocrinology 57:329.

140. Packman, P.M.; Rothschild, J.A. (1976) Morphine inhibition of ovulation: reversal by naloxone. Endocrinology 99:7. 
141. Kalra, S.P.; Simpkins, J.W. (1981) Evidence for a noradrenergic mediation of opiod effects on luteinizing hormone secretion. Endocrinology 109: 776 .

142. Pang, C.N.; Zimmermann, E.; Sawyer, C.H. (1977) Morphine inhibition of the preovulatory surges of plasma luteinizing hormone and follicle stimulating hormone in the rat. Endocrinology 101:1726.

143. Quigley, M.E.; Yen, S.S.C. (1980) The role of endogenous opiates on LH secretion during the menstrual cycle. J. Clin. Endocrinol. Metab. 51:179.

144. Bruni, J.F.; Van Vugt, D.; Marshall, S.; Meites, J. (1977) Effects of naloxone, morphine, and methionine enkephalin on serum prolactin, luteinizing hormone, follicle stimulating hormone, thyroid stimulating hormone, and growth hormone. Life Sci. 21:461.

145. Kalra, S.P.; Crowley, W.R. (1982) Epinephrine synthesis inhibitors block naloxone-induced LH release. Endocrinology 82:1403.

146. Morrell, J.L.; McGinty, J.; Pfaff, D.W. (1983) Some steroid hormone concentrating cells in the medial basal hypothalamus (MBH) and anteroir pituitary contain B-Endorphin or dynorphin. Abstract 27.1 Soc. for Neurosci. 13th Ann. Meeting.

147. Van Vugt, K.D.A.; Aylsworth, C.F.; Sylvester, P.W.; Leung, F.C.; Meites, J. (1981) Evidence for hypothalamic noradrenergic involvement in naloxone-induced stimulation of luteinizing hormone release. Neuroendocrinology 33:261.

148. Meldrum, B. (1982) Pharmacology of GABA. Clinical Neuropharm. 5:293.

149. Enna, S.J. (1981) Neuropharmacological and clinical aspects of gamma-aminobutyric acid (GABA). In: Neuropharmacology of Central Nervous System and Behavioral Disorders, G.C. Palmer (ed.) Academic Press, New York, p. 507.

150. Tappaz, M.L.; Brownstein, M.J.; Kopin, I.J. (1977) Glutamate decarboxylase (GAD) and gamma-aminobutyric acid (GABA) in discrete nuclei of hypothalamus and substantia nigra. Brain Res. 125:109.

151. Van Der Heyden, J.A.M.; De Kloet, E.R.; Koif, J.; Versteeg, KD.H.G. (1979) GABA content of discrete brain nuclei and spinal cord of the rat. J. Neurochem. 33:857.

152. Vincent, S.R.; Hokfelt, T.; Wu, J-Y. (1982) GABA neuron systems of hypothalamus and the pituitary gland. Neuroendocrinology $34: 117$. 
153. Dreifuss, J.J.; Kelly, J.S.; Krnjevic, K. (1969) Cortical inhibition and gamma-aminobutyric acid. Exp. Brain Res. 9:137.

154. Bowery, N.G.; Price, G.W.; Hudson, A.L.; Hill, D.R.; Wilkin, G.P.; Turnbull, M.J. (1984) GABA receptor multiplicity. Neuropharmacology 23:219.

155. Dunlap, K. (1981) Two types of gamma-aminobutyric acid receptors on embryonic sensory neurones. Br. J. Pharmacology 75:579.

156. Desarmenien, M.; Feltz, P.; Loeffler, J.P.; Occhipinti, G.; Santangelo, F. (1982) Multiple GABA receptors on A deta and C primary afferent neurones in the adult rat. Br. J. Pharmacology 76 :289p.

157. Desarmenien, M.; Feltz, P.; Occhipinti, G.; Santangelo, F.; Schlichter, R. (1984) coexistence of GABA A and GABA B receptors on A delta and C primary afferents. Br. J. Pharmacology 81:327.

158. Simmonds, M.A. (1983) Multiple GABA receptors and associated regulatory sites. Trends in Neurosciences 378:279.

159. Bowery, N.G.; Doble, A.; Hill, D.R.; Hudson, KA.L.; Shaw, J.S.; Turnbull, M.J.; Warrington, R. (1981) Bicuculline-insensitive GABA receptors on peripheral autonomic nerve terminals. Eur. J. Pharmacol. 71:53.

160. Hill, D.R.; Bowerz, N.G. (1981) 3H-GABA bind to bicucullineinsensitive GABA b sites in rat brain. Nature 290:149.

161. Bowery, N.G.; Hill, D.R.; Hudson, A.L. (1983) Characteristics of GABA $B$ receptor binding sites on rat whole brain synaptic membranes. Br. J. Pharmacol. 78:191.

162. Curtis, D.R.; Duggan, A.W.; Felix, D.; Johnston, G.A.R. (1971) Bicuculline, an antagonist of GABA and synaptic inhibition in the spinal cord. Brain Res. 32:69.

163. Muhyaddin, M.; Roberts, P.J.; Woodruff, B.N. 91982) Presynaptic gammaaminobutyric acid receptors in the rat anococcygeus muscle and their antagonism by 5-aminovaleric acid. Br. J. Pharmacology 77: 163 .

164. Muhyaddin, M.S.; Roberts, P.J.; Woodruff, G.N. (1983) Presynaptic $G A B A B$ receptors and the regulation of $[3 \mathrm{H}]$ noradrenaline release form rat anococcygeus muscle. Eur. J. DPharmacology 92:9.

165. Jennes, L.; Stumpf, W.E.; Tappaz, M.L. (1983) Anatomical relationships of dopaminergic and GABAergin systems with the GnRH systems in the septo-hypothalamic area. Exp. Brain Res. 50:91. 
161. Bowery, N.G.; Hudson, A.L. (1979) Gamma-aminobutyric acid reduces the evoked release of $[3 \mathrm{H}]$-noradrenaline from sympathetic nerve terminals. Br. J. Pharmacol. 66:108p.

162. Bowery, N.G.; Hill, D.R.; Hudson, A.L.; Doble, A.; Middlemiss, D.N.; Shaw, J.; Turnbull, M. (1980) Baclofen decreases neurotransmitter release in the mammalian CNS by an action at a novel GABA receptor. Nature 293:92.

163. Ondo, J.G. (1974) Gamma-aminobutyric acid effects on pituitary gonadotropin secretion. Science 186:738.

164. Pass, K.A., Ondo, J.G. (1977) The effects of Gamma-aminobutyric acid on prolactin and gonadotropin secretion in the unanesthetized rat. Endocrinology 100: 1437.

165. Vijayan, E.; McCann, S.M. (1978) The effects of intraventricular injection of gamma-aminobutyric acid (GABA) on prolactin and gonadotropin release in conscious female rats. Brain Res. 155:35.

166. Negro-Vilar, A.; Vijayan, E.; McCann, S.M. (1980) The effects of intraventricular gamma-aminobutyric acid (GABA) on hypothalamic catecholamines and LHRH and on pituitary hormone release. Brain Res. Bull. 5:239.

167. Wuttke, W.; Mansky, T.; Stock, DK.W.; Sandmann, R. (1981) Modulatory actions of estradiol on catecholamine and GABA turnover and effects on serum prolactin and LH release. In: K. Fure, J.A. Gustaffson, D.L. Wettenberg (eds.) Steroid hormone regulation of the brain. Pergamon, 0xford, p. 135.

168. Mansky, T.; Mestres-Ventura, P.; Wuttke, W. (1982) Involvement of GABA in the feedback actions of estradiol on gonadotropin and prolactin release: hypothalamic GABA and catecholamine turnover rates. Brain Res. 231:353.

169. Lamberts, R.; Vijayan, E.; Graf, M.; Minsky, T.; Wuttke, W. (1983) Involvement of preoptic-anterior hypothalamic CABA neurons in the regulation of pituitary $\mathrm{LH}$ and prolactin release. Exp. Brain Res. 523:356.

170. Sar, M.; Stumpf, KW.E.; Tappaz, M.L. (1983) Localization of 3H-estradiol in preoptic GABAergic neurons. Fed. Proc. 42:495.

171. Duvilenski, KB.; Maines, V.M.; Debeljuk, L. (1983) GABA-related enzymes in the hypothalamus of rats treated with estradiol. Eur. J. Pharmacol. 89:259. 
172. Wallis, C.J.; Lattge, W.G. (1980) Influence of estrogen and progesterone on glutamic acid decarboxylase activity in discrete regions of rat brain. J. Neurochemistry 34:609.

173. Banzan, A.M.; Donoso, A.D. (1982) Failure of ovulation caused by GABA in the immature rat gives pregnant mare gonadotropin. Endocrinology 110: 2180 .

174. Palkovits, M. (1973) Isolated removal of hypothalamic or other brain nuclei of the rat. Brain Res. 59:449.

175. Lowry, 0.H.; Rosenbrough, M.; Farr, A.; Randall, R. (1951) Protein measurement with the Folin phenol reagent. J. Biol. Chem. 193:265.

176. Passon, P.G.; Peuler, J.D. (1973) A simplified radiometric assay for plasma norepinephrine and epinephrine. Analytical Biochem. $51: 618$.

177. Sole, M.J.; Hussain, M.N. (1977) A simple, specific radioenzymatic assay for the simultaneous measurement of picogram quantities of norepinephrine, epinephrine, and dopamine in plasma and tissues. Biochem. Med. 18:301.

178. Peuler, J.D.; Johnson, G.A. (1977) Simultaneous single isotope radioenzymatic assay of plasma norepinephrine, epinephrine, and dopamine. Life Sci. 21:625.

179. Anden, N.E.; Corrodi, H.; Dahlstrom, A.; Fuxe, K.; Hokfelt, T. (1966) Effects of tyrosine hydroxylase inhibition on the amine levels on central monoamine neurons. Life Sce. 5:561.

180. Weiner, N.I. (1974) A critical assessment of the methods for the determination of monoamine synthesis turnover rates in vivo. Adv. Biochem. Psychopharm. 12:143.

181. Rodbard, D.; Rayford, P.L.; Ross, G.T. (1970) Statistical quality control of radioimmunoassays. In: /Statistics in Endocrinology/, McArthur, J.W.; Colton, T.; (eds), p 411-429 (MIT press, Cambridge.

182. Nett, T.M.; Akbar, A.M.; Niswender, G.D.; Hedland, M.T.; White, W.F. (1973) A radioimmunoassay for gonadotropin-releasing hormone in serum. J. Clin. Endocrinol. Metab. 36:880.

183. Piyachaturawater, P.; Pedroza, E.; Huang, W.K.; Arimura, A.; Schally, A.B. (1980) Studies on the iodination of LHRH and the biological and immunological activities of the products. Life Sci. 26:1309. 
184. Simpsons, J.W.; Kalra, P.S.; Kalra, S.P. (1980) Temporal alterations in luteinizing hormones-releasing hormone concentrations in several discrete brain regions: effects of estrogen-progesterone and norepinephrine synthesis inhibitions. Endocrinology 107:573.

185. Terry, L.C.; Crowley, W.R.; Johnson, M.D. (1982) Regulation of episodic growth hormone secretion by the central epinephrine system. Studies in the chronically cannulated rat. J. Clin. Invest. 69: 104 .

186. Everett, J.W.; Sawyer, C.H. (1950) A 24 hour periodicity in the LH release apparatus of female rat disclosed by barbiturate sedation. Endocrinology 47:198.

187. Kalra, S.P.; Simpkins, J.W.; Kalra, P.S. (1981) Progesteroneinduced changes in hypothalamic luteinizing hormone-releasing hormone and catecholamines: differential effects of pentobarbital. Endocrinology 108:1299.

188. Wise, P.N.; Rance, N.; Selmanoff, M.; Barraclough, C.A. (1981) Changes in radioimmunoassayable luteinizing hormone-releasing hormone in discrete brain areas of the rat at various times on proestrus, diestrus day 1 , and after phenobarbital administration. Endocrinology 108:2179.

189. Advis, J.P.; Drause, J.E.; McKelvy, J.F. (1983) Evidence that the endopeptidase-catalyzed luteinizing hormone releasing hormone cleavage contributes to the regulation of median eminence LHRH levels during positive steroid feedback. Endocrinology 112:1147.

190. Barder, N.; Merand, Y.; Rouleau, D.; Garon, M.; Dupont, A. (1981) Changes in B-endorphin content of discrete hypothalamic nuclei during the estrous cycle of the rat. Brain Res. 204:491.

191. Wardlaw, S.L. Thoron, L.; Frontz, A.G. (1982) Effects of sex steroids on brain B-endorphin. Brain Res. 245:327.

192. Knuth, U.A.; Sikanel, G.S.; Casanueva, F.F.; Havlicek, V.; Friesen, H.G. (1983) Changes in beta-endorphin content in discrete areas of the hypothalamus throughout proestrus and diestrus of the rat. Life Sci. 33:1443.

193. Wehrenberg, W.B.; Wardlaw, S.L.; Frantz, A.G.; Ferin, M. (1982) B-endorphin in hypophyseal portal blood: variations throughout the mentstrual cycle. Endocrinology 111:879.

194. Bhanot, M.; Wilkinson, M. (1983) Opiatergic control of LH secretion is eliminated by gonadectomy. Endocrinology 112: 399 . 
195. Blankstein, J.; Reyes, R.I.; Winter, J.S.D.; Faiman, KC.; (1981) Endorphins and the regulation of the hyman menstrual cycle. Clin. Endo. 14:287.

196. Quigley, M.E.; Yen, S.S.C. (1980) The role of endogenous opiates on $\mathrm{LH}$ secretion during the menstrual cycle. J. Clin. Endo. Metab. $51: 179$.

197. Lightman, S.L.; Jacobs, H.S.; Maguire, A.K.; McGarrick, G.; Jeffcoate, S.L. (1981) Climacteric flashing: clinical and endocrine response to infusion of nalozone. Brit. J. Obstet. Gynecol. $88: 919$.

198. Dreuva, S.V.; LaPlante, E.; Kordon, c. (1982) Alphal-adrenergic receptor involvement in the $\mathrm{Lh}$ surge in ovariectomized, estrogenprimed rats. Eur. J. Pharmacol. 81:341.

199. Engberg, G.; Elam M.; Svensoon, T. (1981) Effect of adrenaline synthesis inhibition on brain noradrenaline neurons in locus coeruleris. Brain Res. 223:49.

200. Negro-Vilar, A. (1982) The median eminence as a model to study presynaptic regulation of neural peptide release. Peptides 3:305.

201. Shivers, B.0.; Harlan, R.E.; Morrell, J.I.; Pfaff, D.W. (1983) Absence of oestradiol concentration in cell nuclei of LHRH-immunoreactive neurons. Nature 304:345.

202. Sar, M.; Stumpf, W.e. (1981) Central noradrenergic neurones concentrate 3H-oestradiol. Nature 289:500.

203. Gudelsky, G.A.; Porter, J.C. (1979) Morphine and opioid peptideinduced inhibition of the release of dopamine from tuberoinfundibular neurons. Life Sci. 25:1697.

204. Cicero, T.J.; Schainker, B.A.; Meyer, E.R. (1979) Endogenous opioids participate in the regulation of the hypothalamic-pituitary-luteinizing hormone axis and testosterone's negative feedback control of luteinizing hormone. Endocrinology 104:1286.

205. Van Vugt, D.A.; Sylvester, P.W.; Aylsworth, C.F.; Meittes, J. (1982) Counteraction of gonadal steroid inhibition of luteinizing hormone release by naloxone. Neuroendocrinology 34:247.

206. Dupont, A.; Barden, N.; Cusan, L.; Merand, Y.; Labrie, F.; Vandry, H. (1980) B-endorphin and met-enkephalins: their distribution, modulation by estrogens and haloperidal, and role in neuroendocrine control. Sec. Proc. 39:2544. 
207. Kumar, M.S.A.; Chen, C.L.; Muther, T.F. (1979) Changes in the pituitary and hypothalamic content of methionine-enkephalin during the estrous cycle of rats. Life Sci. 25:1687.

208. Schulz, R.; Wilhelm, A.; Pirke, K.M.; Gramsch, K.C.; Herz, A. (1981) B-endorphin and dynorphin control serum luteinizing hormone level in immature female rats. Nature 294:757.

209. Marko, M. (1982) Inhibitory effects of a new opioid compound on reproductive endocrinology in male rats. Acta Endocrinol. 99:85.

210. Roth, R.H.; Salzman, R.M.; Nowychy, M.C. (1978) Impulse flow and short term regulation of transmitter biosynthesis in central catecholaminergic neurons. In: Psychopharmacology: A generation of progress. Lipton, M.A., DiMascio, A.; Killman, K.F. (eds.) Raven Press, NY, p. 185.

211. Reichardt, L.T.; Kelly, R.B. (1983) A molecular description of nerve terminal function. Ann. Rev. Biochem. 52:871.

212. Karbon, W.; Duman, R.; Enna, S.J. (1983) Biochemical identification of multiple GABA B binding sites: association with noradrenergic terminals in rat forebrain. Brain Res. 274:393.

213. Demarest, K.T.; Moore, D.K.E. (1979) Comparsion of dopamine synthesis regulation in the terminals of digrostriatal, mesolimbic, tuberoinfundibular, and tuberohypophyseal neurons. J. Neural Trans. 46:263.

214. Hohn, K.G.; Wuttke, W. (1978) Changes in catecholamine turnover in the anterior part of the medial basal hypothalamus and the medial preoptic area in response to hyperprolactinemia in ovariectomized rats. Brain Res. 1:241.

215. Mansky, T.; Duker, E.; Wuttke, W. (1983) Hypothalamic and limbic GABA concentrations and turnover rates and glutamate concentrations following induction of hyperprolactinemia in ovariectomized rats. Neurosci. Lett. 39:267.

216. Drouva, S.W.; Laplante, E.; Kordon, C. (1982) Alpha 1-adrenergic receptor involvement in the $\mathrm{LH}$ surge in ovariectomized, estrogenprimed rats. Eur. J. Pharmacol. 81:341.

217. Kendall, D.A.; Tonge, S.R. (1977) Effects of testosterone and ethinylestradiol on the synthesis and uptake of noradrenaline ad 5-hydroxytryptamine $i$ rat hindbrain: evidence for a presynpatic regulation of monoamine synthesis. Br. J. Pharmacol. 60:310P. 
218. Luine, V.N.; Rhodes, J.C. (1983) Gonadal hormone regulation of MAO and other enzymes in hypothalamic areas. Neuroendocrinology $36: 235$.

219. Savoy-Morre, R.T.; Schwartz, N.B., Duncan, J.A.; Marshall, J.C. (1980) Pituitary gonadotropin-releasing hormone receptors during the rat estrous cycle. Science 209:942.

220. Kawakami, M.; Yashioka, E.; Konda, N.; Arita, J.; Visessuvan, S. (1975) Data on the sites of stimulatory feedback action of gonadal steroids indispensable for luteinizing hormone release in the rat. 
Benjamin Aaron Adler was born in Killeen, Texas, January 27, 1959. He received his primary and secondary education in Tennessee and attended the University of Tennessee, Knoxville, where he was awarded the degree of Bachelor of Arts (with honors) in 1980.

Mr. Adler entered the University of Tennessee Center for the Health Sciences Graduate School of Medical Sciences in July, 1980, and was awarded a Graduate Teaching Assistantship in Pharmacology. Mr. Adler will continue his training as a research fellow in neurochemistry at the Sloan-Kettering Memorial Cancer Institute in July, 1984. 